\title{
FIBCD1 is a Conserved Receptor for Chondroitin Sulphate Proteoglycans of the Brain Extracellular Matrix and a Candidate Gene for a Complex Neurodevelopmental Disorder
}

Christopher W Fell ${ }^{1,2,3} \dagger$, Astrid Hagelkruys ${ }^{4} \dagger$, Ana Cicvaric ${ }^{5,6}$, Marion Horrer ${ }^{4}$, Lucy Liu ${ }^{7}$, Joshua Shing Shun $\mathrm{Li}^{7}$, Johannes Stadlmann ${ }^{4,8}$, Anton A Polyansky ${ }^{9}$, Stefan Mereiter ${ }^{4}$, Miguel Angel Tejada ${ }^{4,10}$, Tomislav Kokotović ${ }^{1,2,3}$, Angelica Scaramuzza ${ }^{1,3}$, Kimberly A Twyman ${ }^{11}$, Michelle M Morrow ${ }^{12}$, Jane Juusola ${ }^{12}$, Huifang Yan $^{13,14}$, Jingmin Wang ${ }^{13,14}$, Margit Burmeister $^{15,16}$, Thomas Levin Andersen ${ }^{17,18}$, Gerald Wirnsberger ${ }^{4,19}$, Uffe Holmskov ${ }^{20}$, Norbert Perrimon $^{7}$, Bojan Zagrović ${ }^{9}$, Francisco J Monje ${ }^{5}$, Jesper Bonnet Moeller ${ }^{20,21}$, Josef M Penninger ${ }^{4,22^{*}}$ and Vanja Nagy ${ }^{1,2,3^{*}}$

${ }^{1}$ Ludwig Boltzmann Institute for Rare and Undiagnosed Diseases, Vienna, Austria.

${ }^{2}$ CeMM, Research Center for Molecular Medicine of the Austrian Academy of Sciences, Vienna, Austria.

${ }^{3}$ Department of Neurology, Medical University of Vienna, Vienna, Austria.

${ }^{4}$ IMBA, Institute of Molecular Biotechnology of the Austrian Academy of Sciences, VBC Vienna BioCenter Campus, Vienna, Austria.

${ }^{5}$ Centre for Physiology and Pharmacology, Department of Neurophysiology and

Neuropharmacology, Medical University of Vienna, Vienna, Austria.

${ }^{6}$ Department of Psychiatry and Behavioral Sciences, Feinberg School of Medicine, Northwestern University, Chicago, IL, USA.

${ }^{7}$ Department of Genetics, Harvard Medical School, Howard Hughes Medical Institute, Boston, USA.

${ }^{8}$ Institute of Biochemistry, University of Natural Resource and Life Sciences, Vienna, Austria.

${ }^{9}$ Department of Structural and Computational Biology, Max Perutz Labs, University of Vienna, Campus Vienna BioCenter 5, A-1030 Vienna, Austria.

${ }^{10}$ Research Unit on Women's Health-Institute of Health Research INCLIVA, Valencia, Spain

${ }^{11}$ Mercy Kids Autism Center, Saint Louis, MO, USA.

${ }^{12}$ GeneDx, Gaithersburg, MD, USA.

${ }^{13}$ Department of Pediatrics, Peking University First Hospital, Beijing, China.

14 Joint International Research Center of Translational and Clinical Research, Beijing, China.

${ }^{15}$ Michigan Neuroscience Institute, University of Michigan, Ann Arbor, MI, USA.

${ }^{16}$ Departments of Computational Medicine \& Bioinformatics, Psychiatry and Human Genetics, University of Michigan, Ann Arbor, MI, USA.

${ }^{17}$ Clinical Cell Biology, Department of Pathology, Odense University Hospital, Odense, Denmark.

${ }^{18}$ Pathology Research Unit, Department of Clinical Research and Department of Molecular Medicine, University of Southern Denmark, Odense, Denmark.

${ }^{19}$ Apeiron Biologics AG, Vienna BioCenter Campus, Vienna, Austria.

${ }^{20}$ Cancer and Inflammation Research, Department of Molecular Medicine, University of Southern Denmark, Odense, Denmark.

${ }^{21}$ Danish Institute for Advanced Study, University of Southern Denmark, Odense, Denmark.

${ }^{22}$ Department of Medical Genetics, Life Science Institute, University of British Columbia, Vancouver, Canada. 
*Corresponding authors:

Vanja Nagy, vanja.nagy@,rud.lbg.ac.at c/o CeMM, Lazarettgasse 14, AKH, BT 25.3, 1090, Vienna, Austria.

Josef M. Penninger, josef.penninger@ubc.ca. Life Sciences Institute, Vancouver Campus, 2350 Health Sciences Mall, Vancouver, BC Canada V6T 1 Z3.

$\uparrow$ Authors contributed equally 
bioRxiv preprint doi: https://doi.org/10.1101/2021.09.09.459581; this version posted September 10, 2021. The copyright holder for this preprint (which was not certified by peer review) is the author/funder. All rights reserved. No reuse allowed without permission.

\section{ABSTRACT}

2 The brain extracellular matrix $(\mathrm{ECM})$ is enriched in chondroitin sulphate proteoglycans

3 (CSPGs) with variable sulphate modifications that intimately participate in brain maturation

4 and function. Very little is known about how the changing biophysical properties of the CSPGs

5 are signalled to neurons. Here, we report Fibrinogen C Domain Containing 1 (FIBCD1), a

6 known chitin-binding receptor of the innate immune system, to be highly expressed in the

7 hippocampus and to specifically bind CSPGs containing 4-O sulphate modification (CS-4S).

8 Cultured Fibcdl knockout (KO) neurons lack phenotypic and transcriptomic responses to

9 CSPG stimulation. Further, Fibcd1 KO mice exhibit accumulation of CS-4S, likely resulting in deficits of hippocampal-dependent learning tasks and abrogated synaptic remodelling, a phenotype rescued by enzymatic digestion of CSPGs. Likewise, neuronal specific knockdown of a Fibcdl orthologue in flies results in neuronal morphological changes at the neuromuscular junctions and behavioural defects. Finally, we report two undiagnosed patients with a complex neurodevelopmental disorder with deleterious variants in FIBCD1, strongly implicating FIBCD1 in the development of the disease. Taken together, our results demonstrate that FIBCD1 is a novel, evolutionarily conserved component of ECM sulphation recognition that is crucial for neuronal development and function. 
bioRxiv preprint doi: https://doi.org/10.1101/2021.09.09.459581; this version posted September 10, 2021. The copyright holder for this preprint (which was not certified by peer review) is the author/funder. All rights reserved. No reuse allowed without permission.

\section{INTRODUCTION}

The brain extracellular matrix $(\mathrm{ECM})$ is a dynamic microenvironment that plays a critical role in the development and maintenance of the nervous system ${ }^{1,2}$. The ECM is structurally heterogenous and is composed primarily of glycans and glycoconjugates (proteoglycans, glycoproteins and glycolipids). Glycans coordinate and are essential for many neurodevelopmental processes, including axon outgrowth and guidance, synaptogenesis, migration and synaptic plasticity ${ }^{2-4}$. There are many inherited human disorders caused by disruptions to the glycosylation pathways. While multiple systems are often affected, most disorders also involve the central nervous system (CNS), with accompanying symptoms including congenital malformations, epilepsy, intellectual disability and developmental delay $^{5,6}$. Additional connections have been made between altered glycosylation, ECM composition and autism spectrum disorder (ASD), but the molecular mechanisms remain poorly understood ${ }^{7}$.

Proteoglycans are composed of negatively charged glycosaminoglycans (GAGs), which consists of repeating disaccharide units, covalently joined to a core protein. A seminal GAG is chondroitin sulphate (CS), a component of chondroitin sulphate proteoglycans (CSPGs). Different spatiotemporal distributions of CSPGs with variable sulphate modifications correlate with specific and discrete developmental stages as part of the dramatic reorganisation of the ECM that accompanies and regulates brain maturation ${ }^{2,8,9}$. This includes closure of the "critical period' of heightened synaptic plasticity, when CSPGs condense into lattice-like structures around neurons, known as peri-neuronal nets (PNNs), which restrict juvenile synaptic plasticity and participate in memory formation, retention and extinction ${ }^{1,10,11}$.

Few cell-surface receptors for CSPGs have been identified. Receptor Protein Tyrosine Phosphatase sigma (РTP $\sigma)$ and its subfamily member Leukocyte Common Antigen-Related (LAR), as well as the Nogo receptor family members, Nogo66 receptor-1 and 3 (NgR1 and 3) were demonstrated to bind $\mathrm{CSPGs}^{12-14}$, however, their role in the brain is unclear. Less is known 
bioRxiv preprint doi: https://doi.org/10.1101/2021.09.09.459581; this version posted September 10, 2021. The copyright holder for this preprint (which was not certified by peer review) is the author/funder. All rights reserved. No reuse allowed without permission. regarding recognition of specifically sulphated GAGs on CSPGs. For example, CS-4,6S (or CS-E) recognition was reported for Contactin-1 (CNTN1) and in the lungs for Receptor for Advanced Glycation End Products (RAGE) ${ }^{15,16}$. RAGE is also associated with Alzheimer pathology ${ }^{17}$. Whether CNTN1 or RAGE brain functions are linked to CS-4,6S recognition and the role of CS-4,6S in the brain is poorly understood. To date, associations between disruptions to proteoglycan receptor function and human disease have not been reported.

Here, we identify Fibrinogen C Domain Containing 1 (FIBCD1) as a novel CSPG receptor. Previous work has determined FIBCD1 to be expressed in mucosal epithelial tissues, with highest expression in the human respiratory and gastrointestinal tracts, testes, placenta and brain. FIBCD1 is a type 2 transmembrane protein with high homology to ficolins and has been shown to act as a pattern recognition receptor of chitin, found in the cell walls of fungi ${ }^{18}$. FIBCD1 consists of a short N-terminal cytoplasmic tail, transmembrane domain, coiled-coil region through which FIBCD1 forms homotetramers, poly-cationic region and a C-terminal extracellular fibrinogen-related domain (FReD) which participates in ligand interactions ${ }^{18}$. FIBCD1 was shown to limit fungal outgrowth, regulate the gut fungal mycobiome and dampen intestinal inflammation ${ }^{19,20}$. FIBCD1 has also been shown to have an endocytic function and solving of the FReD crystal structure revealed potential binding sites for GAGs such as $\mathrm{CS}^{21}$. Despite its high expression in the brain, no function for FIBCD1 in the nervous system has been reported. Here, we demonstrate that FIBCD1 is critical for the function of the nervous system of mice and flies. Additionally, we find FIBCDI loss-of-function variants in two unrelated patients contributing to a complex neurodevelopmental disorder (NDD) symptomatology that includes ASD.

\section{RESULTS}


bioRxiv preprint doi: https://doi.org/10.1101/2021.09.09.459581; this version posted September 10, 2021. The copyright holder for this preprint (which was not certified by peer review) is the author/funder. All rights reserved. No reuse allowed without permission.

\section{Fibcd1 is expressed in the mouse brain}

As the biological function of FIBCD1 in the CNS has not been explored, we first examined its expression pattern in the mouse brain. In situ hybridization (ISH) using complementary DNA probe pairs against Fibcdl mRNA in adult mouse coronal brain section revealed strong localisation of Fibcdl in the pyramidal cell layer of the hippocampus, granule cells of the dentate gyrus, dispersed cells of the cortex, the medial habenula and hypothalamus (Fig. 1A). Using publicly available datasets of bulk RNA seq of sorted brain cell population, brainrnaseq.org ${ }^{22}$, we noted Fibcdl expression to be highest in neurons, and virtually absent from all other cell types sequenced (Fig. S1A). While RT-qPCR of 6 different brain regions determined that some Fibcdl transcripts can be observed in the olfactory bulb as well, expression is highest in the hippocampus (Fig. 1B and Fig. S1B-C). Fibcd1 transcript levels were high in embryonic mouse brain and dropped to their lowest levels at postnatal day (P) 7 and again increased during postnatal brain development to return to their high embryonic levels at P25 (Fig. 1C and Fig. S1B, D).

\section{Fibed1 binds to chondroitin sulphate proteoglycans with a $-4 \mathrm{~S}$ modification}

GAGs of proteoglycans are post-translationally modified by the addition of sulphate groups at different positions by sulfonyltransferases ${ }^{23}$. These include, but are not limited to, unsulphated (CS-0S), sulphated at carbon 4 (CS-4S, CS-A) and/or at carbon 6 (CS-6S, CS-C and CS-4,6S, CS-E) comprising the so-called 'sulphation code.' As an abundance of CS-4S and CS-6S in the brain ECM was described to be critical for maturation of the brain ${ }^{8,24,25}$, we sought to determine whether FIBCD1 binds these GAGs as previously hypothesised ${ }^{21}$. Top binding poses for CS4S and CS-6S were identified using in silico molecular docking and an X-ray structure of the 
bioRxiv preprint doi: https://doi.org/10.1101/2021.09.09.459581; this version posted September 10, 2021. The copyright holder for this preprint (which was not certified by peer review) is the author/funder. All rights reserved. No reuse allowed without permission. extracellular FReD (PDB 4M7F), followed by post-rescoring of docking solutions as described previously ${ }^{26}$. According to the scoring function, CS-4S exhibits a better fit to the FReD as compared to CS-6S (45.3 vs 43.3), with the orientations of the two ligands on the FReD surface being nearly orthogonal to each other (Fig. 1D and Fig. S2A). Importantly, the orientation of CS-4S, with its sulphate group packing tightly into a pocket formed by Y405, H415, and Y431 of FReD, leads to a more favourable electrostatic interaction and subsequently lower binding free energy $\left(\Delta \Delta \mathrm{G}\right.$ value of $\left.-1.3 \mathrm{~kJ} \mathrm{~mol}^{-1}\right)$ as predicted by a linear model, published elsewhere ${ }^{27}$. To characterise binding affinities of FIBCD1 to CS-4S and CS-6S we performed competitive ELISA experiments as described previously ${ }^{18}$. Using a previously reported FIBCD1 ligand, acetylated BSA, and increasing concentrations of CS-4S or CS-6S, we determined a strong preference of FIBCD1 to bind CS-4S over CS-6S, with an approximately 10 -fold lower $\mathrm{IC}_{50}$ concentration of CS-4S compared to CS-6S (Fig. 1E). To assess FIBCD1 binding specificity to CS-4S in a cellular context, we cloned V5-tagged full-length mouse WT Fibcd1 cDNA and a truncated version without the FReD (Fibcd1 $1^{4 F R e D}$ ) (Fig. S2B). We overexpressed the two FIBCD1 constructs in the mouse N2a cell line and by RT-qPCR and immunoblot analyses confirmed overexpression of FIBCD1 and V5-reactive bands at predicted molecular weights (Fig. S2C-E). We then incubated the cells with fluoresceinamine (FITC)-tagged CS-4S, polysulphated CS (CS-PS) and dermatan sulphate (DS) and acquired the cells by flow cytometry. We determined that cells expressing full length WT Fibcdl showed increased $\mathrm{V5}^{+} / \mathrm{FITC}^{+}$fluorescence intensity in comparison to cells expressing empty vector or Fibcd $1^{4 F R e D}$, but this was not the case for cells incubated with CS-PS or DS, confirming preferred binding of Fibcd1-expressing cells to CS-4S, dependent on the FReD (Fig. 1F).

We next asked whether FIBCD1 is a bonafide receptor for CSPGs in hippocampal neurons with high expression of Fibcdl. We aimed to determine cellular phenotypic and transcriptomic responses to CSPGs in primary hippocampal cultures. CSPGs are repulsive to neuronal adhesion, neurite outgrown, growth cone formation, axonal regeneration and 
bioRxiv preprint doi: https://doi.org/10.1101/2021.09.09.459581; this version posted September 10, 2021. The copyright holder for this preprint (which was not certified by peer review) is the author/funder. All rights reserved. No reuse allowed without permission. neurogenesis in culture ${ }^{12,28}$. We reasoned that if FIBCD1 is a receptor for CSPGs, then cells deficient in FIBCD1 would not exhibit the same responses as WTs as was shown for canonical CSPG receptors, such as PTP $\sigma$ previously ${ }^{13}$. We obtained Fibcd1 KO mice (MGI:5007144 ${ }^{29}$ ) and validated the absence of Fibcdl mRNA transcript in the KO hippocampi (Fig. S3A). The mice were viable, healthy and exhibited no obvious abnormalities (Fig. S3B-D). We harvested primary hippocampal neurons from embryonic (E)18.5 Fibcd1 WT and KO littermate animals and plated them on coverslips pre-coated with CSPGs containing a mixture of sulphated GAGs. We assessed primary neuronal morphologies after 2 and 14 days in vitro (DIV) by analysing cells that stain positive for the neuronal-specific marker Microtubule-associated protein 2 (MAP2). At DIV2, we found the adherence of Fibcd1 WT neurons was partially abrogated by the presence of CSPG coating, but not in cultures plated on CSPGs after treatment with the enzyme Chondroitinase $\mathrm{ABC}(\mathrm{ChABC})$, which cleaves the GAG chains into soluble disaccharides and tetrasaccharides, leaving the core protein intact as described previously (Fig. $2 \mathrm{~A})^{28,30}$. At DIV14, we found a dramatic increase in neuronal somata aggregation in cultures plated on CSPGs, also prevented by ChABC pre-digestion, again in agreement with previous literature (Fig. 2B) ${ }^{28}$. In contrast, neurons cultured from Fibcd1 KO hippocampi showed slight, but not significant, DIV2 adherence impairment and slight, but also not significant, DIV14 somata aggregations, indicating that Fibcd $1 \mathrm{KO}$ neurons are resistant to CSPG coating-induced phenotypes. Likely, the residual detection of CSPGs in Fibcdl KOs was due to the presence of other CSPG receptors, such as $\mathrm{PTP} \sigma^{13}$. Taken together, these data confirm FIBCD1 binds GAGs, particularly CS-4S, and mediates CSPG-induced cellular phenotypes.

To investigate transcriptional responses to FIBCD1 binding of CSPGs, we isolated RNA from primary hippocampal neurons plated on coverslips coated with CSPGs (Fibcd1 $\mathrm{WT}^{\mathrm{CSPG}}$, Fibcd1 $\mathrm{KO}^{\mathrm{CSPG}}$ ) and without (Fibcd1 WT, Fibcd1 KO) at DIV3. We performed bulk RNA-sequencing with poly-A enrichment using 4 to 5 biological replicates per condition. We reasoned an early time point after plating transcriptional changes would more likely reflect 
bioRxiv preprint doi: https://doi.org/10.1101/2021.09.09.459581; this version posted September 10, 2021. The copyright holder for this preprint (which was not certified by peer review) is the author/funder. All rights reserved. No reuse allowed without permission. cellular developmental effects of FIBCD1-CSPG binding as opposed to secondary effects such as increased cell stress, soma aggregation or dendritic fasciculation. Hierarchical clustering showed small intra-group differences and distinct separation between groups by genotype (WT or KO) and treatment (+/- CSPG) (Fig. S4A). Comparison of differentially expressed genes (DEGs, FDR $<0.05$ ) between Fibcdl KO and WT cells (without CSPG) revealed 462 significant DEGs with Fibcdl being the most downregulated DEG, as expected (Fig. S4B). We noted that a number of the top enriched DEGs in the Fibcdl KO vs. WT condition to be genes specifically expressed in non-neuronal cells (e.g. Pdgfra, Olig2), suggesting that DEGs may be reflecting differences between WT and KO cultures in glia numbers, which are technically challenging to control for. We therefore explored our data further comparing only between conditions within the same genotype, i.e. Fibcdl $\mathrm{WT}^{\mathrm{CSPG}} \mathrm{vs} \mathrm{WT}$ and Fibcdl $\mathrm{KO}^{\mathrm{CSPG}} \mathrm{vs} \mathrm{KO}$.

Comparison between $\mathrm{WT}^{\mathrm{CSPG}}$ vs WT revealed 462 significant DEGs, of which the majority (396) were downregulated. Comparison between $\mathrm{KO}^{\mathrm{CSPG}}$ vs $\mathrm{KO}$ revealed 345 significant DEGs, of which again the majority (301) were downregulated (Fig. 2C). We crossreferenced DEGs identified in the WT and KO datasets to reveal a set of genes that are responding to CSPGs in both genotypes and those that are dependent on Fibcd1 expression (Fig. 2D). Among the top dysregulated genes common to both genotypes, independent of Fibcdl expression, was Thbsl, recently shown to be necessary and sufficient for axon regeneration after injury ${ }^{31}$, normally inhibited by the formation of glial CSPG scars ${ }^{13}$, suggesting that the effects of CSPGs may be mediated by Thbs 1 gene regulation in hippocampal neurons. Many of the remaining genes are involved in binding or remodelling of the actin cytoskeleton (Acta2, Tagln, Shroom3, Nes, Actin, Palld, Ajuba, Flnb) which reflect the morphological perturbations induced by plating the cells on CSPGs. Gene ontology (GO) term enrichment analysis for downregulated genes revealed terms such as "extracellular matrix binding" and "extracellular matrix structural component" in Fibcdl WT cells upon CSPG treatment (Fig. 2E), which suggests that Fibcd1 not only engages with the components of the 
bioRxiv preprint doi: https://doi.org/10.1101/2021.09.09.459581; this version posted September 10, 2021. The copyright holder for this preprint (which was not certified by peer review) is the author/funder. All rights reserved. No reuse allowed without permission.

ECM, but also facilitates transcriptional regulation of genes known to play a role in the ECM.

Intriguingly, the third-most enriched term was "integrin binding", reflecting a number of integrin subunits and integrin-related genes that are significantly downregulated in WT cells upon CSPG treatment (Fig. S4C). We next analysed the DEGs unique to the WT cellular response to CSPGs which are dependent on Fibcd1 expression (Fig. 2D). Among the genes dysregulated in response to CSPGs only in the WT cultures are genes coding for integrin subunits (Itga1, Itgam), integrin binding and/or modulation (Adamts8, Tln1) ${ }^{32,33}$, genes involved in the synthesis or degradation of ECM components (Adamts8, Hspg2, Cemip, Coll2al $)^{34}$ and, finally, genes involved in binding to the ECM and adhesion of cells to each other and to the ECM $(F \ln c \text {, Wisp1, Tln1 })^{33,35-38}$. Together, these genes represent the transcriptional fingerprint of primary hippocampal neurons mediated by Fibcd1 binding to CSPG.

\section{CS-4S abundance is increased in the Fibcd1 KO hippocampus}

Previous work in a non-neuronal context has shown FIBCD1 to have an endocytic function ${ }^{18,21}$. Having demonstrated FIBCD1 preferential binds to CS-4S, we hypothesised that FIBCD1 may have a role in endocytosing cell-free extracellular CS-4S and/or CSPGs containing CS-4S in the brain and that a lack of FIBCD1 may cause aberrant accumulation of either or both molecules. Since CSPGs are known to condense into peri-neuronal nets (PNNs), critical for memory formation, retention and extinction ${ }^{11,39}$, we first looked for any changes in PNNs in the Fibcdl KO brain. We found no apparent difference in the hippocampal PNNs between adult WT and $\mathrm{KO}$ coronal sections stained with fluorescently-tagged Wisteria floribunda agglutinin (WFA), a lectin that selectively labels CSPGs within PNNs (Fig. 3A) ${ }^{40}$. We also quantified amounts of sulphated GAGs (sGAG) in adult mouse hippocampi lysates, using a 1,9dimethylmethylene blue based assay (DMMB, which reacts with sGAGs and precipitates) and 
bioRxiv preprint doi: https://doi.org/10.1101/2021.09.09.459581; this version posted September 10, 2021. The copyright holder for this preprint (which was not certified by peer review) is the author/funder. All rights reserved. No reuse allowed without permission.

suggest there's no detectable difference in general CSPG levels between Fibcd1 WT and KO

brains. To determine if particularly sulphated GAGs may be accumulating in the absence of

FIBCD1 we surveyed the hippocampal glycome composition using high performance liquid chromatography (HPLC) of WT and KO mice hippocampi. HPLC analysis determined a relative increase in the ratio of CS-4S compared to other identified GAGs in the Fibcd1 KO brains as compared to control littermates (Fig. 3C). Further, Western blot analysis using specific antibodies against differentially sulphated GAGs determined a significant increase of CS-4S abundance in the FibcdlKO hippocampi as compared to controls, while CS-0S and CS-6S remained unchanged (Fig. 3D). These data indicate that while total GAG levels and overall WFA-reactive PNN-associated CSPG abundance remain unchanged, FIBCD1 deficiency leads to a specific accumulation of GAGs containing CS-4S in the hippocampus, possibly due to an inability of cells to bind and endocytose CS-4S GAGs.

\section{Fibcd1 deficiency leads to defects in hippocampal-dependent learning and long-term}

\section{potentiation in mice}

To determine the behavioural consequences of CS-4S accumulation in the Fibcdl mouse model, we subjected Fibcdl WT and KO adult mice to a series of hippocampal-dependent learning tasks. Additionally, 15T MRI volumetric analysis revealed no significant differences in total brain volume, or 11 other isolated brain regions as compared to control littermates determining no overt structural abnormalities in the brains of mice with a FIBCD1 deficiency (Fig. S3D). Behaviourally, we first established that there is no difference in baseline anxiety levels between Fibcdl WT and KO mice as assessed by the Elevated Plus Maze (EPM) (Fig. S5A). We also detected no difference in the acquisition and retention of spatial learning between Fibcd1 WT and KO mice, as assessed by the Morris Water Maze (MWM) (Fig. S5B- 
bioRxiv preprint doi: https://doi.org/10.1101/2021.09.09.459581; this version posted September 10, 2021. The copyright holder for this preprint (which was not certified by peer review) is the author/funder. All rights reserved. No reuse allowed without permission. C). Nociceptive responses to noxious chemicals or heat stimulation revealed no deficiencies in sensory nervous system processing of acute pain (Fig. S5D). However, we found that Fibcd1 KO mice were significantly impaired in spatial working memory as assessed by spontaneous alternation in the Y-Maze (Fig. 4A). Further, we found that Fibcdl KO animals were significantly impaired in fear-associated learning, as assessed by inhibitory avoidance (IA) task, mouse hippocampal development and/or function.

We next examined paired-pulse-induced facilitation, a form of short-term pre-synaptic

\section{Fibcd1 deficiency induced synaptic dysfunction are rescued by CSPG digestion}

To validate our behavioural findings and ascertain the possible effects of CS-4S accumulation in synaptic function we next performed field recordings of acute hippocampal slices from adult Fibcdl WT and KO mice pre-incubated with ChABC or penicillinase (Pen, a treatment control that has no endogenous substrate in the brain). We hypothesised that deficiencies caused by the accumulation of GAGs containing CS-4S in the Fibcd1 KO hippocampus could be rescued by digestion with $\mathrm{ChABC}$, as is the case with other neuropathies associated with increased CSPG levels (e.g. Alzheimer's disease ${ }^{41,42}$ ).

Therefore, we examined the electrical properties of the CA3 Schaffer-collateral to CA1 circuit, a key pathway implicated in the formation and maintenance of spatial memories ${ }^{43}$. We first analysed basal properties of synaptic transmission using standard input/output protocols and found no significant differences between all conditions (Fig. S5E-F), indicating the ChABC treatment does not alter the properties of basal synaptic transmission in agreement with previous literature ${ }^{44}$ and indeed, no differences between pen-treated Fibcdl WT and KO hippocampi. plasticity directly related to neurotransmitter release ${ }^{45}$. We observed no differences between 
bioRxiv preprint doi: https://doi.org/10.1101/2021.09.09.459581; this version posted September 10, 2021. The copyright holder for this preprint (which was not certified by peer review) is the author/funder. All rights reserved. No reuse allowed without permission. compared to Pen-treated WT slices (Fig. 4C-D). Remarkably, this reduction was restored to

WT levels in the ChABC-treated KO slices (Fig. 4C-D). Finally, we examined the effects of theta-burst stimulation (TBS) induced synaptic long-term potentiation (LTP) such as the kind recorded during learning events in mice. Consistent with previous literature ${ }^{44,46}, \mathrm{ChABC}$ treatment reduced, but did not abolish, potentiation in WT slices, starting at the first recorded pulse (Fig. 4E, blue traces). We found slices from KO mice pre-treated with Pen to exhibit reduced potentiation similar to WT ChABC-treated slices (Fig. 4E, dark blue vs dark red traces), but, remarkably, this deficit was again rescued in $\mathrm{KO}$ slices pre-treated with $\mathrm{ChABC}$ (Fig. 4E, pink trace and Fig. S5G-H).

\section{Fibcd1 neuronal function is evolutionarily conserved in Drosophila melanogaster}

We next investigated if the role of Fibcd1 in the nervous system is conserved in other species. CG10359 is a putative Fibcd1 orthologue in Drosophila melanogaster (D. melanogaster), with a high degree of FReD amino acid sequence homology (Fig. S6A) between human and mouse Fibcd1 and D. melanogaster CG10359 (hereafter referred to as $d F i b c d 1$ ). As of yet, dFibcd1 has no assigned function. To assess the function of $d F i b c d 1$, we performed RNA interference (RNAi)-mediated $d F i b c d l$ knockdown. We crossed three independent RNAi constructs targeting $d F i b c d 1$ (downstream of $U A S$ promoter sequence, hereafter as lines \#1, \#2 and \#3) with lines expressing GAL4 under the control of either the tubulin (tub) promoter for whole body RNAi expression or the neuronal Synaptobrevin promoter (Nsyb) for neuronal expression

$$
\text { so we proceeded only with flies with neuronal knockdown of } d F i b c d 1 \text {. }
$$


bioRxiv preprint doi: https://doi.org/10.1101/2021.09.09.459581; this version posted September 10, 2021. The copyright holder for this preprint (which was not certified by peer review) is the author/funder. All rights reserved. No reuse allowed without permission. Neuronal knockdown of $d F i b c d 1$ resulted in abnormal neuronal development,

visualized in neuronal morphology at the larva neuromuscular junction (NMJ) (Fig. 4F). All neuronal RNAi lines exhibited reduced number of pre-synaptic boutons (Fig. 4G) and line 3 further exhibited reduced degree of neuronal branching, suggesting a reduction in neuronal function (Fig. 4H). To assess if these developmental defects also manifested as neurological phenotypes in adults, we assessed the climbing behaviour of these flies by negative geotaxis assay. We found that neuronal knockdown of $d F i b c d 1$ resulted in reduced climbing ability when compared to control flies expressing control RNAi targeting luciferase (Fig. 4I and Fig. S6C). Taken together, our results suggest a critical role for Fibcd1 in D. melanogaster survival and neuronal development and function.

\section{Characterisation of human FIBCD1 expression and function}

We next asked whether the expression and function of Fibcdl is conserved in humans. We profiled FIBCDI expression using a cDNA array from 48 different human tissues and determined that the brain is the third highest FIBCD1 expressing tissue in humans (Fig. 5A). A further FIBCD1 gene expression analysis of cDNA array from 24 different human brain regions determined that FIBCD1 expression is highest in the hippocampus, followed by the hypothalamus and cortex, very similar to the Fibcdl expression profile in the mouse brain (Fig. 5A, inset). Considering FIBCD1's function in mouse brain and the similarity of expression of Fibcdl transcripts in human and mouse CNS, we reasoned that patients with deleterious variants in FIBCD1 would suffer from neurological dysfunctions. To our knowledge, there are no genetic disorders associated with variants in FIBCD1 to date. The Genome Aggregation Database $\left(\right.$ gnomAD $\left.{ }^{47}\right)$ that documents sequenced human genetic variants, reports 266 variants annotated as missense, stop-gained, frameshift or splice disrupting within the FIBCD1 gene (Fig. S7A). As gnomAD does not report on zygosity or health status of any sequenced 
bioRxiv preprint doi: https://doi.org/10.1101/2021.09.09.459581; this version posted September 10, 2021. The copyright holder for this preprint (which was not certified by peer review) is the author/funder. All rights reserved. No reuse allowed without permission. individual in the database, we searched for undiagnosed rare disease patients with high Combined Annotation Dependent Depletion (CADD) scoring variants in FIBCD1 within our network and through GeneMatcher ${ }^{48}$ and were able to locate 2 unrelated patients with undiagnosed neurodevelopmental disorders. Patient $1(\mathrm{P} 1)$ is a 12 year old nonverbal male from a Caucasian non-consanguineous family (Fig. 5B), with severe autism spectrum disorder (ASD), delayed verbal cognition, anxiety and attention deficit hyperactivity disorder (ADHD). He has high pain tolerance, fine motor coordination deficits and mild facial dysmorphia. Additionally, he experiences frequent allergic rhinitis and sinusitis (Table 1). There is no history of neurological disease in the family, however, several members of the maternal family have learning disabilities. As part of his clinical diagnostic evaluation, whole exome sequencing (WES) was performed at GeneDx, USA (www.genedx.com) and identifying compound heterozygous variants in FIBCD1 Chr9:133805421 C>T; c.85 G>A; p.(G29S) and Chr9:133779621 G>A; c.1216C>T; p.(R406C), with CADD scores of 6.832 and 25.1, respectively, and a de novo variant in CSMD3 Chr8: $113933925 \mathrm{~T}>\mathrm{C}$; c.1564 A>G; p.(K522E) with a CADD score of 24.7. While CSMD3 variants have been reported in association with neurodevelopmental disorders, most published missense variants have population data in gnomAD or internal data at GeneDX, reducing the likelihood that this variant is related to the phenotype $\left({ }^{49}\right.$; GeneDX, Inc. personal communication). Therefore, the FIBCD1 variants were prioritised for further analysis. Sanger sequencing determined each variant was inherited from one of the parents (Fig. 5B). There were no other variants with confirmed association to human disease identified that would match the phenotype or inheritance pattern. Patient 2 (P2) is a nonverbal 3 year old Chinese female from a non-consanguineous family with no history of genetic neurological disease (Fig. 5B), that presented with severe neurodevelopmental disorder (NDD), delayed social and cognitive abilities and delayed sitting and walking. Magnetic resonance imaging (MRI) revealed thickened cortex, decreased white/grey matter ratio, bilateral enlarged frontal gyri and ventriculomegaly (Fig. 5C). The patient also has 
bioRxiv preprint doi: https://doi.org/10.1101/2021.09.09.459581; this version posted September 10, 2021. The copyright holder for this preprint (which was not certified by peer review) is the author/funder. All rights reserved. No reuse allowed without permission. microcephaly and dysmorphic facial features (Table 1). Additionally, recurrent pneumonia was also noted. Clinical genetic testing was performed and revealed inheritance by uniparental disomy (UPD) with mosaicism. Homozygous variants of unknown significance were found in FIBCD1 Chr9:133779470 G>A; c.1367C>T; p.(P456L) with a CADD score of 29, UNC13B

Chr9:35376187; c.1531T>C; p.(C511R) with a CADD score of 28.4, and RIC1 Chr9:5765523; c.2951C $>$ T; p.(A984V) with a CADD score of 28.6. Variants within $U N C 13 B$ and RIC1 were deprioritised from further functional studies due to a lack of clinical similarities with published cases $^{50-52}$.

To determine whether the $F I B C D 1$ variants found in these patients affect protein folding or function we first performed all-atom molecular dynamics (MD) simulations in the microsecond range of the two FIBCDI variants contained within the FReD domain (p.R406C and p.P456L) and the WT as control. In the course of MD simulations, both WT and patient variant conformations stay relatively close to the initial structure, with the backbone root-meansquared-deviations (RMSD) being the highest for R406C, intermediate for P456L and the lowest for WT (Fig. S7B), but never exceeding $2.5 \AA$. In order to compare WT and the two mutant structures, the dominant MD conformations were identified using structural clustering. The dominant P456L and R406C structures, deviate from the dominant WT structure by $1.6 \AA$ and $1.5 \AA$ backbone RMSD, respectively, while being relatively more similar to each other (1.2 $\AA$ ). The largest structural rearrangements induced by the variants take place in the 389-399 and 423-448 loop regions, which surround the ligand binding site (Fig. 5E). Here, the R406C variant has a direct effect due to a disruption of the salt bridge between R406 and D433, which in the WT likely stabilises the mutual arrangement of the two loop regions. In the case of the P456L variant, the effect is rather allosteric, whereby perturbation of the conformational dynamics of the C-terminus, likely due to the removal of the sterically restricted P456, is transmitted towards the upstream 423-448 loop region. Importantly, the similar structural effect of both variants is connected to a similar perturbation of the electrostatic properties on the protein surface in the 
bioRxiv preprint doi: https://doi.org/10.1101/2021.09.09.459581; this version posted September 10, 2021. The copyright holder for this preprint (which was not certified by peer review) is the author/funder. All rights reserved. No reuse allowed without permission. vicinity of the ligand binding site. In particular, both variants significantly increase the negative charge density of the surface patch surrounding the ligand binding site (especially R406C), in stark contrast with the WT where the corresponding surface is positively charged (Fig. 5E). We expect that this perturbation significantly weakens the binding of negatively charged phosphorylated ligands by the mutated FReDs.

To substantiate these observations, we generated HEK293T cell lines stably overexpressing FLAG-tagged human WT FIBCD1 cDNA and each of the variants G29S, R406C and P456L, as well as the $\mathrm{W} 6$ * variant located in gnomAD database (Fig. S7A) which generates a premature STOP codon at the $6^{\text {th }}$ amino acid of FIBCD1, and results in a nonfunctional protein that serves as a negative control. We confirmed expression in each overexpressing cell line, barring $\mathrm{W}^{*}$, by immunofluorescence (Fig. S7C). We next asked if the variants identified in our patients functionally perturbed FIBCD1:CS-4S binding, as indicated by the molecular dynamics study. We incubated HEK293T cells overexpressing WT, W6*, G29S, R406C and P456L FIBCD1 cDNAs with FITC-tagged CS-4S and acquired by flow cytometry. As with mouse WT Fibcd1 we determined that cells expressing full length human WT FIBCD1 showed increased percentage of $\mathrm{FITC}^{+}$cells relative to unstained cells (Fig. 1F) or cells expressing FIBCD1_W6*. Intriguingly, this was not the case for cells expressing any of the patient variants, which exhibited similar percentage of $\mathrm{FITC}^{+}$cells as the untransduced control (Fig. 5F). Together these data suggest that while the FIBCDI variants identified in patients did not affect protein expression, they disrupted the binding of FIBCD1 to CS-4S. Further, our molecular docking experiments suggest that, for the R406C and P456L variants, the disturbed binding may be due to a disruption of the surface electrostatic charge of the CS-4S binding pocket of FIBCD1's FReD. Taken together, we conclude that P1 and 2 carry variants deleterious to FIBCD1 function potentially contributing to their symptoms and reveal FIBCD1 as a novel candidate gene for NDD. 
bioRxiv preprint doi: https://doi.org/10.1101/2021.09.09.459581; this version posted September 10, 2021. The copyright holder for this preprint (which was not certified by peer review) is the author/funder. All rights reserved. No reuse allowed without permission.

\section{DISCUSSION}

Here we report that FIBCD1, highly expressed in the mammalian brain, is a novel receptor of CSPGs, which preferentially binds to CS-4S GAGs and mediates a transcriptional program required for cell-cell and cell-matrix interactions. Using genetically modified mice and flies, we find that FIBCD1 is critical for neuronal maturation and function, whose downregulation leads to neurodevelopmental impairments and hippocampal-dependent learning deficiencies, likely resulting from aberrant accumulation of CS-4S. Additionally, we have identified 2 unrelated patients with complex NDDs that include ASD, carrying deleterious variants within the FIBCD1 gene, implicating FIBCD1 as critical to CNS development in humans and as a novel risk gene for NDDs.

FIBCD1 is an endocytic lectin, reported to bind chitin on cellular walls of pathogens and to regulate the innate immune response to candida infections ${ }^{18,19}$. We provide computational, biochemical, cellular and in vivo evidence that FIBCD1 also has endogenous ligands in the brain and intimately participates in the regulation of ECM composition through endocytosis or receptor-mediated signalling, or both. Indeed, transcriptomic changes upon CSPG stimulation of FIBCD1 WT and KO primary hippocampal cultures reveal a novel liganddependent signalling function for FIBCD1, primarily encompassing genes involved in ECM binding and structure. Interestingly, a number of DEGs were integrin subunits or integrinrelated genes, molecules well known for interacting with the ECM and signalling during neuronal development and synaptic activity ${ }^{1,4}$. Considering that closely related proteins containing FReDs have been shown to directly interact with integrins ${ }^{53}$, it is tempting to speculate a physical Fibcd1:integrin interaction, the mechanism of which remains to be uncovered. We cross-referenced the DEGs present in both the $\mathrm{WT}^{\mathrm{CSPG}}$ vs WT and $\mathrm{KO}^{\mathrm{CSPG}}$ vs KO datasets to identify the genes specifically regulated by Fibcd1 binding to CSPGs. We identified a number of genes coding for integrin subunits or integrin binding and/or modulation 
bioRxiv preprint doi: https://doi.org/10.1101/2021.09.09.459581; this version posted September 10, 2021. The copyright holder for this preprint (which was not certified by peer review) is the author/funder. All rights reserved. No reuse allowed without permission. as well as genes involved in the synthesis or degradation of ECM components and, finally,

genes involved in binding to the ECM and adhesion of cells to the ECM. While the functions of many of these genes have been elucidated in a non-neuronal context, it's likely that their function is largely conserved in neurons and, therefore, these genes make up the transcriptional fingerprint regulated by FIBCD1's interaction with CSPGs in primary hippocampal neurons.

The accumulation of CS-4S in the Fibcd1 KO mouse hippocampi, and the ChABCmediated rescue of LTP, strongly support the primary role of FIBCD1 as an endocytic receptor. However, it is unclear whether FIBCD1 binds entire CSPGs or its specifically sulphated GAG components and how this binding activates transcriptomic changes noted in neuronal cultures in vivo. The complete rescue of LTP deficits by ChABC digestion of CSPGs suggests that the hippocampus develops normally in the absence of FIBCD1 and it is the pathological accumulation of GAGs containing CS-4S over time that is responsible for the observed behavioural and synaptic phenotypes. This is in contrast to the dependence of $d F i b c d 1$ expression in D. melanogaster survival and neuronal development as exhibited by the lethality of the full body $d F i b c d 1$ knock-down flies, suggesting that Fibcdl may have developed a more specialised role in mammals. Nevertheless, it will be of great interest to delineate the role of CS-4S during activity-driven synaptic activity, in what context it is released from the ECM and how it contributes to hippocampal function.

It is widely recognised that brain ECM composition is critical for CNS development and function and there is growing evidence that deleterious variants in genes encoding glycoproteins, enzymes involved in glycosylation, or those required for their clearance and degradation contribute to neurodevelopmental dysfunctions, such as $\mathrm{ASD}^{7}$. Here, we presented evidence for an additional risk gene, $F I B C D 1$, in two patients that exhibit symptoms of severe neurodevelopmental dysfunctions, including delayed social, cognitive and verbal abilities, ASD, ADHD, facial dysmorphias and structural brain anomalies. P2 was too young at last 
bioRxiv preprint doi: https://doi.org/10.1101/2021.09.09.459581; this version posted September 10, 2021. The copyright holder for this preprint (which was not certified by peer review) is the author/funder. All rights reserved. No reuse allowed without permission. examination to be fully evaluated for ASD or ID, however, while exhibiting similar symptoms

as P1, was more affected. Intriguingly, signs of immune system dysfunction such as recurring allergic rhinitis, sinusitis and pneumonia in both patients is in line with the literature describing FIBCD1 in immune responses ${ }^{54}$. In addition to $F I B C D 1$ variants, P2's exome sequencing revealed additional variants of unknown significance (VUS) in $U N C 13 B$ and RIC1. UNC13B encodes a pre-synaptic protein highly expressed in the brain, MUNC13-2, that has recently been associated with partial focal epilepsy ${ }^{52}$, not found in P2, and was therefore dismissed as potentially causative in this case. Variants in RICl gene have recently been associated with autosomal recessive CATIFA Syndrome (cleft lip, cataract, tooth abnormality, intellectual disability, facial dysmorphism, attention-deficit hyperactivity disorder, OMIM: $618761)^{50,51}$. With the exception of P2's micrognathia, she exhibits none of the hallmark symptoms of CATIFA syndrome (cleft lip, cataracts, tooth abnormalities). However, the contribution of the RIC1 variant to the overall clinical pathology of the patient cannot be ruled out, even if unlikely.

In silico molecular simulation studies and cellular assays have determined the deleteriousness of the identified $F I B C D 1$ variants. Molecular modelling analysis has suggested that the FReD variants, R406C (P1) and P456L (P2), both lead to FIBCD1 loss-of-function by disrupting the binding pocket's electrostatic charge and diminishing the affinity to its GAG ligand, which is consistent with our cellular assay for FIBCD1:CS-4S binding. However, it is less clear how the other P1 variant, G29S, disrupts binding of FIBCD1 to CS-4S. While we find the glycine at this residue is largely conserved among other species, the mouse orthologue contains the same substitution of glycine to serine as in P1, yet this substitution in the human $F I B C D 1$ orthologue was similarly disruptive of binding to GAGs as the other variants. How the function of G29 residue diverges from mouse to human, whether it is important for structural confirmation of FIBCD1, targeting, or downstream signalling remains to be elucidated. Nevertheless, we demonstrated all three FIBCD1 variants to be deleterious to protein function 
bioRxiv preprint doi: https://doi.org/10.1101/2021.09.09.459581; this version posted September 10, 2021. The copyright holder for this preprint (which was not certified by peer review) is the author/funder. All rights reserved. No reuse allowed without permission. of FIBCD1 and in view of the data in the model organisms and cell culture, is likely to be causative of the patients' symptoms. Full understanding of the neuropathology caused by deleterious $F I B C D 1$ variants awaits more clinical cases for comparison of their clinical symptoms.

Overall, FIBCD1 is a regulator of CS-4S content in the hippocampal ECM and a mediator of ECM signalling. FIBCD1 is a critical regulator of synaptic plasticity events underlying certain types of learning and memory in mice and a novel risk gene for a complex form of neurodevelopmental disorder.

\section{AUTHOR CONTRIBUTIONS}

Conceptualisation: V.N. Formal Analysis: C.W.F., A.H., A.C., L.L., J.S.S.L., M.A.T., T.K., S.M., J.S., A.A.P., A.S., M.M.M., J.J., J.B.M., V.N. Funding Acquisition: J.P., V.N. Investigation: C.W.F., A.H., A.C., L.L., J.S.S.L, M.A.T., M.H., S.M., J.S., A.A.P., A.S., K.A.T., H.Y., J.W., T.L.A., G.W., J.B.M., V.N. Resources: N.P., B.Z., F.Q.M., J.B.M., J.M.P., V.N. Supervision: U.H., N.P., B.Z., F.Q.M., J.B.M., J.M.P., V.N. Visualisation: C.W.F., A.H., A.C., M.H., L.L., J.S.S.L., S.M., M.A.T., J.S., A.A.P., J.B.M., V.N. Writing - original draft: C.W.F., V.N., with contribution from all authors.

\section{ACKNOWLEDGMENTS}

We thank Malene Hyggelbjerg Nielsen for excellent technical assistance with the ISH data. We are thankful to all members of the IMP-IMBA Bio-optics Core Facility for assistance in cell sorting and imaging as well as the Molecular Biology Service for their help. Moreover, we thank the Preclinical Phenotyping Facility, the Preclinical Imaging Facility and the Next 
bioRxiv preprint doi: https://doi.org/10.1101/2021.09.09.459581; this version posted September 10, 2021. The copyright holder for this preprint (which was not certified by peer review) is the author/funder. All rights reserved. No reuse allowed without permission.

member of Vienna BioCenter (VBC), Austria.

C.W.F. is funded by a DOC fellowship of the Austrian Academy of Sciences (OeAW):

25525; L.L. is a fellow of the Damon Runyon Cancer Research Foundation (DRG-2319-18);

S.M. is funded by the European Union's Horizon 2020 research and innovation programme under the Marie Sklodowska-Curie grant agreement No. 841319; J.B.M. is funded by the Novo Nordisk foundation; J.M.P. is supported by the Austrian Federal Ministry of Education, Science and Research, the Austrian Academy of Sciences and the City of Vienna and grants from the Austrian Science Fund (FWF) Wittgenstein award (Z 271-B19), the T. von Zastrow foundation, and a Canada 150 Research Chairs Program (F18-01336); V.N. is funded by Ludwig Boltzmann Gesellschaft core funding.

\section{DECLARATIONS OF INTEREST}

J.J. and M.M.M. are employees of GeneDx, Inc. 
bioRxiv preprint doi: https://doi.org/10.1101/2021.09.09.459581; this version posted September 10, 2021. The copyright holder for this preprint (which was not certified by peer review) is the author/funder. All rights reserved. No reuse allowed without permission.

\section{Patients and Whole Exome Sequencing}

All procedures were performed following informed consent and approval from patients and relatives.

\section{Patient 1}

Using genomic DNA from the proband and parents, the exonic regions and flanking splice junctions of the genome were captured using the IDT xGen Exome Research Panel v1.0 (Integrated DNA Technologies, Coralville, IA). Massively parallel (NextGen) sequencing was done on an Illumina system with $100 \mathrm{bp}$ or greater paired-end reads. Reads were aligned to human genome build GRCh37/UCSC hg19, and analysed for sequence variants using a customdeveloped analysis tool. Additional sequencing technology and variant interpretation protocol has been previously described ${ }^{55}$. The general assertion criteria for variant classification are publicly available on the GeneDx ClinVar submission page (http://www.ncbi.nlm.nih.gov/clinvar/submitters/26957/).

\section{Patient 2}

Procedures were in accordance with the ethical standards and approval of the Medical Ethics Committee of Peking University First Hospital. The IRB number is No. [2005]004. Patients were sequenced and analysed as described previously ${ }^{56}$, with sequencing performed by Joy Oriental Co. (Beijing, China).

\section{Population Genetics}

CADD scores and amino acid positions for FIBCD1 variants present in the population were extracted from GnomAD ${ }^{47}$ and visualised using PopViz ${ }^{57}$. 
bioRxiv preprint doi: https://doi.org/10.1101/2021.09.09.459581; this version posted September 10, 2021. The copyright holder for this preprint (which was not certified by peer review) is the author/funder. All rights reserved. No reuse allowed without permission.

Animals

\section{Mus musculus}

Fibcd1tm1Lex mice (MGI: 5007144) ${ }^{29}$ were bred on a C57BL/6J genetic background. Mouse genotypes were assessed by PCR (see Supplementary Table 1 for genotyping primer sequences). Of note, only age- and sex-matched littermates from respective crosses were used for experiments. All mice were housed at the Comparative Medicine Mousehouse Vienna BioCenter, Vienna, Austria, maintained at a 12-h light/dark cycle and provided with food and to EU-directive 2010/63/EU.

\section{In situ hybridisation}

The brain tissue was dissected from two 8-10 weeks old C57B6J mice and fixed in buffered 4\% paraformaldehyde, dehydrated and paraffin-embedded. 3.5- $\mu$ m-thick frontal sections were in situ hybridized with an enhanced RNAScope 2.5 high-definition procedure (310035, ACD Bioscience), as described previously ${ }^{58}$. The sections were hybridized with 20 probe pairs for mouse Fibcdl mRNA (524021, ACD Bioscience, targeting nucleotide 629 - 1567) or probe diluent as negative control. The probe pairs were branch amplified as instructed by the manufacturer, and further tyramide-enhanced using digoxigenin-conjugated tyramide (NEL748001KT, PerkinElmer) followed by alkaline phosphatase-conjugated sheep antidigoxigenin FAB fragments (11093274910, Roche) and visualization with Liquid Permanent 
bioRxiv preprint doi: https://doi.org/10.1101/2021.09.09.459581; this version posted September 10, 2021. The copyright holder for this preprint (which was not certified by peer review) is the author/funder. All rights reserved. No reuse allowed without permission.

\section{RNA-sequencing}

RNA was isolated using Qiagen RNeasy Mini kit (74104). Library prep, sequencing and alignment were done at the Vienna BioCenter Next Generation Sequencing Facility. RNA was quantified on a Qubit Fluorometric Quantitation system (Life Technologies) and RNA integrity score calculated using a Bioanalyzer (Agilent). Poly-A enrichment was performed using NEBNext Poly(A) mRNA Magnetic Isolation Module (NEB \#E7490) and library prep performed using NEBNext Ultra II Directional RNA Library Prep Kit for Illumina (NEB \#E7760) and sequenced on an Illumina HiSeq 3000/4000, 50bp single-read.

\section{RNA-seq analysis}

Demultiplexing, quality control, and alignment to the genome was done by the VBC Next Generation Sequencing Facility (Vienna, Austria). Calculation of differentially expressed genes (DEGs) was performed using Bioconductor DESeq2 package ${ }^{59}$. All DEGs located on the X or Y chromosomes were excluded due to uncontrollable distributions of male and female E18.5 pups from which hippocampal neurons were harvested. Sequencing data was uploaded and analysed on the Galaxy web platform (www.usegalaxy.eu $)^{60}$. GO term enrichment analysis was performed using WebGestalt ${ }^{61}$, over-representation analysis method.

\section{$\underline{\text { RT-qPCR }}$}

\section{Mouse}

For mouse Fibcdl expression analysis by RT-qPCR, tissues and cells were isolated and homogenized in TRIzol reagent (Invitrogen). Total RNA was isolated according to the manufacturer's instructions. RNA was reverse transcribed with the iScript cDNA synthesis kit 
bioRxiv preprint doi: https://doi.org/10.1101/2021.09.09.459581; this version posted September 10, 2021. The copyright holder for this preprint (which was not certified by peer review) is the author/funder. All rights reserved. No reuse allowed without permission. (Bio-Rad). Real-time PCR analysis was performed with GoTaq qPCR master mix (Promega) on a CFX384 system (Bio-Rad). Data were normalized to values for the housekeeping gene Gapdh. See Supplementary Table 1 for a list of primers used in this study.

\section{Human}

Human cDNA panels were obtained from Origene: TissueScan, Human Brain cDNA Array (\#HBRT101), TissueScan, Human Normal cDNA Array (\#HMRT304). Master mixes containing primer pairs against $F I B C D 1$ or $B 2 M$ (Beta-2-microglobulin, housekeeping gene) were prepared with iTaq Universal SYBR Green Supermix (Bio-Rad \#1725122). The mastermixes were dispensed into each well containing cDNA and incubated on ice for 15 minutes to allow the cDNA to dissolve, then briefly vortexed. Reactions were run on Applied Biosystems StepOne Plus machine with standard settings including the melt curve. Data were normalised to values for the housekeeping gene $B 2 M$. See Supplementary Table 1 for a list of primers.

\section{In Silico Modelling of FIBCD1}

\section{Docking}

In silico molecular docking was performed using GOLD software version 5.2.2. $2^{62}$ and an X-ray structure of the extracellular FReD (PDB 4M7F) ${ }^{21}$. The post-rescoring of docking solutions (100 in total) was carried out as described previously ${ }^{26}$. The binding free energy of CS-4S and CS-6S to FReD domain was estimated using PRODIGY-LIGAND ${ }^{27}$ after refinement of the complexes using HADDOCK2.2 web-server ${ }^{63}$.

\section{Patient Variant Modelling}

The initial protein configuration was taken from the X-ray structure of the FReD (PDB: 4M7F; aa 239-458), where single point mutations R406C and P456L were introduced using PyMol ${ }^{64}$. 
bioRxiv preprint doi: https://doi.org/10.1101/2021.09.09.459581; this version posted September 10, 2021. The copyright holder for this preprint (which was not certified by peer review) is the author/funder. All rights reserved. No reuse allowed without permission. simulations in rectangular boxes $\left(6 \times 6 \times 6 \mathrm{~nm}^{3}\right)$ filled with $\sim 6000$ explicit water molecules. A total of $1 \mu$ s of MD statistics was collected for each system. All MD simulations and the analysis were performed using GROMACS 5.1.4 package $^{65}$ and Amber99SB-ILDN force field ${ }^{66}$. After initial energy minimization, all systems were solvated using TIP3P water model ${ }^{67}$. The solvated systems had neutral net charge and effective $\mathrm{NaCl}$ concentration of $0.1 \mathrm{M}$. These systems were again energy-minimized and subjected to an MD equilibration of 30000 steps using a $0.5 \mathrm{fs}$ time step with position restraints applied to all protein atoms (restraining force constants $\mathrm{Fx}=\mathrm{Fy}=\mathrm{Fz}=1000 \mathrm{~kJ} \mathrm{~mol}^{-1} \mathrm{~nm}^{-1}$ ) and 250000 steps using a $1 \mathrm{fs}$ time step without any restraints. Finally, production runs were carried out for all systems using a 2 fs time step. A twin-range $(10 / 12 \AA)$ spherical cut-off function was used to truncate van der Waals interactions. Electrostatic interactions were treated using the particle-mesh Ewald summation with a real space cutoff 12 and $1.2 \AA$ grid with fourth-order spline interpolation. MD simulations were carried out using 3D periodic boundary conditions in the isothermal-isobaric (NPT) ensemble with an isotropic pressure of 1.013 bar and a constant temperature of $310 \mathrm{~K}$. The pressure and temperature were controlled using Nose-Hoover thermostat ${ }^{68}$ and a Parrinello-Rahman barostat $^{69}$ with 0.5 and 10 ps relaxation parameters, respectively, and a compressibility of 4.5 $\times 10^{-5} \mathrm{bar}^{-1}$ for the barostat. Protein and solvent molecules were coupled to both thermostat and barostat separately. Bond lengths were constrained using LINCS $^{70}$. Root-mean-squared deviations (RMSD) from the starting configuration were calculated using rms utility (GROMACS) over all backbone atoms. Conformational clustering of MD trajectories was performed using cluster utility (GROMACS) with the applied RMSD cut-off for backbone atoms of neighboring structures of $0.9 \AA-$ a minimum value at which only a single dominant state was identified for WT. Electrostatic potential was calculated and mapped onto the protein solvent accessible surface using the APBS web-service (https://server.poissonboltzmann.org) ${ }^{71}$. Protein structures were visualized using $\mathrm{PyMol}^{64}$. 
bioRxiv preprint doi: https://doi.org/10.1101/2021.09.09.459581; this version posted September 10, 2021. The copyright holder for this preprint (which was not certified by peer review) is the author/funder. All rights reserved. No reuse allowed without permission. Binding assays

Characterisation of FIBCD1 binding specificity to chondroitin sulphate 4S (CS-4S) and chondroitin sulphate 6S (CS-6S) was performed through ELISA-based inhibition experiments essentially as described previously ${ }^{18}$. In brief, microtiter plates (MaxiSorp, NUNC) were coated with $1 \mu \mathrm{g} / \mathrm{ml}$ acetylated BSA (Sigma) and blocked with TBS containing $0.05 \%$ Tween. Recombinant FIBCD1-FReD ${ }^{18}$ was added to each well in a constant concentration of $100 \mathrm{ng} / \mathrm{ml}$ in TBS containing $0.05 \%$ Tween and $5 \mathrm{mM} \mathrm{CaCl}_{2}$ together with 2-fold dilutions of CS-4S and CS-6S (Amsbio). After incubation overnight at $4{ }^{\circ} \mathrm{C}$ and washing, the wells were incubated for 2 hours at room temperature with $1 \mu \mathrm{g} / \mathrm{ml}$ biotinylated anti-FIBCD1 (clone 11-14-25), before washed and developed using HRP-conjugated streptavidin and TMB substrate.

\section{$\underline{\text { Tissue Culture }}$}

\section{Primary Neurons}

Timed pregnancy E18.5 pups were sacrificed by decapitation, the hippocampi dissected into 1x Hank's Buffered Saline Solution (HBSS, Gibco \#14185045) with 100 U/ml penicillin/streptomycin (Biowest \#L0022-020). The tissue was minced, incubated with trypsin $(0.025 \%)$ for 15 minutes at $37^{\circ} \mathrm{C}$, inverting every $5 \mathrm{mins}$, and the trypsin inactivated with $10 \%$ FCS-containing media. The tissues were then washed 3 times with HBSS and triturated with heat-polished glass pipettes. 200,000 dissociated cells were plated in $1 \mathrm{ml}$ of Neurobasal medium (ThermoFisher \#21103049) supplemented with 10\% FCS, 2mM L-glutamine (Gibco \#25030149), 1x B27 (Gibco \#17504001), 10mM Hepes (Gibco \#15630056), 100 U/ml pen/strep in a 12 -well plate and incubated at $37^{\circ} \mathrm{C}, 5 \% \mathrm{CO}_{2} .50 \%$ of media was exchanged to FCS-free medium after 24 hours and then every 36 hours. Cells were plated on coverslips coated with $0-4 \mu \mathrm{g} / \mathrm{ml}$ CSPGs (Merck \#CC117) with and without prior ChABC (Sigma-Aldrich C3667) digestion as described previously ${ }^{13,28}$. 
bioRxiv preprint doi: https://doi.org/10.1101/2021.09.09.459581; this version posted September 10, 2021. The copyright holder for this preprint (which was not certified by peer review) is the author/funder. All rights reserved. No reuse allowed without permission.

\section{Mouse}

Fibcd1 mouse cDNA with 3' V5 tag was ordered as a G-block from IDT and cloned along with $\Delta \mathrm{FReD}$ construct via restriction enzyme insertion cloning, using 5' XhoI and 3' EcoRI restriction enzyme sites. The constructs were cloned into a custom pMSCV-IRES-mCherry plasmid, see supplementary data for construct sequences.

Fibcd1 constructs were packaged into virus by $\mathrm{CaCl}_{2}$ transfecting $70-80 \%$ confluent

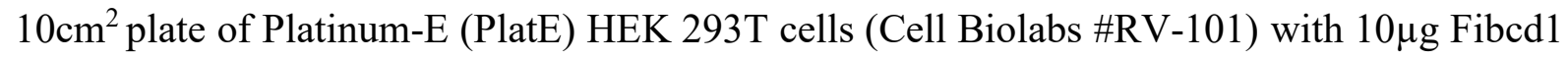
construct and $2 \mu \mathrm{g}$ gag/pol plasmid. The media was exchanged next day to remove transfection mixture. N2a cells' media was exchanged with virus-containing supernatant at 48- and 72-hours post-transfection with $8 \mu \mathrm{g} / \mathrm{ml}$ polybrene (Sigma \#H9268). N2a cells were expanded and FACS sorted for mCherry+ cells.

N2a cells stably expressing full-length V5-tagged FIBCD1, FIBCD1 lacking the fibrinogen domain $(\triangle \mathrm{FReD})$ or the empty vector (pMSCV-IRES-mCherry) were grown in DMEM supplemented with $10 \%$ foetal calf serum, $100 \mathrm{U} / \mathrm{ml}$ penicillin (Sigma) and $100 \mu \mathrm{g} / \mathrm{ml}$ streptomycin sulphate (Sigma).

\section{Human}

hFIBCD1 cDNA was ordered from Origene (\#RC206180) and sub-cloned by Gateway cloning (Thermo) into a custom plasmid (via pDONR201) with 3' 3xFLAG tags, mCherry and Blasticidine resistance selection markers, sequences are available in supplementary data. The PCR primers before the $\mathrm{BP}$ reaction were designed to remove the 3' STOP codon present in the Origene clone to allow read-through to the 3' 3xFLAG tags. Point variants were introduced into hFibcd 1 cDNA while cloned in the intermediate pDONR201 plasmid using the Q5 site-directed mutagenesis kit (NEB \#E0554), following the manufacturer's protocol, and the resultant clones 
bioRxiv preprint doi: https://doi.org/10.1101/2021.09.09.459581; this version posted September 10, 2021. The copyright holder for this preprint (which was not certified by peer review) is the author/funder. All rights reserved. No reuse allowed without permission. destination plasmid.

Cloned plasmids were packaged in Lenti-X 293T cells (Takara Biosciences \#632180), transfected using Lipofectamine 2000 (Thermo \#11668027), following the manufacturer's protocol. Per well of a 6 well plate, 1200ng of Fibcd1 plasmid was mixed with $150 \mu 1$ OptiMem (Gibco \#31985062), 700ng pGag/pol, 460ng pVSVg and 280ng pAdVAntage (Promega \#E1711) and transfected for 6-8 hours. Virus-containing supernatant was collected at 48 and 72 hours post-transfection.

HEK $293 \mathrm{~T}$ cells were transduced by spin infection using the above lentivirus and $6 \mu \mathrm{g} / \mathrm{ml}$ polybrene and transduced clones were selected using $14 \mu \mathrm{g} / \mathrm{ml}$ blasticidine for 48 hours. Stably transduced cells were maintained in DMEM (Thermo \#11960044), 10\% FCS, pen/strep and sodium pyruvate. Transduced cells were periodically re-selected with $14 \mu \mathrm{g} / \mathrm{ml}$ blasticidine for at least 48 hours.

\section{Flow cytometry}

\section{Mouse}

N2a cells stably expressing full-length V5-tagged mFIBCD1, mFIBCD1 lacking the fibrinogen domain $(\triangle \mathrm{FReD})$ or the empty vector (pMSCV-IRES-mCherry) were washed once with PBS and incubated for 4 hours with $100 \mu \mathrm{g} / \mathrm{ml}$ fluoresceinamine labelled glycosaminoglycans: 4-Osulfated chondroitin sulphate (AMS.CSR-FACS-A1, AMSBIO), poly-sulphated chondroitin sulphate (AMS.CSR-FACS-P1, AMSBIO) or dermatan sulphate (AMS.CSR-FADS-B1, AMSBIO) in DMEM. See Supplementary Table 2 for a list of flow cytometry antibodies used in this study. The staining medium was removed, cells were collected by gentle flushing with PBS and fluorescence was measured by FACS LSR Fortessa (BD). The experiment was performed in three independent replicates and analysed by FlowJo v10.6 (FlowJo LLC). 
bioRxiv preprint doi: https://doi.org/10.1101/2021.09.09.459581; this version posted September 10, 2021. The copyright holder for this preprint (which was not certified by peer review) is the author/funder. All rights reserved. No reuse allowed without permission.

\section{Human}

Untransduced HEK 293T cells or those stably expressing full length C-terminally 3xFLAG tagged hFIBCD1, hFIBCD1_W6*, hFIBCD1_G29S, hFIBCD1_R406C, hFIBCD1_P456L were seeded in full media. The next day, cells were washed 1x with PBS and trypsinised for precisely 1.5 minutes, pelleted at $4^{\circ} \mathrm{C}$, and resuspended in $10 \mu \mathrm{g} / \mathrm{ml} 4-\mathrm{O}$-sulfated chondroitin sulphate (AMS.CSR-FACS-A1, Amsbio) diluted in freshly prepared PBS $\left(0.8 \mathrm{mM} \mathrm{CaCl}_{2}\right)$ and incubated in a humidified incubator for 45 minutes. The cells were washed 1x in ice-cold PBS $(0.8 \mathrm{mM} \mathrm{CaCl} 2)$ and acquired on a LSRFortessa Cell Analyzer (BD Biosciences). The experiment was performed in two independent replicates and analysed by FlowJo v10.6.1 (FlowJo LLC).

\section{Protein isolation, Immunoprecipitations, and Western blots}

For protein extraction, hippocampi tissues were manually homogenized in $300 \mu \mathrm{l} \mathrm{ChAC}$ buffer (40 mM Tris-HCl pH 8.0, 40 mM sodium acetate, C3667, Sigma) containing Benzonase supplemented with Halt protease/phosphatase inhibitor cocktail (Thermo Scientific). After 10 minutes full-speed centrifugation, the supernatant containing the soluble protein fraction was separated from the pellet (insoluble fraction), which was resuspended in $300 \mu \mathrm{l} \mathrm{ChABC}$ buffer. Two aliquots of each fraction were brought to a protein concentration of $3 \mu \mathrm{g} / \mu \mathrm{l}(75 \mu \mathrm{g}$ protein in $25 \mu \mathrm{l} \mathrm{ChABC}$ buffer) and one aliquot of each fraction was further incubated with $\mathrm{ChABC}$ for 12 hours at $37^{\circ} \mathrm{C}$. After adding $25 \mu \mathrm{l}$ of Lämmli buffer, samples were heated 5 minutes at $95^{\circ} \mathrm{C}$ and $30 \mu 1$ were separated by SDS-PAGE and transferred onto PVDF membranes (Immobilion-P, Merck Millipore) according to standard protocols. Blots were blocked for 1 hour with 5\% milk in TBST (1x TBS and $0.1 \%$ Tween-20) and were then incubated overnight at $4^{\circ} \mathrm{C}$ with primary antibodies $(1: 100$, anti CS-0S, $1 \mathrm{~B} 5$; anti CS-4S, 2B6, antiCs-6S, 3B3; amsbio) diluted in 5\% milk in TBST. Blots were washed 3 times in TBST for 5 minutes and were then incubated with HRP-conjugated secondary anti-mouse-IgG-H\&L chain (Promega) 
bioRxiv preprint doi: https://doi.org/10.1101/2021.09.09.459581; this version posted September 10, 2021. The copyright holder for this preprint (which was not certified by peer review) is the author/funder. All rights reserved. No reuse allowed without permission. or anti-rabbit-IgG-F(ab')2 (GE Healthcare) antibody for 1 hour at room temperature, washed 3 times in TBST for 5 minutes and visualized using enhanced chemiluminescence (ECL, GE Healthcare). See Supplementary Table 2 for a list of antibodies used in this study. $\beta$-Actin was used to control for protein loading.

\section{Immunoprecipitation}

N2a cells expressing FIBCD1, FIBCD1 $\triangle \mathrm{FReD}$ or empty vector were washed twice with PBS and lysed in Hunt buffer (20 mM Tris-HCl pH 8.0, $100 \mathrm{mM}$ sodium chloride, $1 \mathrm{mM}$ EDTA, 0.5\% NP-40) supplemented with Halt protease/phosphatase inhibitor cocktail (Thermo Scientific) in 3 consecutive freeze and thaw steps. After full-speed centrifugation, the supernatant containing the soluble protein fraction was further used. An equal amount $(500 \mu \mathrm{g})$ of each protein lysate was precleared for 1 hour with magnetic Protein G Dynabeads (Invitrogen) and immunopurified with $40 \mu 1$ washed anti-V5 agarose beads (Sigma) overnight at 4C. After 5 washing steps in Hunt buffer, input (1/16 of the immunoprecipitation corresponding to $30 \mu \mathrm{g}$ ) and immunoprecipitation samples were separated by SDS-PAGE, blotted and stained with an antibody against V5 (ab15828, 1:2000 dilution), and Western blotting was performed as described above.

\section{$\underline{\text { Immunofluorescence/IHC }}$}

\section{Primary Neurons}

At 2 or 14 days after plating (DIV2 and DIV14, respectively), primary neuronal cultures were washed with PBS and then fixed in $4 \%$ PFA with $4 \%$ glucose for 10 minutes at room temperature, and subsequently quenched with $10 \mu \mathrm{M}$ glycine/PBS for 10 minutes at room temperature. They were then washed twice with $0.01 \%$ Triton-X/PBS (PBST), permeabilized with $0.25 \%$ Triton-X/PBS for 3 minutes and blocked in 5\% NGS for 1 hour. Primary antibodies were incubated overnight at $4^{\circ} \mathrm{C}$ and washed 3 times in PBST. Secondary antibodies were 
bioRxiv preprint doi: https://doi.org/10.1101/2021.09.09.459581; this version posted September 10, 2021. The copyright holder for this preprint (which was not certified by peer review) is the author/funder. All rights reserved. No reuse allowed without permission. incubated for 1 hour at room temperature and washed 3 times with PBST before mounting in ProLong Gold Antifade Mountant (Thermo \#P10144). Images were acquired on fluorescent microscope (Leica), acquiring semi-random fields of the coverslips. Images were analysed manually using ImageJ. Experimenters were blinded to genotype and plating conditions during image analysis.

\section{Drosophila melanogaster}

Wandering third instar female larvae were dissected in $\mathrm{Ca}+$ free PBS and fixed in $4 \%$ paraformaldehyde for 20 minutes. Larval body walls were blocked in serum, then incubated in primary antibodies overnight and secondary antibodies at room temperature for 2 hours while rocking. Samples were mounted in Prolong Diamond (Invitrogen) for analysis using the Zeiss LSM780 confocal microscope. Bouton number and axon branching were all identified using the anti-HRP antibody using ImageJ (NIH).

\section{HEK 293 T cells}

Untransduced HEK 293T cells and HEK 293T cells stably expressing full length 3xFLAG tagged (C-terminal) hFIBCD1, hFIBCD1_W6*, hFIBCD1_G29S, hFIBCD1_R406C, hFIBCD1_P456L were seeded onto glass coverslips. The next day, the cells were rinsed 1x with PBS and fixed in 4\% PFA (supplemented with $4 \%$ glucose) for 10 minutes at room temperature, then quenched for 10 minutes with PBS $(0.01 \mathrm{M}$ glycine) for another 10 minutes at room temperature. The cells were washed $2 \mathrm{x}$ with PBS then permeabalised with $0.25 \%$ Triton-X PBS for 1.5 minutes, washed 1x with PBS and blocked for 1 hour with 5\% normal goat serum at room temperature. Primary antibodies (anti-FLAG, 1:1000) were added overnight at $4^{\circ} \mathrm{C}$, washed $2 \mathrm{x}$ with PBS, then secondary antibodies added (Alexa Fluor Anti-mouse 546, 1:500) and DAPI (1:2000) incubated at room temperature for 1 hour, washed again $2 \mathrm{x}$ with 
bioRxiv preprint doi: https://doi.org/10.1101/2021.09.09.459581; this version posted September 10, 2021. The copyright holder for this preprint (which was not certified by peer review) is the author/funder. All rights reserved. No reuse allowed without permission.

MRI imaging

Anaesthetised male C57B16/J mice (12 month of age) and their Fibcdl KO littermates were imaged in the Preclinical Imaging Facility at Vienna Biocentre Core Facilities (pcPHENO, VBCF), member of Vienna Biocentre (VBC), Austria, as described previously ${ }^{72}$. Briefly, a 15.2 Tesla MRI (Brucker BioSpec, Ettlingen Germany) was used to image brains of anaesthetised animals (isoflurane $4 \%$ induction, maintenance with $1.5 \%$, Vana $\mathrm{GmbH}$ ) with a 3D fast long angle shot (FLASH) sequence with magnetization transfer pulse. Each 3D image set was manually segmented using Amira 5.6 (Visualization Science Group) using The Paxinos mouse brain atlas as a reference ${ }^{73}$. Values were normalized to brain size, averaged and presented as percentage of total brain volume.

\section{$\underline{\text { PNN visualisation with WFA }}$}

Brain was dissected from 8-10 week-old Fibcdl WT and KO mice and fixed in 4\% paraformaldehyde and paraffin-embedded followed by $20 \mu \mathrm{m}$ coronal sectioning. For staining, the tissues were re-hydrated with PBS, permeabilized in $0.5 \%$ Triton-X PBS for 15 mins at room temperature (RT) followed by blocking in $10 \%$ goat serum diluted in $0.25 \%$ Triton-X PBS for 1 hour at RT. After $2 \times 3$ mins washes with $0.1 \%$ tween-20 PBS, endogenous IgGs were blocked using goat $\mathrm{F}(\mathrm{ab})$ anti-mouse IgG (1:2000) diluted in $0.1 \%$ tween-20 PBS for 1 hour at RT. Next, tissues were washed $3 \mathrm{x} 3$ mins in $0.1 \%$ tween-20 PBS. Fluorescein Wisteria Floribunda Lectin (FL-1351, 1:500, Vector Laboratories) was diluted 1:500 in 0.1\% tween-20 PBS with 2\% goat serum and DAPI (Roth \#6335, 1:2000) for 1 hour at RT. Tissues were washed 3x 3mins in $0.1 \%$ tween-20 PBS and mounted using Fluoromount Aqueous Mounting Medium (Sigma \#F4680). Images were acquired using Vectra Polaris (Akoya). 
bioRxiv preprint doi: https://doi.org/10.1101/2021.09.09.459581; this version posted September 10, 2021. The copyright holder for this preprint (which was not certified by peer review) is the author/funder. All rights reserved. No reuse allowed without permission. $\underline{\text { Tissue sGAG quantification }}$

11-13-week-old Fibcd1 WT and KO mice (mix of male and female) were sacrificed by $\mathrm{CO}_{2}$ asphyxiation and the hippocampi dissected out and snap frozen in liquid nitrogen. Samples were weighed and analysed for sulphated GAG (sGAG) amounts using Blyscan Glycosaminoglycan Assay kit (Biocolor \#B1000), following the manufacturer's instructions, including Papain extraction (Sigma \#P3125).

\section{$\underline{\text { HPLC }}$}

Chondroitin sulphate was extracted from defatted, pronase digested mouse microdissected hippocampi (CA1 region) and digested using Chondroitinase ABC (from Proteus vulgaris, Sigma-Aldrich \#C3667). The resulting glycosaminoglycan-disaccharides were fluorescently labelled with 2-aminobenzamide by reductive amination and were analysed according to previous literature ${ }^{74}$. Identity of glycosaminoglycan-derived disaccharides was inferred from retention time alignment with the major constituents of chondroitin sulphate sodium salt from shark cartilage (Sigma-Aldrich, C4384), and bovine trachea (Sigma-Aldrich \#C9819).

\section{$\underline{\text { Behaviour assays }}$}

\section{Mouse}

Elevated Plus Maze were performed as described previously using an automated activity system (TSE-Systems, Germany) $)^{72}$. Mice were trained in the Morris Water Maze (pcPHENO, VBCF) as described previously ${ }^{72}$. T-Maze was performed as described previously ${ }^{72}$.

\section{Drosophila negative geotaxis assay}

Female Nsyb-Gal4 animals were crossed with the UAS-RNAi lines targeting CG10359. Female offspring were tested at 10d after eclosion. Offspring were flipped every third day and no more than 10 flies were kept in each vial. Flies were knocked-out with $\mathrm{CO}_{2}$, sorted into batches of 3- 
bioRxiv preprint doi: https://doi.org/10.1101/2021.09.09.459581; this version posted September 10, 2021. The copyright holder for this preprint (which was not certified by peer review) is the author/funder. All rights reserved. No reuse allowed without permission. 7 and given $25 \mathrm{~h}$ to recover before testing. On the day of testing, flies were flipped into empty vials and given $10-15 \mathrm{~m}$ to recover. The climbing index is the percentage of flies that pass the $5 \mathrm{~cm}$ mark in $5 \mathrm{~s}$ after gently tapping to the bottom of a plastic vial.

\section{Acute hippocampal slice preparation and electrophysiological recordings}

Memory-related synaptic plasticity and electrophysiological recordings were studied ex vivo in hippocampal slices essentially as previously described ${ }^{75-80}$. Briefly, mice were sacrificed by rapid cervical dislocation and swift sharp-blade decapitation. Brains were rapidly extracted and immediately immersed in a frosty artificial cerebrospinal fluid solution (aCSF) containing (in $\mathrm{mM}$ ): $125 \mathrm{NaCl}, 2.5 \mathrm{KCl}, 25 \mathrm{NaHCO}_{3}, 2 \mathrm{CaCl}_{2}, 1 \mathrm{MgCl}_{2}, 25$ D-glucose, and $1.25 \mathrm{NaH}_{2} \mathrm{PO}_{4}$ (all from Sigma-Aldrich). In all experimental conditions, aCSF was continuously bubbled with a mixture of $95 \%$ oxygen and 5\% carbon dioxide (Carbogen). Hippocampi were dissected while submerged in aCSF and transverse slices (300 $\mu \mathrm{m}$ in thickness) were obtained using a McIlwain Tissue Chopper (Mickle Laboratory Engineering, UK). Slices were quickly transferred to a custom-built submerged recovery chamber, where they rested for at least 1 hour submerged in $100 \mathrm{ml}$ of aCSF maintained at $30 \pm 2{ }^{\circ} \mathrm{C}$. For enzymatic treatments, slices were transferred to independent home-made digestion chambers containing $15 \mathrm{~mL}$ of aCSF (with $0.1 \%$ bovine serum albumin) plus $0.2 \mathrm{U} / \mathrm{mL}$ of either Penicillinase (Pen) (Sigma-Aldrich \#61305) or Proteus vulgaris Chondroitinase-ABC (ChABC) (Sigma-Aldrich\#C3667). Slices were enzymatically treated for 2 hours at $37^{\circ} \mathrm{C}$. After enzymatic treatment, slices were rinsed in separated beakers containing $100 \mathrm{~mL}$ of $\mathrm{aCSF}\left(32 \pm 1{ }^{\circ} \mathrm{C}\right)$ and gently transferred back to their corresponding recovery chamber for subsequent electrophysiological analysis. The synaptic function was studied by examining the electrical properties of the CA3-Schaffer collateral to CA1 circuit. The CA3-CA1 Schaffer collateral pathway was stimulated electrically via a home-made bipolar tungsten electrode insulated to the tip (50 $\mu \mathrm{m}$ tip diameter) and using an ISO-STIM 01D isolator stimulator (NPI Electronics, Tamm, Germany). Evoked field excitatory postsynaptic 
bioRxiv preprint doi: https://doi.org/10.1101/2021.09.09.459581; this version posted September 10, 2021. The copyright holder for this preprint (which was not certified by peer review) is the author/funder. All rights reserved. No reuse allowed without permission. potentials (fEPSPs) were recorded at the CA1 area using aCSF-filled glass micropipettes (2$4 \mathrm{M} \Omega$ ) located about $400 \mu \mathrm{m}$ away from the stimulating electrode. Input/output curves were obtained by delivering increasing pulses of voltage (100 $\mu$ s in duration) between $0-9 \mathrm{~V}$ with a delta of $1 \mathrm{~V}$ and $10 \mathrm{~s}$ between pulses. The strength of synaptic transmission was determined in each case from the decaying slope of recorded fEPSPs. To examine paired-pulse-induced synaptic facilitation, two pulses of voltage with a strength eliciting $40 \%$ of the maximum inducible fEPSPs amplitude as determined by input/output measurements ( $40 \% \mathrm{fEPSP}_{\max }$ ) were delivered at variable inter-pulse intervals ranging between $20-100 \mathrm{~ms}$ with a delta increment of $20 \mathrm{~ms}$ (pulse pairs delivered every $10 \mathrm{~s}$ ). The decaying slopes of the evoked fEPSPs for each consecutive pair of pulses was measured and the strength of synaptic potentiation was determined from the $2^{\text {nd }} / 1^{\text {st }}$ fEPSPs slope ratio. To study long-term potentiation, basal synaptic transmission (baseline) was examined for at least $20 \mathrm{~min}$ by recording stable fEPSPs in response to $40 \%$ fEPSP $_{\max }$ stimulating voltage pulses (100 $\mu$ s duration; fEPSPs elicited at $0.03 \mathrm{~Hz}$ ). After recording a steady baseline, a theta-burst stimulation (TBS) protocol was applied, consisting of five trains of $40 \% \mathrm{fEPSP}_{\max }$ stimulating voltage pulses at $100 \mathrm{~Hz}(100 \mu \mathrm{s} /$ pulse, with $4 \mathrm{~s}$ intertrain interval). Postsynaptic signal in response to baseline stimulating conditions was measured for 35-70 $\mathrm{min}$ as indicated in figure legends. Synaptic potentiation was determined by examining the temporal course of the decaying fEPSPs slopes following TBS, normalized to baseline values. Data from fEPSPs slopes attained when measuring long term potentiation were averaged for every 2 minutes. All recordings were made using an AxoClamp-2B amplifier (Bridge mode) and a Digidata-1440 interface (Axon Instruments). Data (5-22 slices/condition) were analysed using the pClamp-10 Program software (CA/Molecular Devices, USA). , 
bioRxiv preprint doi: https://doi.org/10.1101/2021.09.09.459581; this version posted September 10, 2021. The copyright holder for this preprint (which was not certified by peer review) is the author/funder. All rights reserved. No reuse allowed without permission.

\section{$\underline{\text { Sequence alignment }}$}

Human and mouse Fibcd1 and Drosophila CG10359 'Fibrinogen C-terminal' protein sequences were acquired from Uniprot.org. Multiple sequence alignment (MSA) was done using ClustalO algorithm (https://www.ebi.ac.uk/Tools/msa/clustalo/) ${ }^{81}$.

\section{$\underline{\text { Statistical analysis }}$}

\section{Flow cytometry}

Samples analysed by 1-way ANOVA.

\section{Immunofluorescence}

Images were counted manually and analysed by 1-way ANOVA. Experimenters were blinded to genotype and condition during analysis.

\section{Mouse behaviour}

Data was analysed by unpaired Student's t-test. $\mathrm{n}=$ an individual mouse.

\section{Drosophila}

All data sets were organized and analysed in Microsoft Excel and Prism. Statistical test type listed in the figure legends. Data sets with equal variance were analysed using ANOVA and Dunnett's post-hoc analysis for multiple comparison. Significance is defined as $\mathrm{P}<0.05$ and error bars are shown as standard error of the mean (SEM) unless otherwise noted.

\section{Electrophysiology}

Two-way ANOVA with repeated measures was used to compare values between treatment groups for input/output, paired-pulse and LTP set of data as depicted in scatter charts comparing pairs of values. Two-way ANOVA was used to compare values between treatment groups at a single time or voltage point as depicted in bar charts. Data values are represented as mean \pm

S.E.M. ( $\mathrm{p}$ values $<0.05$ were considered statistically significant). ${ }^{*} p \leq 0.05 ; * * p \leq 0.01 ; * * * p$ $\leq 0.001 ; * * * * p \leq 0.0001$ 
bioRxiv preprint doi: https://doi.org/10.1101/2021.09.09.459581; this version posted September 10, 2021. The copyright holder for this preprint (which was not certified by peer review) is the author/funder. All rights reserved. No reuse allowed without permission.

\section{Table of oligonucleotide sequences}

Genotyping primers:

\begin{tabular}{|l|l|}
\hline Fibcd1 WT & $\begin{array}{l}\text { CGCTGGTCTTGCTGGAAG } \\
\text { TCTTCTCTTCCCTCTGCACA }\end{array}$ \\
\hline Fibcd1 KO & $\begin{array}{l}\text { GCAGCGCATCGCCTTCTATC } \\
\text { TGGCACAGGTTAAGGAATT }\end{array}$ \\
\hline
\end{tabular}

Primers for qPCR:

\begin{tabular}{|l|l|}
\hline Gapdh & $\begin{array}{l}\text { GTCGGTGTGAACGGATTTGG } \\
\text { GACTCCACGACATACTCAGC }\end{array}$ \\
\hline$m$ Fibcd1(ex1-2) & $\begin{array}{l}\text { CTGGAAGATGGTCCACGAG } \\
\text { CCGTGCACAGGACATAACTG }\end{array}$ \\
\hline$m$ Fibcd1(ex3-4) & $\begin{array}{l}\text { TCAAGGCTGACCTTCAGAGG } \\
\text { GAAGCCAGCTGGGTAGTGAG }\end{array}$ \\
\hline$m$ Fibcd1(ex4-5) & CAGCTGGCTTCCAGGTCTAC \\
\hline CCAibcd1 & CAGGACGATGGAAAAGTTCA \\
\hline & GATCCTCTTGAGCCTACTC \\
\hline
\end{tabular}

Table of additional materials

\begin{tabular}{|l|l|}
\hline Antibodies for immunoblots: & \\
\hline$\beta$-Actin & A5316 (Sigma) \\
\hline CS-0S (1B5) & 270431-CS (Amsbio) \\
\hline CS-4S (2B6) & 270432-CS (Amsbio) \\
\hline CS-6S (3B3) & 270433-CS (Amsbio) \\
\hline Anti-V5 tag & Ab15828 (Abcam) \\
\hline & \\
\hline Fluorescent Sugars for Flow Cytometry: & \\
\hline Fluoresceinamine Labeled Sodium Chondroitin Sulfate A (A1) & AMS.CSR-FACS-A1 (Amsbio) \\
\hline Fluoresceinamine Labeled Sodium Chondroitin Poly-Sulfate (P1) & AMS.CSR-FACS-P1 (Amsbio) \\
\hline Fluoresceinamine Labeled Sodium Dermatan Sulfate (B1) & AMS.CSR-FADS-B1 (Amsbio) \\
\hline & \\
\hline Antibodies/dyes for immunofluorescence: & \\
\hline MAP2 & Millipore 05-346 \\
\hline FLAG (M2) & Sigma F1804 \\
\hline Alexa Fluor® 546 anti-mouse & Thermo A-11003 \\
\hline Goat F(ab) anti mouse (IgG) & Abcam (ab6668) \\
\hline Alexa Fluor 647 AffiniPure Goat Anti-Horseradish Peroxidase & Jackson Immunoresearch \\
\hline Mouse anti-nc82 (Bruchpilot) & Developmental Hybridoma Studies \\
\hline DAPI & Bank \\
\hline WFA-488 & Carl Roth \\
\hline & Vector Laboratories (FL-1351) \\
\hline
\end{tabular}

\section{Table of Drosophila Reagents}


bioRxiv preprint doi: https://doi.org/10.1101/2021.09.09.459581; this version posted September 10, 2021. The copyright holder for this preprint (which was not certified by peer review) is the author/funder. All rights reserved. No reuse allowed without permission.

\begin{tabular}{|c|c|}
\hline$\underline{\text { Stock }}$ & $\underline{\text { RRID/source }}$ \\
\hline$y[1] w\left[^{*}\right] ; P\{w[+m C]=r 4-G A L 4\} 3$ & BDSC_33832 \\
\hline $\mathrm{y}[1] \mathrm{v}[1] ; \mathrm{P}\{\mathrm{y}[+\mathrm{t} 7.7] \mathrm{v}[+\mathrm{t} 1.8]=T R i P . \mathrm{HMJ} 30271\}$ attP40 & BDSC_63703 \\
\hline w1118; P\{GD2280\}v4128/TM3 & FlyBase_FBst0464025 \\
\hline $\mathrm{P}\{\mathrm{KK} 105143\} \mathrm{VIE}-260 \mathrm{~B}$ & FlyBase_FBst0474536 \\
\hline$y[1] w\left[{ }^{*}\right] ; P\left\{w\left[+m^{*}\right]=n S y b-G A L 4 . S\right\} 3$ & BDSC_51635 \\
\hline$y[1] w\left[^{*}\right] ; P\{w[+m C]=t u b P-G A L 4\} L L 7 / T M 3, S b[1]$ Ser[1] & BDSC_5138 \\
\hline PBac\{UAS-empty\}VK00037 & Yoon et al., Cell Metabolism, 2017 \\
\hline$y[1]$ v[1]; P\{TRiP.JF01355\}attP2 & BDSC_31603 \\
\hline
\end{tabular}


bioRxiv preprint doi: https://doi.org/10.1101/2021.09.09.459581; this version posted September 10, 2021. The copyright holder for this preprint (which was not certified by peer review) is the author/funder. All rights reserved. No reuse allowed without permission.

Patient 1

Patient 2

\begin{tabular}{|c|c|c|c|}
\hline Background & Sex & $\mathrm{M}$ & $\mathrm{F}$ \\
\hline & Current Age & 12 y.o. & 3 y.o. \\
\hline & Ethnicity & Caucasian & Chinese \\
\hline & Karyogram & $46, \mathrm{XY}$ & $46, \mathrm{XX}$ \\
\hline & Consanguinity & No & No \\
\hline & FIBCD1 Variant & $\begin{array}{c}\text { Compound Het. } \\
\text { Chr9:133805421 C }>\text { T; } \\
\text { Chr9:133779621 G }>\text { A } \\
\text { c.85G }>\text { A ; c. } 1216 \mathrm{C}>\mathrm{T} \\
\text { p.G29S ; p.R406C }\end{array}$ & $\begin{array}{c}\text { Homozygous } \\
\text { Chr9: } 133779470 \mathrm{G}>\mathrm{A} \\
\text { c. } 1367 \mathrm{C}>\mathrm{T} \\
\text { p.P456L }\end{array}$ \\
\hline & $\begin{array}{l}\text { Family } \\
\text { Segregation }\end{array}$ & AR & UPD with mosaicism \\
\hline & Other Variants & $\mathrm{n} / \mathrm{a}$ & $\begin{array}{l}\text { UNC13B (p.C511R) and RIC1 } \\
\text { (p.A984V) }\end{array}$ \\
\hline \multirow[t]{12}{*}{ Neurology } & Diagnosis & Severe ASD & Severe NDD \\
\hline & \multirow{5}{*}{$\begin{array}{l}\text { Psychological } \\
\text { Evaluation }\end{array}$} & Delayed social abilities & Delayed social abilities \\
\hline & & Poor eye contact & \\
\hline & & Borderline delayed cognition & Delayed cognitive abilities \\
\hline & & Anxiety & \\
\hline & & ADHD combined type & \\
\hline & $\begin{array}{l}\text { Sitting and } \\
\text { Walking }\end{array}$ & Normal & Delayed \\
\hline & Language & Nonverbal & Nonverbal \\
\hline & Epilepsy & - & - \\
\hline & $\begin{array}{l}\text { Intellectual } \\
\text { Disability }\end{array}$ & - & Too young to be evaluated \\
\hline & Sensory & $\begin{array}{c}\text { High pain tolerance, sensitive } \\
\text { touch }\end{array}$ & o \\
\hline & Motoric & $\begin{array}{c}\text { Fine motor coordination } \\
\text { deficits }\end{array}$ & $\mathrm{n} / \mathrm{a}$ \\
\hline \multirow[t]{5}{*}{ Neuroradiology } & \multirow{5}{*}{ MRI } & \multirow[b]{5}{*}{$\mathrm{n} / \mathrm{a}$} & Slightly thickened cortex \\
\hline & & & Decreased white matter volume \\
\hline & & & Ventriculomegaly \\
\hline & & & Bilateral enlarged frontal gyri \\
\hline & & & Microcephaly \\
\hline \multirow[t]{5}{*}{ Dysmorphias } & \multirow{5}{*}{ Craniofacial } & Triangular shaped head & Micrognathia \\
\hline & & Hypertelorism & \\
\hline & & Almond-shaped eyes & \\
\hline & & $\begin{array}{c}\text { Posteriorly rotated and low set } \\
\text { ears }\end{array}$ & Low set ears \\
\hline & & Epicanthal folds & \\
\hline \multirow[t]{3}{*}{ Other Systems } & Cardiovascular & - & $\begin{array}{l}\text { Patent ductus arteriosis, resolved at } 6 \\
\text { months }\end{array}$ \\
\hline & Respiratory & - & Recurrent pneumonia \\
\hline & Immune & Allergic rhinitus, sinusitis & - \\
\hline
\end{tabular}


Figure 1:

A

B

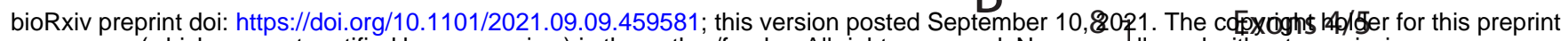

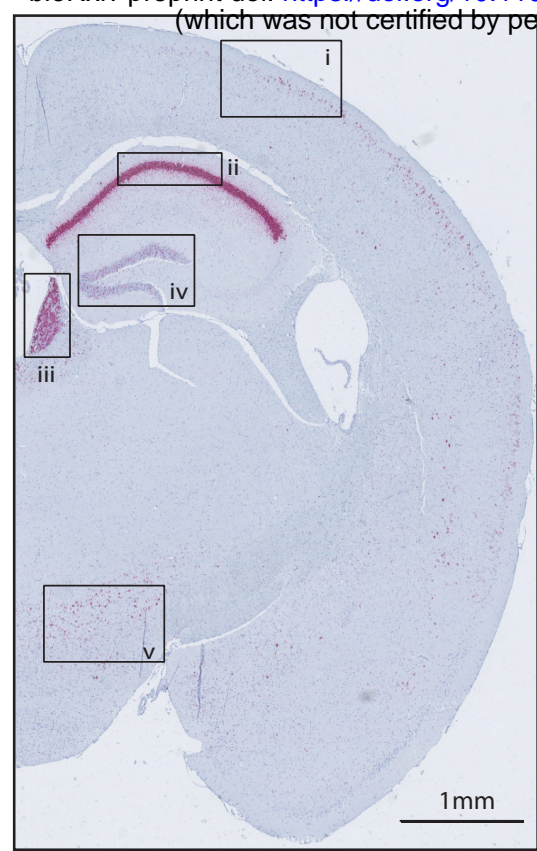

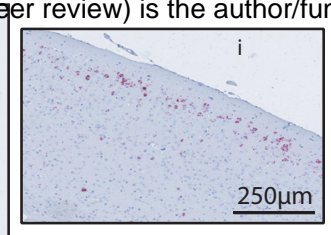
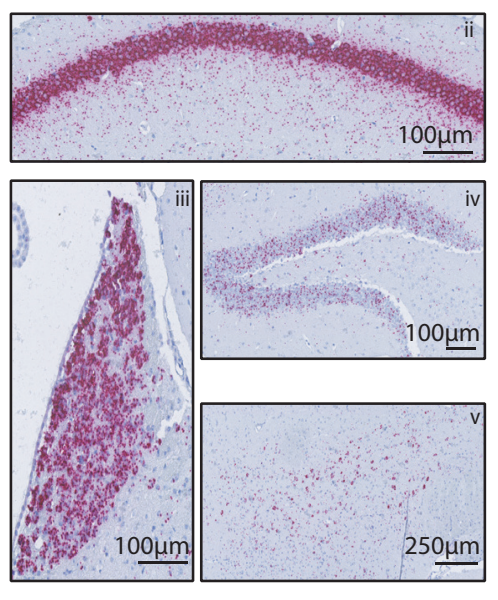

C
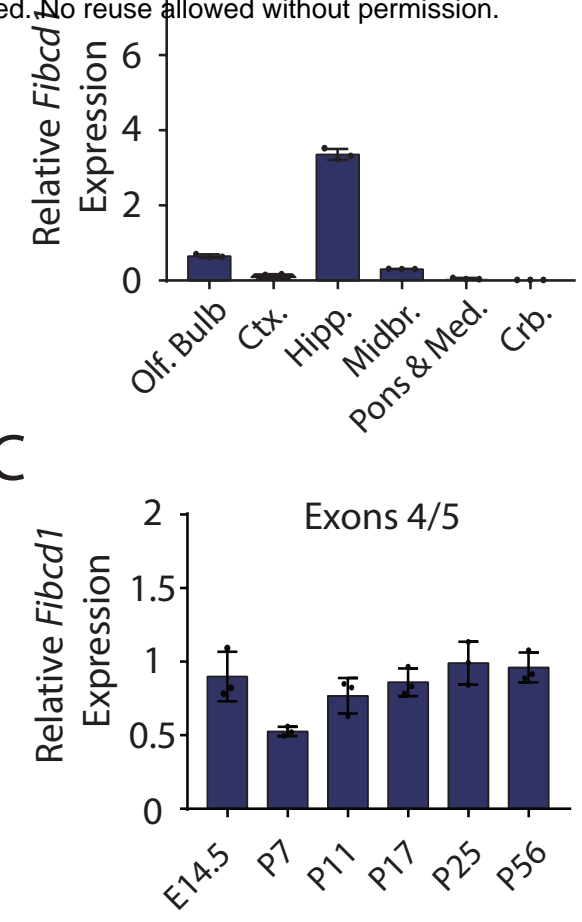

D

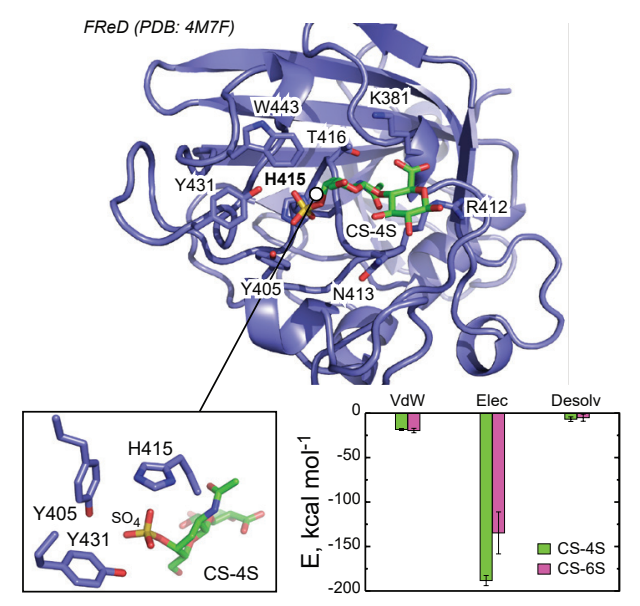

E

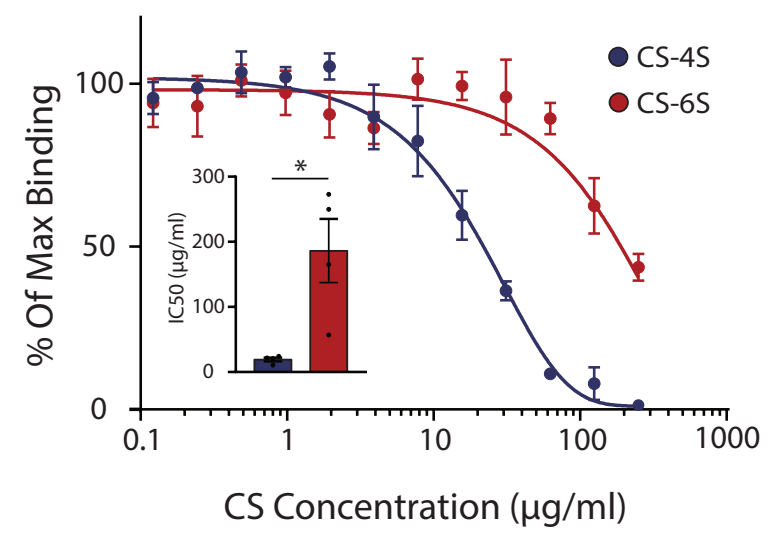

F

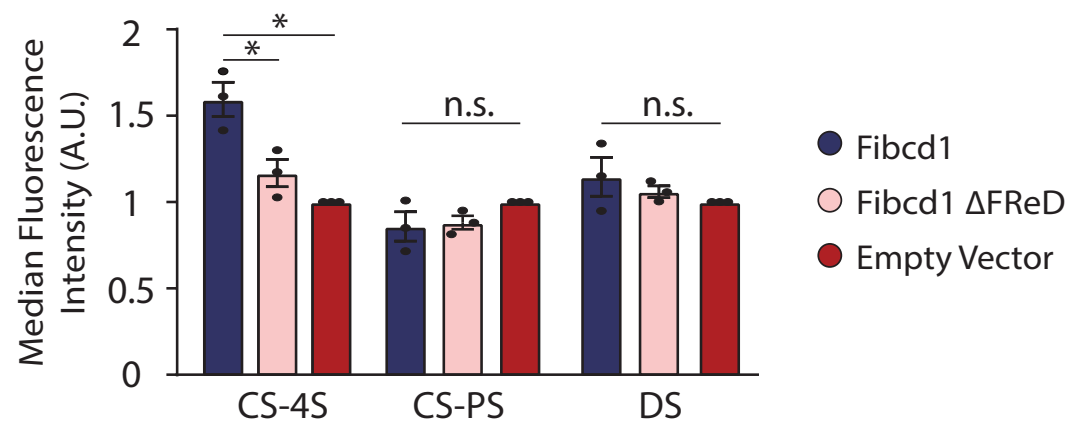


Figure 2:

A bioRxiv preprint doi: https://doi.org/10.1101/2021.09.09.4595\$Mapbi veesDAPAsted September 10, 2021. The copyright holder for this preprint (which was not certified by peer review) is the authorffunder. All rights reserved. No reuse allowed without permission.
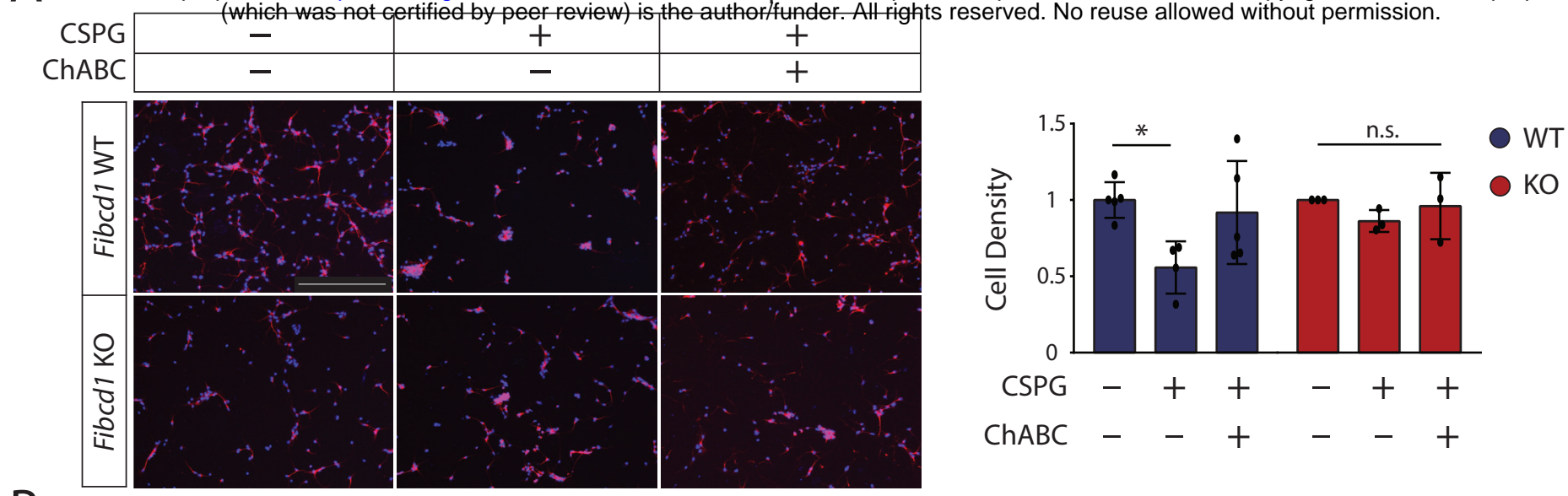

B
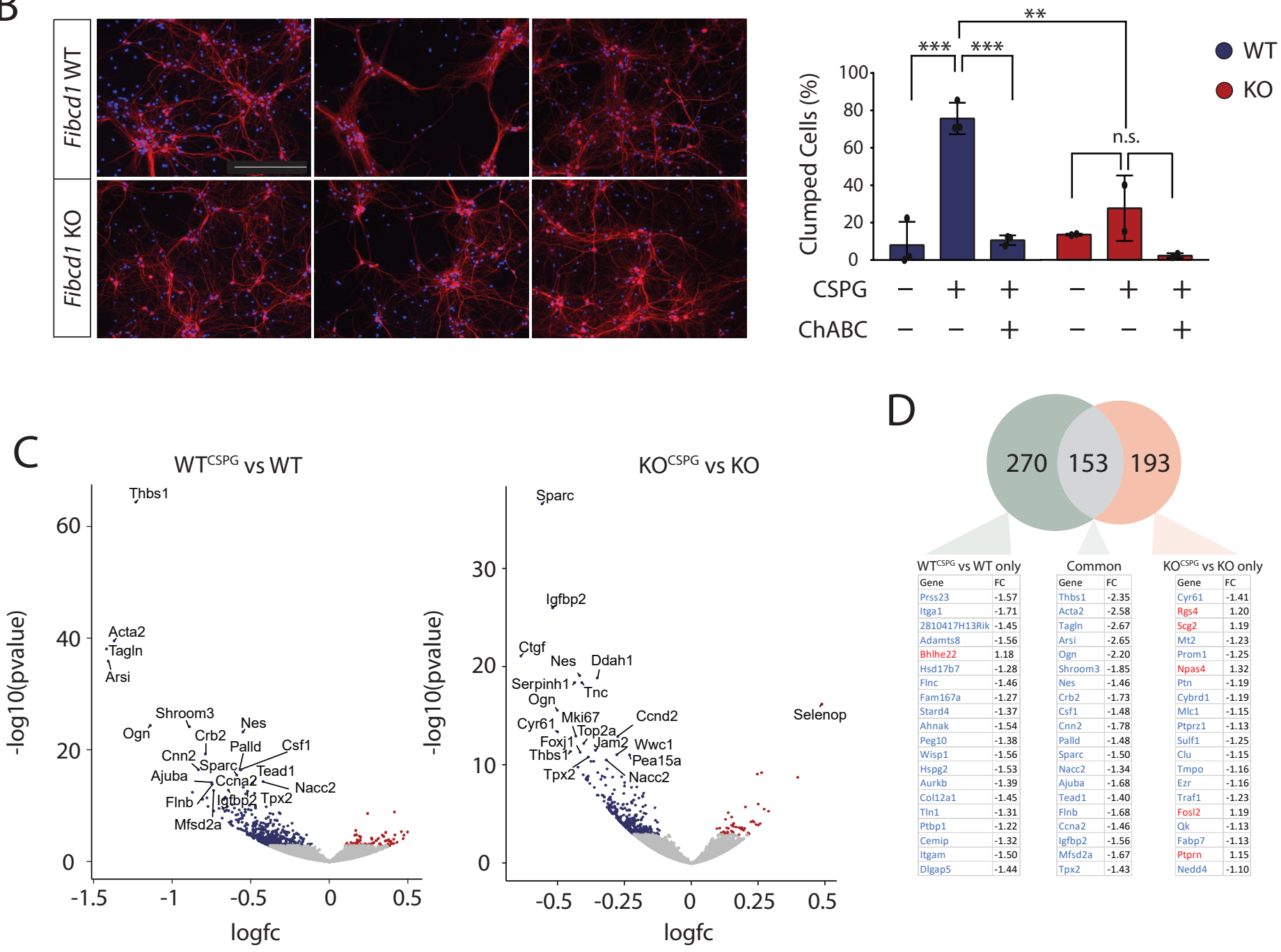

D

$\mathrm{E}$

GO - biological process

WT $T^{\mathrm{CSP}}$ vs. WT

FDR $<0.05$

270153193
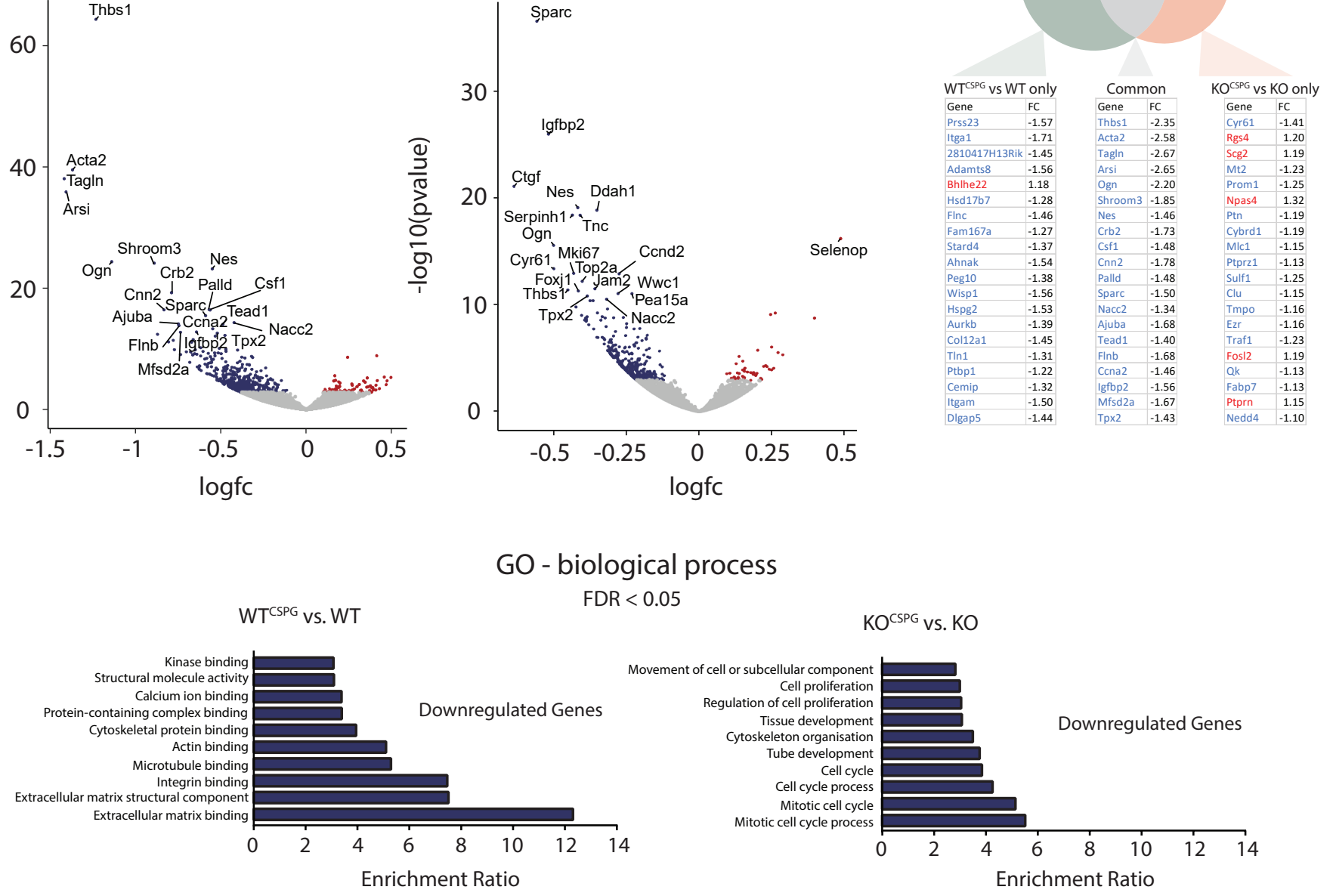
Figure 3:

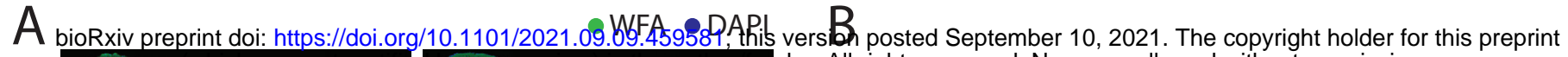
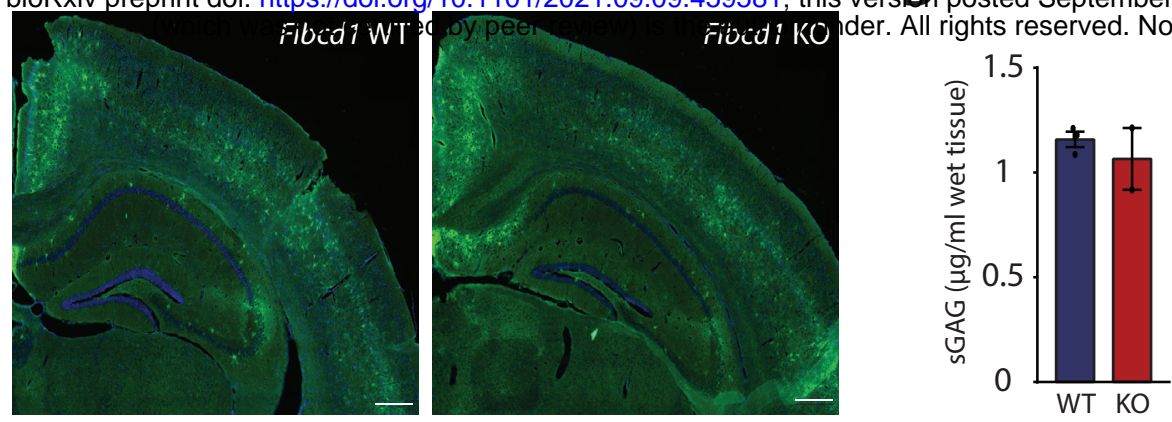

C

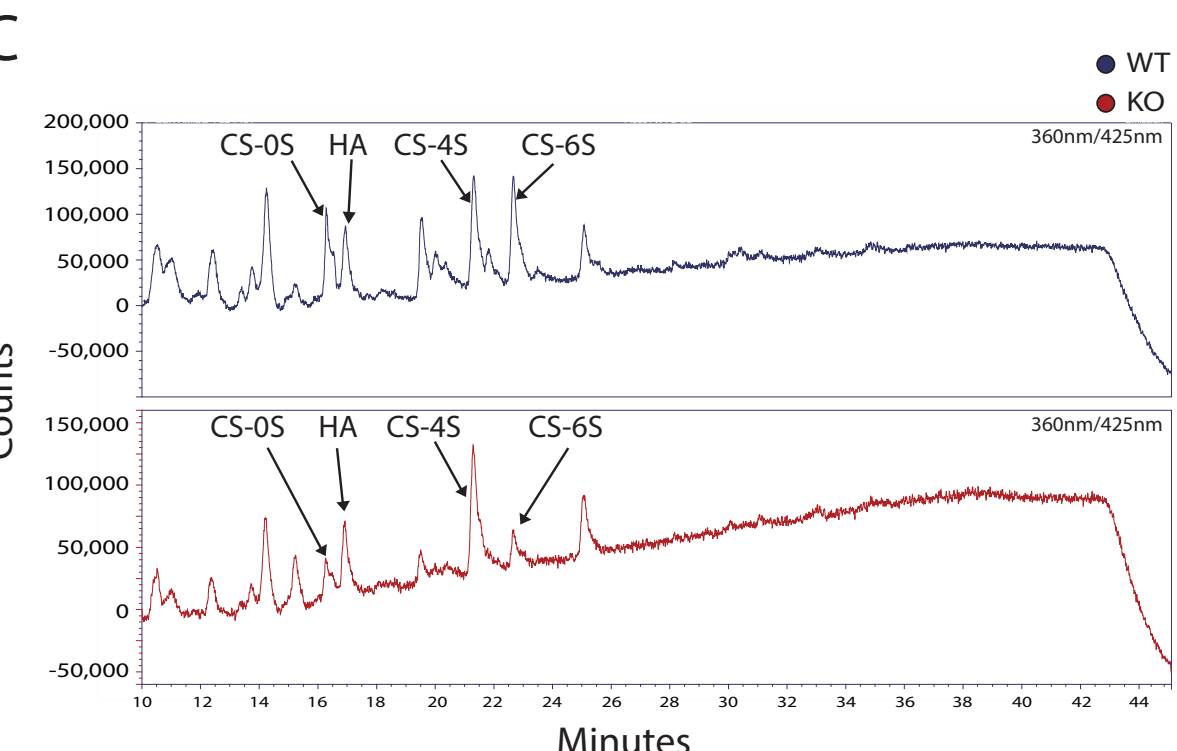

D

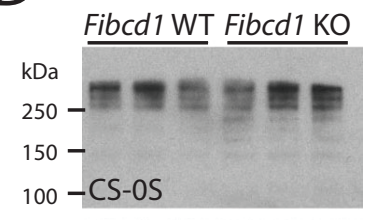

$100-$ CS-OS

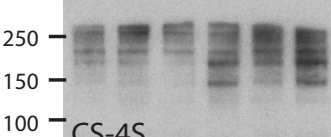

$100-\mathrm{CS}-4 \mathrm{~S}$

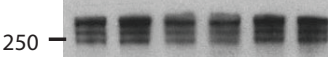

$150-$

100
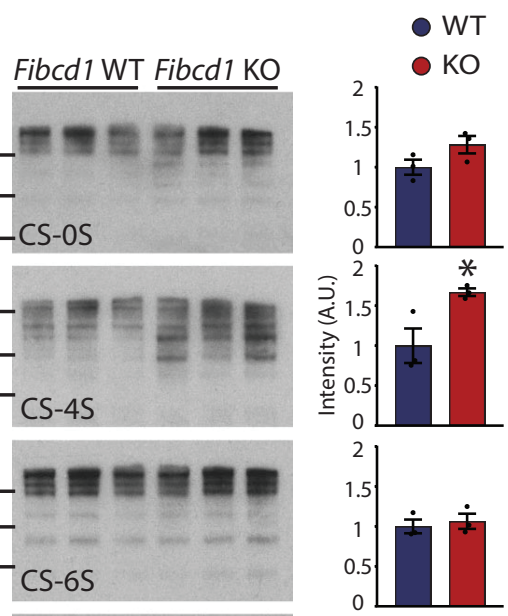

Minutes

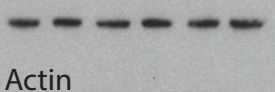


Figure 4

Y-maze

Inhibitory avoidance

A

B

H***

-bioRxiv preprint doi: https://dB.org/10.1101/2021.09.09.459581, this version posted September 10, 2021. The copyright holder for this preprint

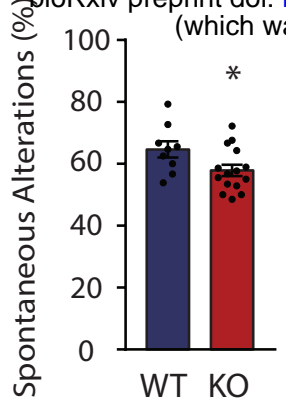

D

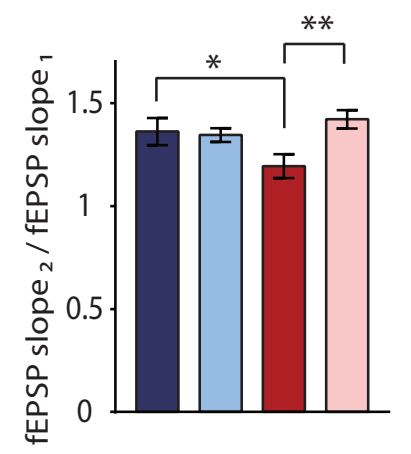

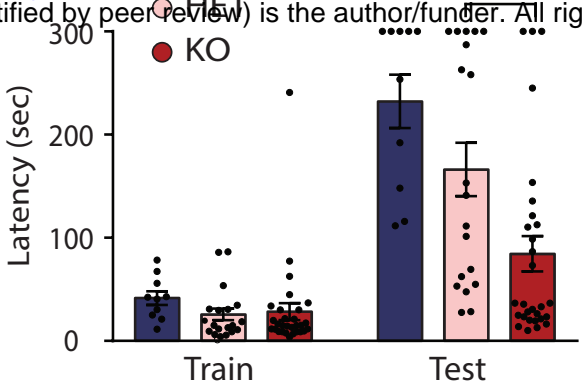

E

- $W T+$ pen

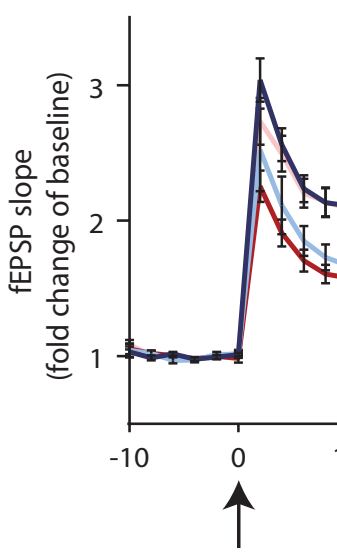

O $W T+C h A B C$

- $\mathrm{KO}+$ pen

$\mathrm{OO}+\mathrm{ChABC}$

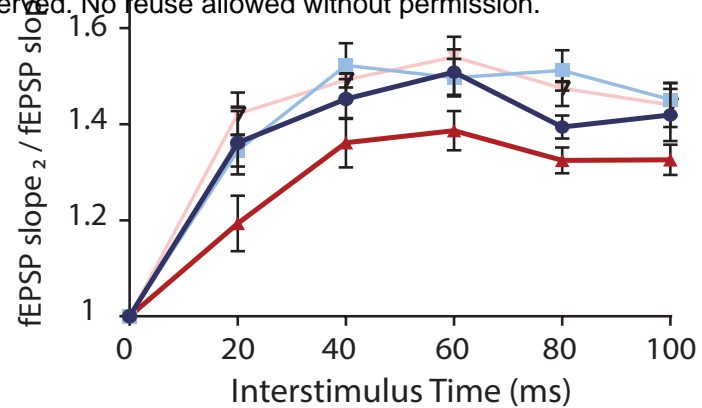

F
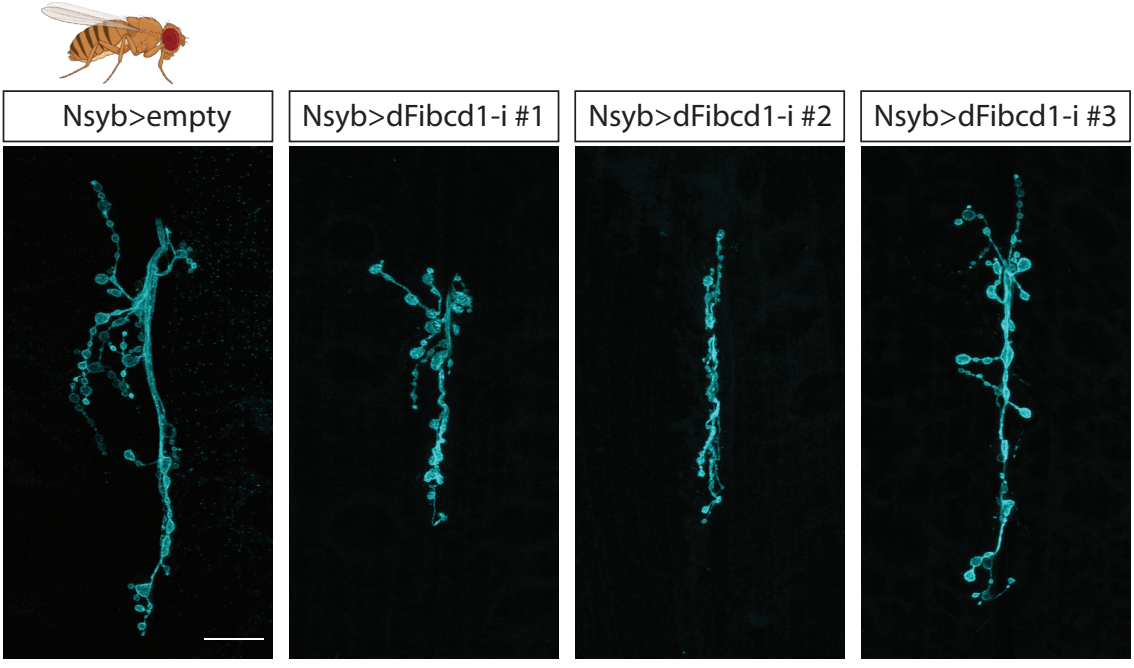

G
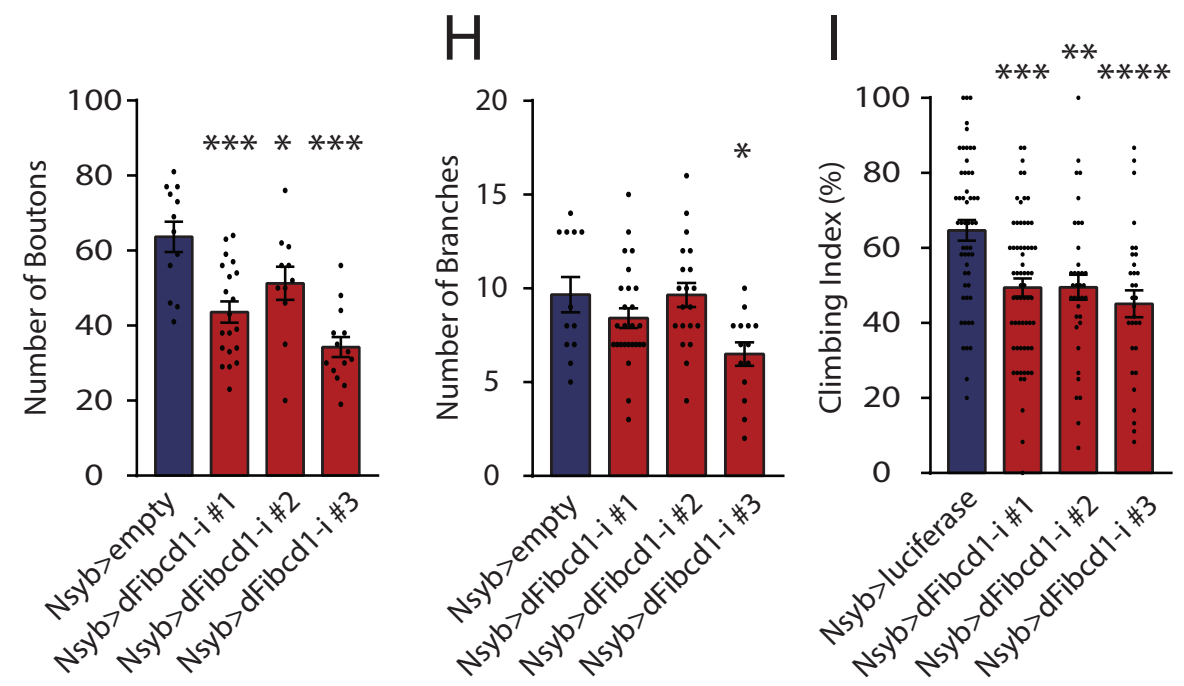
Figure 5

A

B

c.17G>A C.85G>A

c.1216C>T c.1367C>T
p.R406C p.P456L

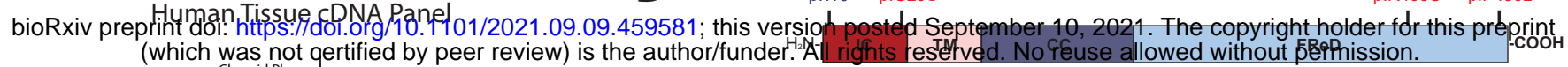

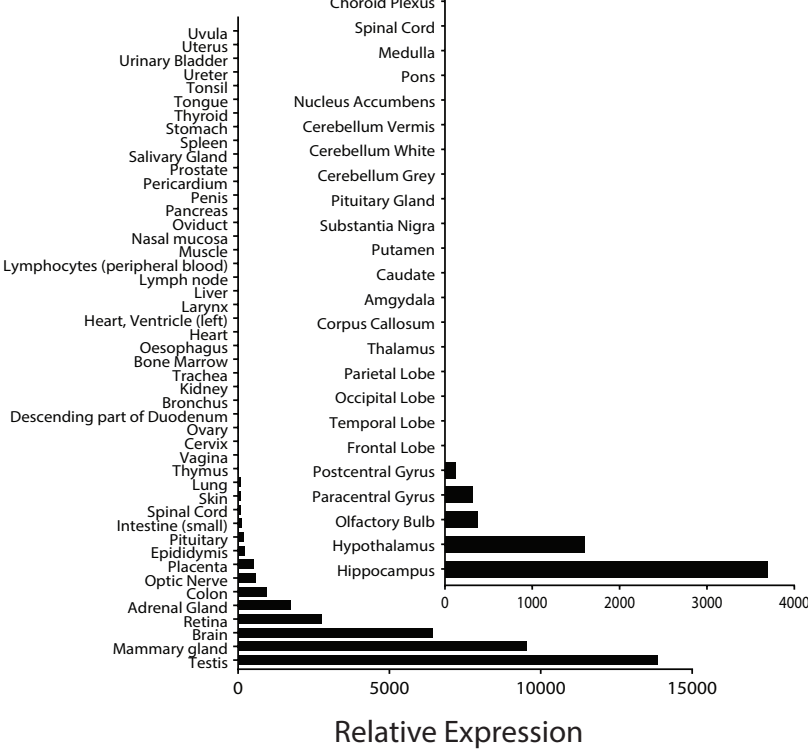

C
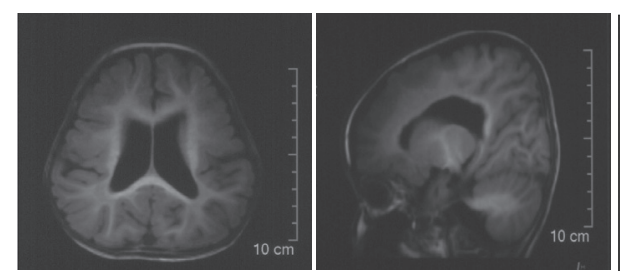

$\mathrm{E}$
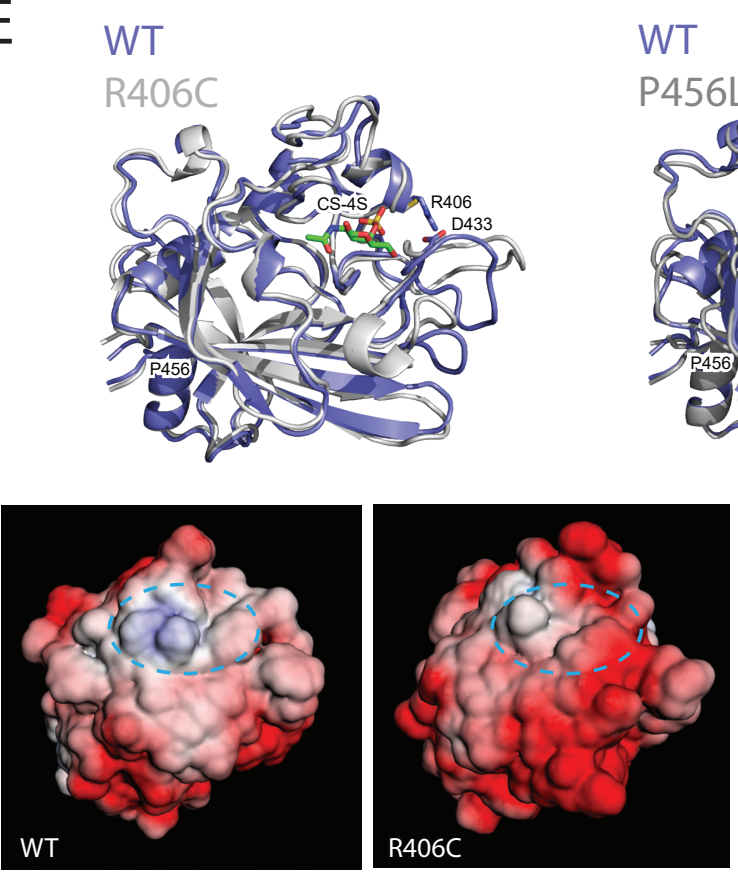

$-4 \mathrm{kT} / \mathrm{e}$

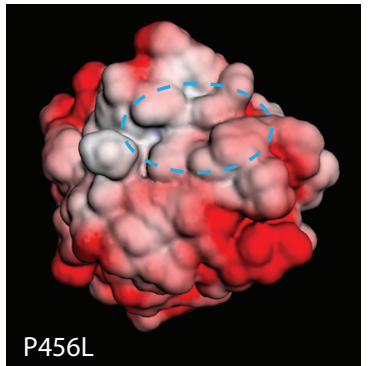

WT

P456L

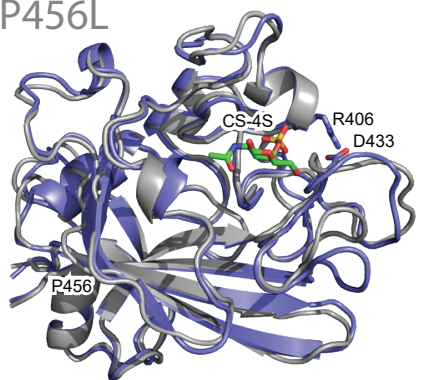

P456L
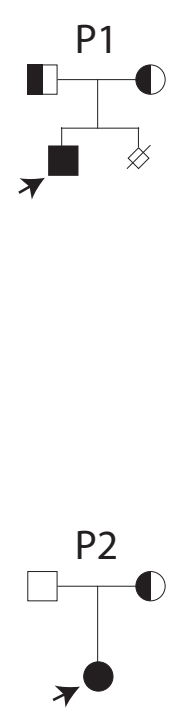

D

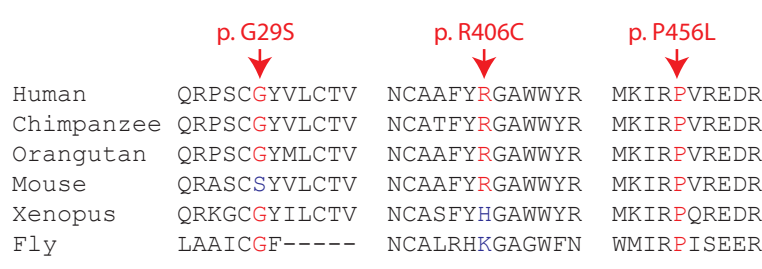

F

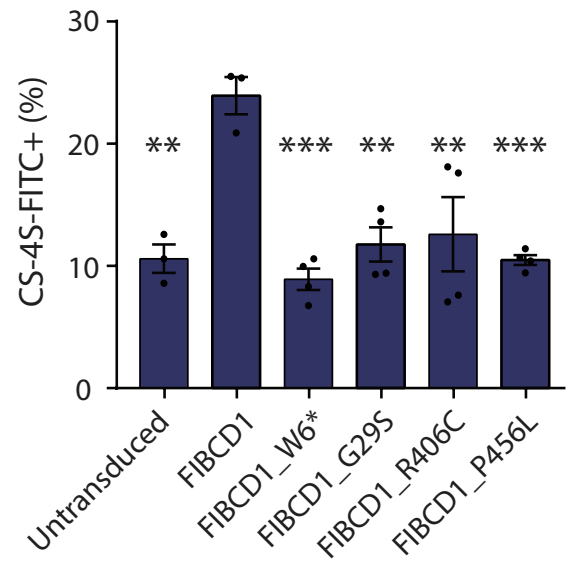


bioRxiv preprint doi: https://doi.org/10.1101/2021.09.09.459581; this version posted September 10, 2021. The copyright holder for this preprint (which was not certified by peer review) is the author/funder. All rights reserved. No reuse allowed without permission.

Figure 1: Fibcd1 is expressed in the adult and developing mouse brain in discrete regions. (A) In-situ hybridisation with probe pairs specific to Fibcd1 mRNA (purple) in mouse wholebrain coronal section, left hemisphere shown. Insets of high Fibcdl expressing regions are (i) cortex, (ii) pyramidal cell layer of hippocampus, (iii) medial habenula, (iv) granule cell layer of the dentate gyrus and (v) hypothalamus. Scale bar sizes are as indicated. Representative of 3 independent experiments. (B) Relative mRNA expression levels of Fibcdl (primers binding to exon 4 and 5) normalised to Gapdh, in the indicated adult mouse brain regions, analysed by RT-qPCR $(\mathrm{n}=3)$. Olf.Bulb = olfactory bulb; Ctx. = cortex; Hipp. = hippocampus; Midbr. = midbrain; Pons \& Med = pons and medulla; Crb. = cerebellum. (C) Relative mRNA expression levels of Fibcdl (primers binding to exon 4 and 5) normalised to Gapdh in the hippocampus of the indicated developmental time points, analysed by RT-qPCR $(n=3)$. Data is represented as mean and error bars represent SD. (D) Top binding pose for in silico docking of CS-4S to FIBCD1 FReD (PDB 4M7F). Inset (left) is the orientation of CS-4S within the FReD binding pocket and (right) binding free energy of CS-4S vs CS-6S. Van der Waals (vdW), electrostatic (Elec) and desolvation (Desolv) components of binding free energy charge. (E) Competitive ELISA with increasing concentrations of CS-4S (blue circles) or $-6 \mathrm{~S}$ (red circles) incubated with recombinant FIBCD1 FReD and immobilised acetylated BSA. Inset is IC50 concentrations for CS-4S and CS-6S. Data is represented as mean and error bars represent SEM. (F) Flow cytometric analysis of N2a cells expressing full-length mFIBCD1, mFIBCD1 $\triangle \mathrm{FReD}$ or empty vector control incubated with FITC-tagged chondroitin-4-sulfate (CS-4S), polysulphated chondroitin sulphate (CS-PS) or dermatan sulphate (DS) $(\mathrm{N}=3)$. Error bars represent SEM. $*=p \leq 0.05$. 
bioRxiv preprint doi: https://doi.org/10.1101/2021.09.09.459581; this version posted September 10, 2021. The copyright holder for this preprint (which was not certified by peer review) is the author/funder. All rights reserved. No reuse allowed without permission. Figure 2: FIBCD1 mediates responses of primary hippocampal cultures to CSPGs.

(A) Left, Representative images of immunofluorescent staining (MAP2, red; DAPI, blue) of primary hippocampal cultures at 2 days in vitro (DIV), plated on +/- CSPG coating with and without prior digestion with $\mathrm{ChABC}$, as indicated. Right, quantification of DIV2 images, showing the number of protruding cells per field normalised to untreated condition. N(WT) = 3; $\mathrm{N}(\mathrm{KO})=2$. (B) Left, representative images of DIV14 neurons, same conditions as (A). Right, quantification of DIV14 images, representing the percentage of clumped cells per field. N(WT) $=3 ; \mathrm{N}(\mathrm{KO})=2$. Error bars represent SD. $*=\mathrm{p} \leq 0.05 ; * *=\mathrm{p} \leq 0.01 ; * * *=\mathrm{p} \leq 0.001$. Scale bar $=$ $250 \mu \mathrm{m}$. (C) Volcano plots of differential gene expression of transcriptomes at DIV2 hippocampal cultures comparing (left) $\mathrm{WT}^{\mathrm{CSPG}}$ vs $\mathrm{WT}$ and $\mathrm{KO}^{\mathrm{CSPG}}$ vs $\mathrm{KO}(\mathrm{FDR}<0.05)$ (right). Significantly upregulated and downregulated genes are shown in red and blue, respectively. The top 20 differentially expressed genes are labelled. (D) Above, Venn diagram of significant DEGs unique to $\mathrm{WT}^{\mathrm{CSPG}}$ vs WT (green, 270 genes), $\mathrm{KO}^{\mathrm{CSPG}}$ vs KO (orange, 193 genes) and common between the two (grey, 153 genes). Below, lists of the 20 most significant DEGs and their fold change for each comparison, showing downregulated DEGs in blue and upregulated in red. (E) GO term enrichment analysis for significantly downregulated genes $(\mathrm{FDR}<0.05)$ in (left) $\mathrm{WT}^{\mathrm{CSPG}}$ vs WT and (right) $\mathrm{KO}^{\mathrm{CSPG}}$ vs KO.

Figure 3: Fibcd1 KO hippocampi have accumulated CS-4S compared to WT littermates. (A) Representative images of WFA-staining of PNNs in a coronal section of Fibcdl WT (left) and KO (right) mouse brains, left hemisphere (WFA, green; DAPI, blue) Scale bar $=400 \mu \mathrm{m}$. (B) Quantification of sulphated GAG amount (per mg of wet tissue) in dissected 11-13 week old Fibcd1 WT and KO hippocampi. Error bars represent SD. (C) HPLC traces (representative of 3 independent experiments) of variously sulphated GAGs (as labelled) in adult Fibcdl WT 
bioRxiv preprint doi: https://doi.org/10.1101/2021.09.09.459581; this version posted September 10, 2021. The copyright holder for this preprint (which was not certified by peer review) is the author/funder. All rights reserved. No reuse allowed without permission. (top, blue) and KO (bottom, red) CA1 pyramidal cell layer hippocampi. Unsulphated CS = CS0S; hyaluronic acid $=\mathrm{HA}$; carbon 4 sulphated CS = CS-4S; carbon 6 sulphated CS = CS-6S. (D) Immunoblot analysis (left) and quantification of signal intensity (right) of littermate WT (blue) versus Fibcdl KO (red) adult hippocampi with antibodies against CS-0S, CS-4S, CS-6S and actin as a loading control. Each lane represents an independent animal $(\mathrm{n}=3)$. Protein marker sizes are indicated. Error bars represent SEM. $* p \leq 0.05$.

\section{Figure 4: Neurological deficits in FIBCD1 deficient mice and flies.}

(A) Percentage of spontaneous alterations in the $\mathrm{Y}$-maze. $\mathrm{N}(\mathrm{WT})=9 ; \mathrm{N}(\mathrm{KO})=15$. (B) Latency to enter the dark (foot shock) chamber during the inhibitory avoidance task at training and testing (24 hours post-training) periods. Fibcd1 WT, heterozygous (HET) and KO mice shown. $\mathrm{N}(\mathrm{WT})=8 ; \mathrm{N}(\mathrm{HET})=19 ; \mathrm{N}(\mathrm{KO})=15$. Error bar represent SEM. (C-D) Paired-pulse facilitation in CA3-CA1 Schaffer collateral pathway of acute hippocampal slices from Fibcd1 WT and KO mice. Pre-treatment with enzymes penicillinase (+pen) or Chondroitinase ABC $(+$ ChABC $)$ is indicated. $\mathrm{N}(\mathrm{WT}+$ pen $)=17 ; \mathrm{N}(\mathrm{KO}+$ pen $)=20 ; \mathrm{N}(\mathrm{WT}+\mathrm{ChABC})=19 ; \mathrm{N}$ $(\mathrm{KO}+\mathrm{ChABC})=25$. $(\mathrm{E})$ Long-term potentiation in CA3-CA1 Schaffer collateral pathways of acute hippocampal slices. Theta burst stimulation (TBS) is at time 0 indicated by the arrow. N $(\mathrm{WT}+$ pen $)=9 ; \mathrm{N}(\mathrm{KO}+$ pen $)=15 ; \mathrm{N}(\mathrm{WT}+\mathrm{ChABC})=6 ; \mathrm{N}(\mathrm{KO}+\mathrm{ChABC})=12$. Inset are representative traces. (F) Immunofluorescent images (representative of 3 independent experiments) of control and neuronal (Nsyb) CG10359 (dFibcd1) RNAi-mediated knockdown D. melanogaster, $3^{\text {rd }}$ instar larvae NMJ (NMJ6/7) stained with anti-horseradish peroxidase antibody. Empty control and RNAi-mediated knockdown of CG10359 (dFibcd1-i) lines 1, 2 and 3 shown. Scale bar $=20 \mu \mathrm{m}$. (G) Quantification of (F), control and CG10359 knockdown lines NMJ neuron bouton number. (H) Quantification of (F), control and CG10359 knockdown lines NMJ neuron axon branch points. (E) Negative geotaxis assay of adult Drosophila control 
bioRxiv preprint doi: https://doi.org/10.1101/2021.09.09.459581; this version posted September 10, 2021. The copyright holder for this preprint (which was not certified by peer review) is the author/funder. All rights reserved. No reuse allowed without permission.

1001

1002

1003

1004

1005

1006

1007

1008

1009

1010

1011

1012

1013

1014

1015

1016

1017

1018

1019

1020

1021

1022

1023

1024

1025

1026 and RNAi lines \#1, \#2 and \#3 compared to control lines expressing RNAi targeting luciferase.

Climbing index represent the percentage of flies that crossed the $5 \mathrm{~cm}$ vial mark within 5 seconds after gentle tapping to the bottom of the vial. $\mathrm{n}$ is the number of tested vials. $\mathrm{N}$ $($ luciferase $)=53 ; \mathrm{N}($ line $\# 1)=63 ; \mathrm{N}($ line $\# 2)=36 ; \mathrm{N}($ line $\# 3)=31$. For flies per vial, see Figure S6C). $*=\mathrm{p} \leq 0.05 ; * *=\mathrm{p} \leq 0.01 ; * * *=\mathrm{p} \leq 0.001$. Error bars represent SEM.

Figure 5: Expression of FIBCD1 in human tissues and properties of FIBCD1 variants identified in 2 cases of undiagnosed neurodevelopmental disorders.

(A) Fibcd1 expression in various human visceral tissues and (inset) brain regions. Expression is plotted relative to the tissue with lowest detectable expression (trachea; inset, choroid plexus) (B) Top, schematic of FIBCD1 protein, with labelled intracellular domain (IC, red), transmembrane domain (TM, pink), coiled coil (CC, dark blue) and FReD in dark blue. Location of patient variants denoted in red, and of control in blue. Family pedigrees of P1 (top) and P2 (bottom) showing affected proband (filled, arrow) and carriers (half-filled, arrow). Right, representative traces of Sanger sequencing to confirm segregation within the family. P1variants are inherited in autosomal recessive manner; P2 exhibits inheritance by uniparental disomy. Above, schematic of FIBCD1 with location of patient variants and p.W6* indicated. (C) P2 MRI images (axial, coronal and sagittal plane) showing ventriculomegaly, slightly thickened cortex and bilateral enlarged gyri. (D) Amino acid sequence conservation sites of patient variants Gly29Ser, Arg406Cys and Pro456Leu in various species. (E) Top, ribbon diagrams of the superposition of the WT FReD domain with R406C (left) and P456L (right) mutants. The loops surrounding the ligand binding site (389-399 and 423-448) exhibit the largest structural rearrangement in both mutants. Bottom, comparison of the electrostatic potential mapped onto the solvent-accessible surface between WT and the two variant FReDs.

(F) Flow cytometric analysis of untransduced HEK293T cells, or expressing constructs with 
bioRxiv preprint doi: https://doi.org/10.1101/2021.09.09.459581; this version posted September 10, 2021. The copyright holder for this preprint (which was not certified by peer review) is the author/funder. All rights reserved. No reuse allowed without permission.

1027 full-length wild-type human FIBCD1, FIBCD1 with the W6* early stop variant as control

1028 (FIBCD1_W6*), or the three patient variants incubated with FITC-tagged CS-4S represented

1029 as percentage of CS-4S-FITC relative to unstained control. Statistics were calculated by 1-way

1030 ANOVA, comparing to the FIBCD1 condition. $* *=<0.01 ; * * *=<0.01 ; * * * *=<0.001$.

1031

1032

1033 
Supplemental Figure 1

A

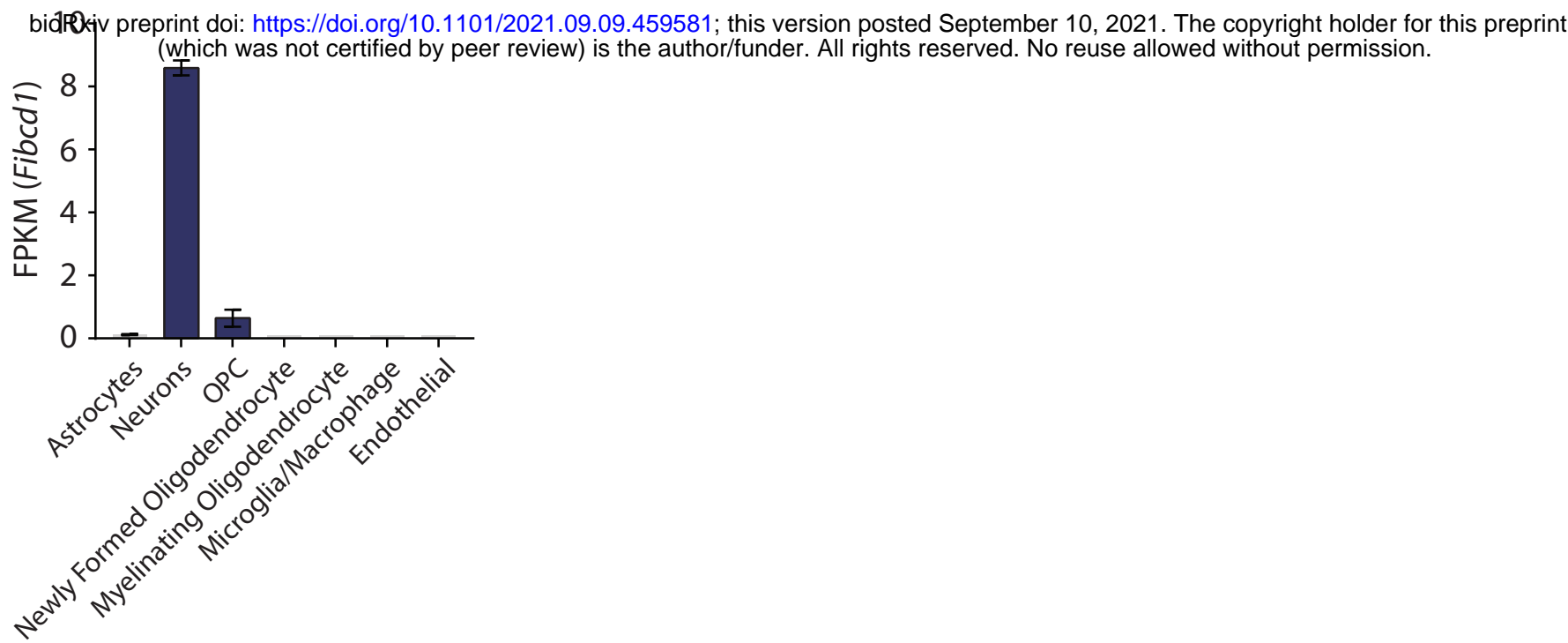

B

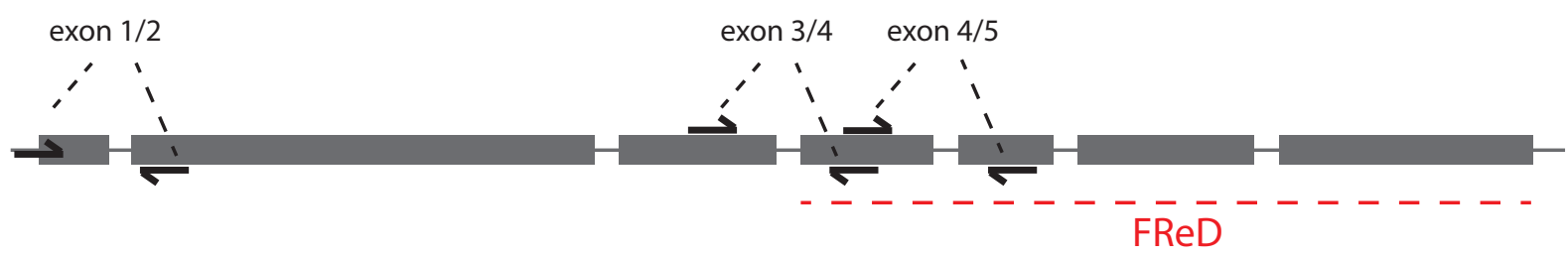

C

Exons $1 / 2 \quad D$

Exons $1 / 2$

Exons $3 / 4$
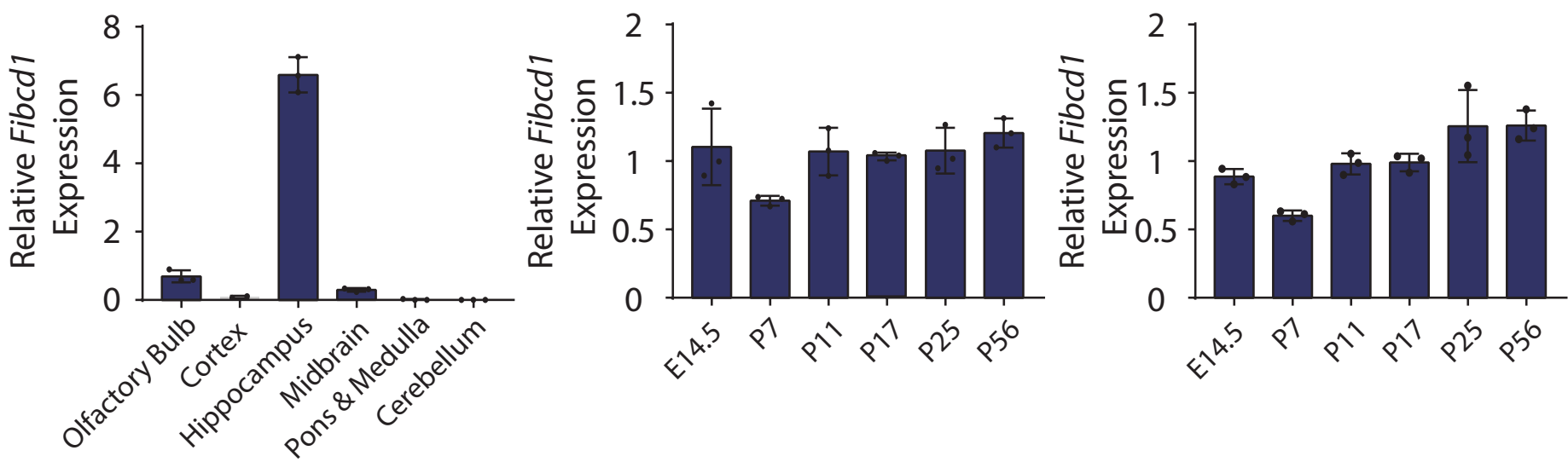
Supplemental Figure 2

A

bioRxiv preprint doi:/https:/doi.org/10.1101/2021.09.09.459581; this version posted September 10, 2021. The copyright holder for this preprint

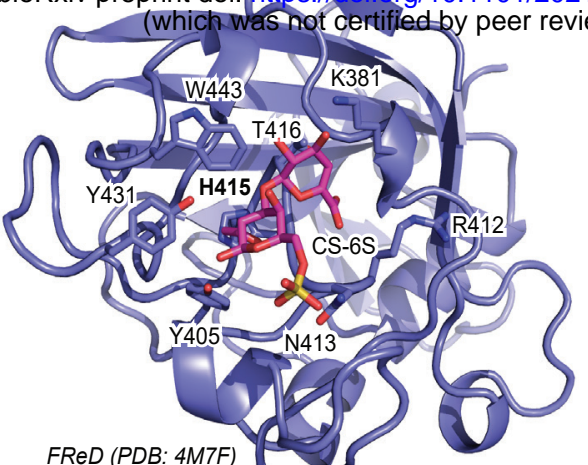

B

FIBCD1

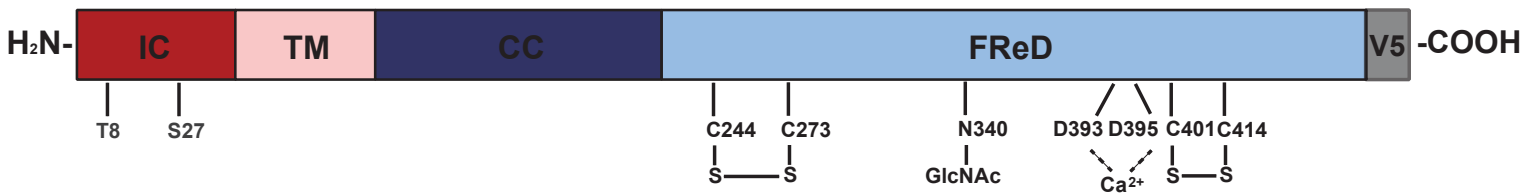

FIBCD1 $\triangle \mathrm{FReD}$

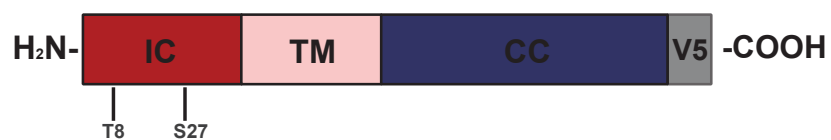

C

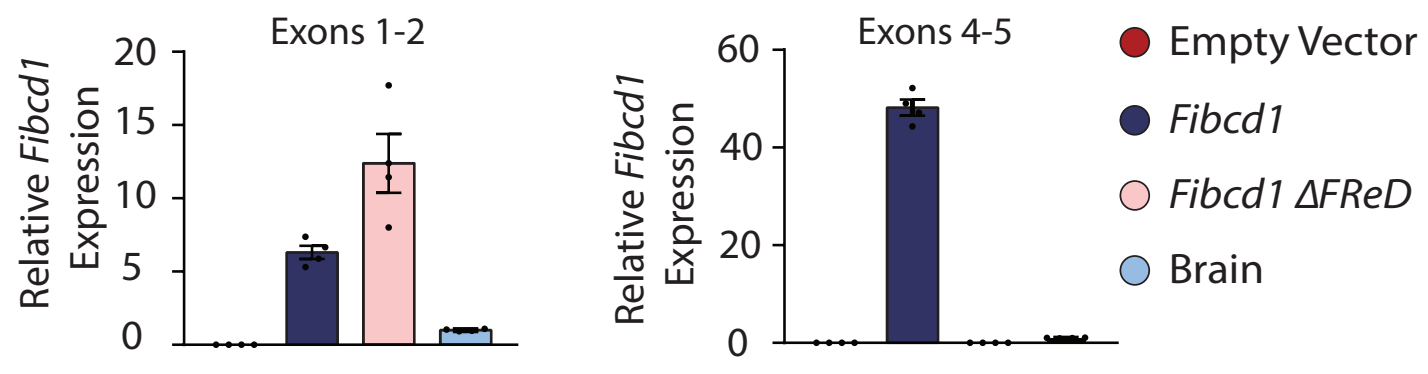

E
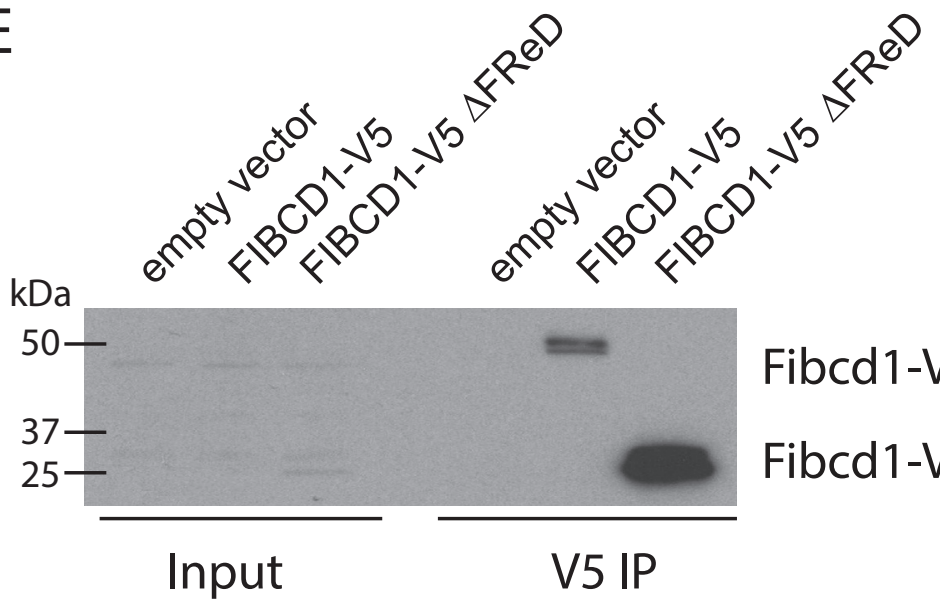

Fibcd1-V5 (55kDa)

Fibcd1-V5 $\triangle$ FReD (28kDa)

Input

V5IP 
Supplemental Figure 3

A

B

bioRxiv preprint doi: https://doi.org/10.1101/2021.09.09.459581; this version postedSeptember 10, 2021. The copyright holder for this preprint
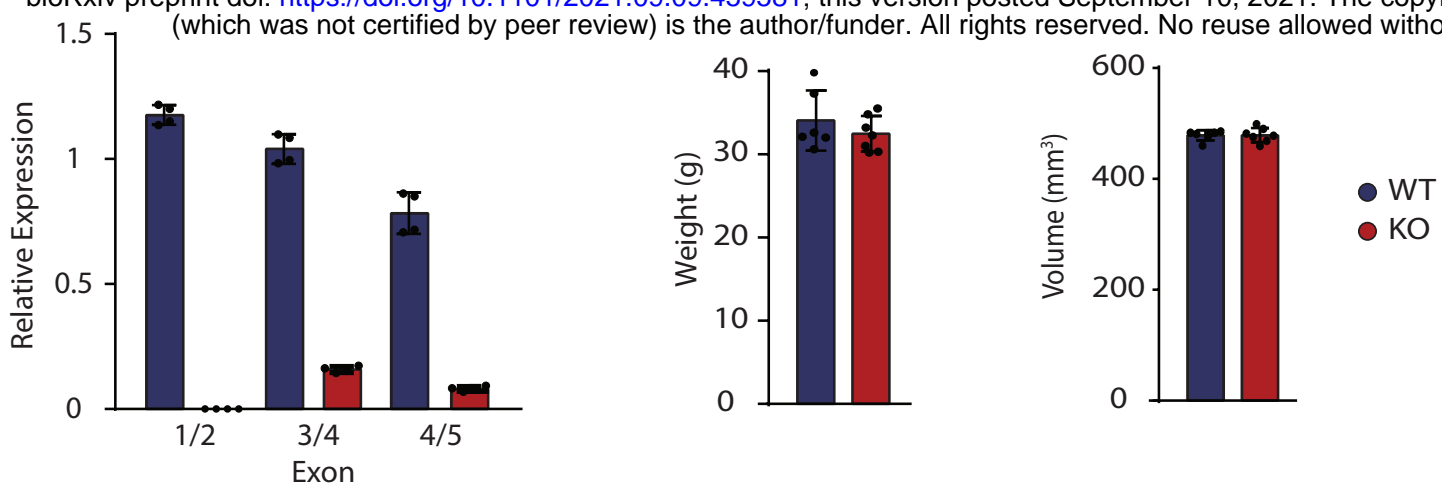

D

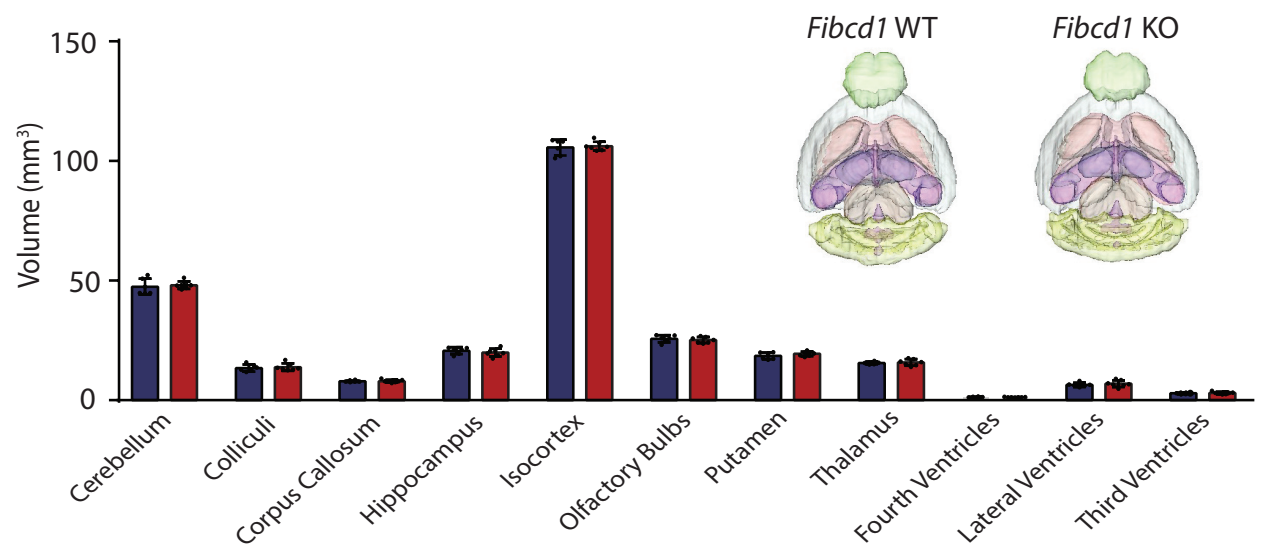




\section{Supplemental Figure 4}

bioRxiv preprint doi: https://doi.org/10.1101/2021.09.09.459581; this version posted September 10, 2021. The copyright holder for this preprint
(which was not certified by peer review) is the author/funder. All rights reserved. No reuse allowed without permission.

A
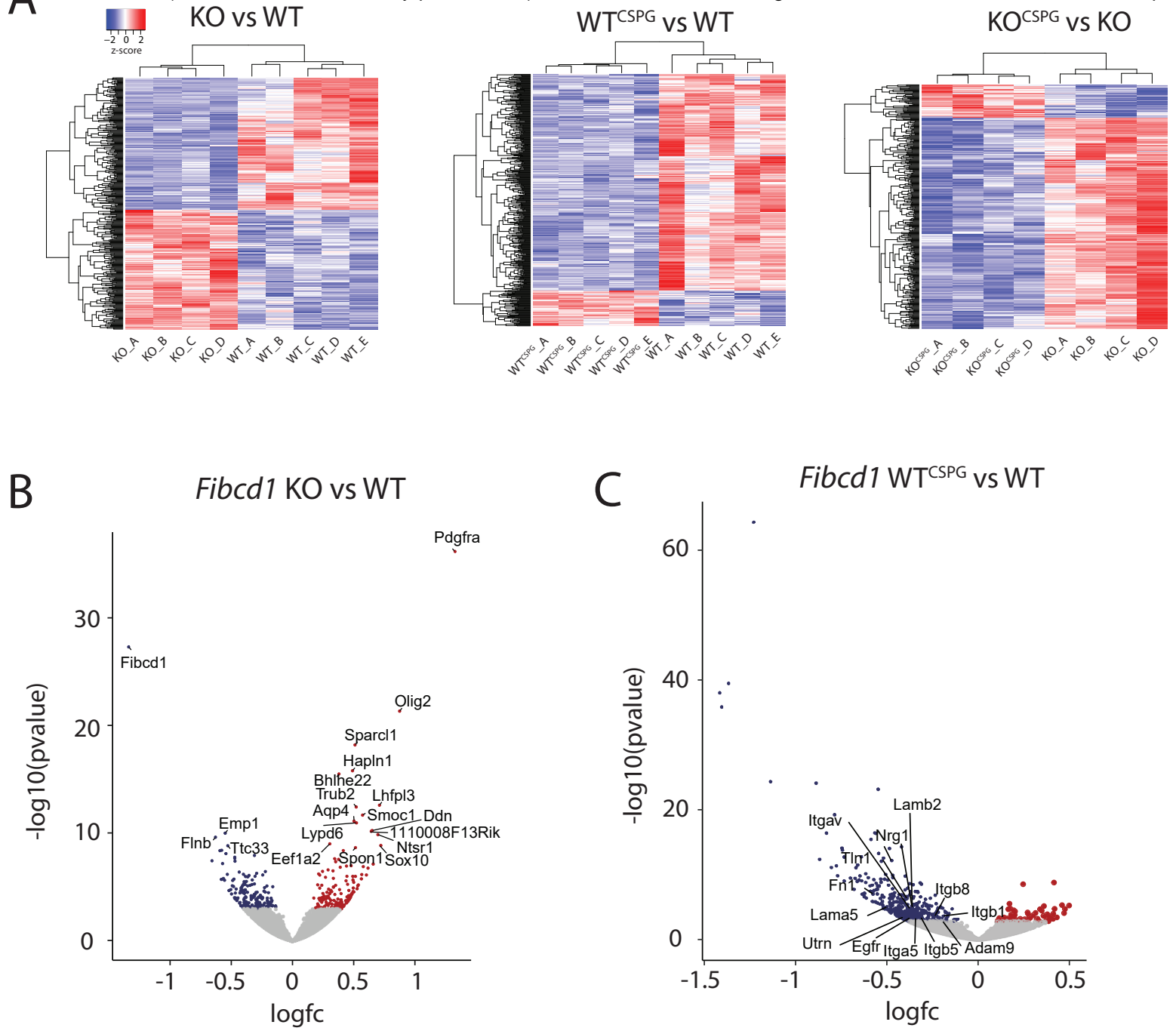
Supplemental Figure 5

A bioRxiv preprint doi: https://doi.org/10.1101/2021.09.09.459581 Bhis version posted September 10, 2021. The copyright holder for this preprint (which was not certified by peer review) is the authorffunder. All rights reserved. No reuse allowed without permission.
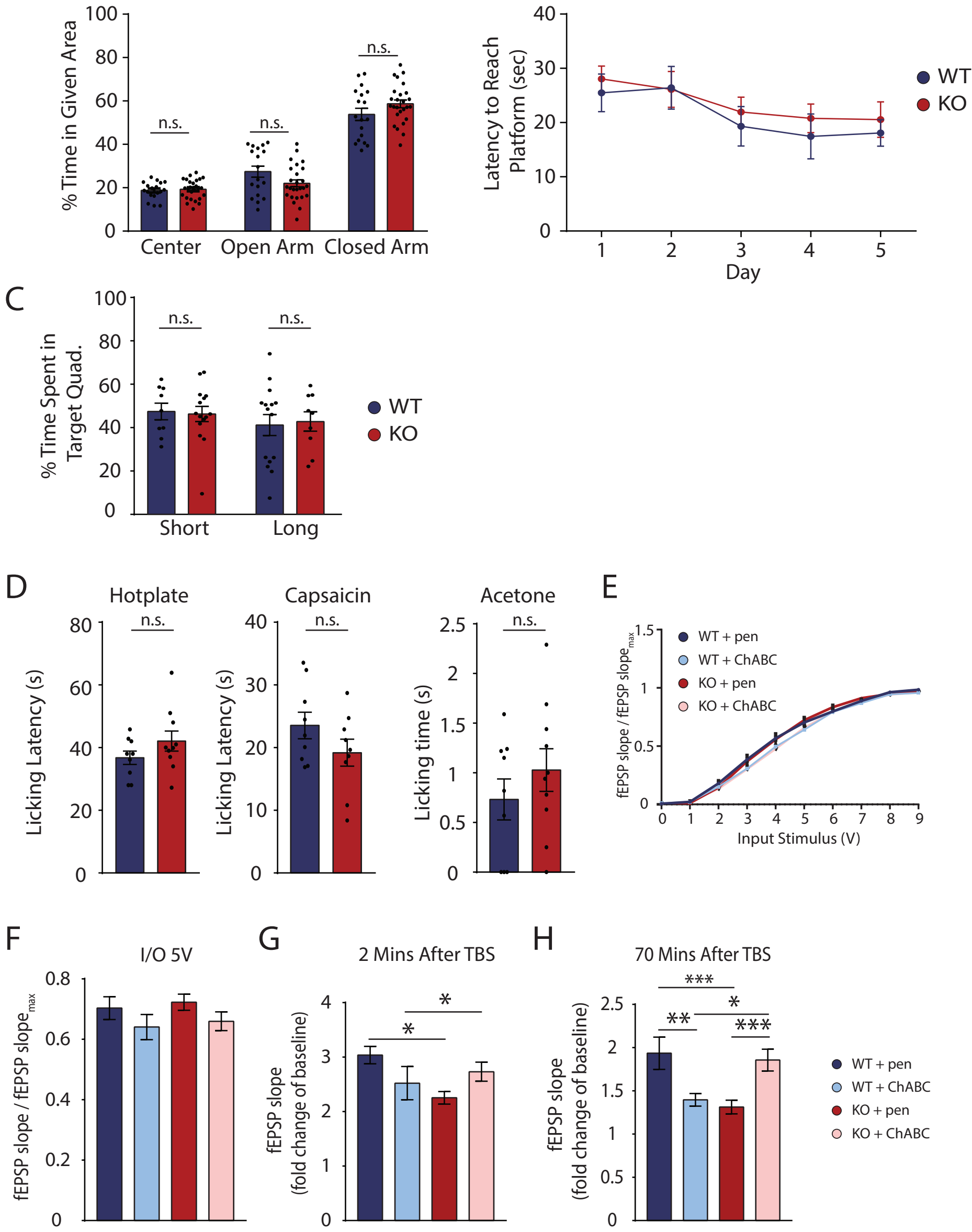


\section{Supplemental Figure 6}

A bioRxiv preprint doi: https://doi.org/10.1101/2021.09.09.459581; this version posted September 10, 2021. The copyright holder for this preprint cLustal $0(1.2 .4$ (which was not certified by peer review) is the author/funder. All rights reserved. No reuse allowed without permission.

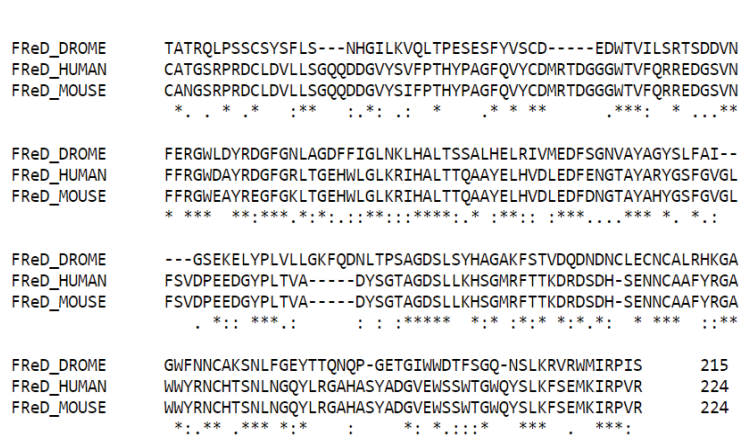

B

\begin{tabular}{|l|c|c|}
\hline \multicolumn{1}{|c|}{ RNAi Line } & $\begin{array}{c}\text { Tub>Gal4 } \\
\text { (Fullbody KD) }\end{array}$ & $\begin{array}{c}\text { Nsyb>Gal4 } \\
\text { (Neuronal KD) }\end{array}$ \\
\hline UAS>CG10359 VDRC ${ }^{102670}$ (Line \#1) & Viable & Viable* $^{*}$ \\
\hline UAS>CG10359 VDRC 4128 (Line \#2) & Semi-lethal & Viable $^{*}$ \\
\hline UAS>CG10359 IR ${ }^{\text {B63703 }(\text { Line \#3) }}$ & Lethal & Viable* $^{*}$ \\
\hline
\end{tabular}

* results in smaller larvae and skewed mendelian ratio

C

Climbing Assay - Sample Size per N

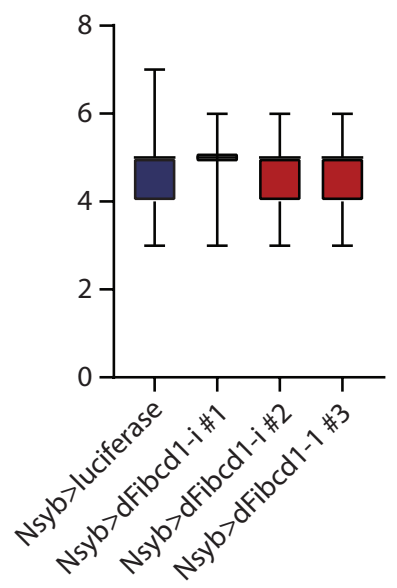


A bioRxiv prepringt doi: https://doi.org/10.1101/2021.09.09.459581; this versidBposted September 10, 2021. The copyright holder for this preprint (which was not certified by peer review) is the author/funder. All rights reserved. No reuse allowed without permission.
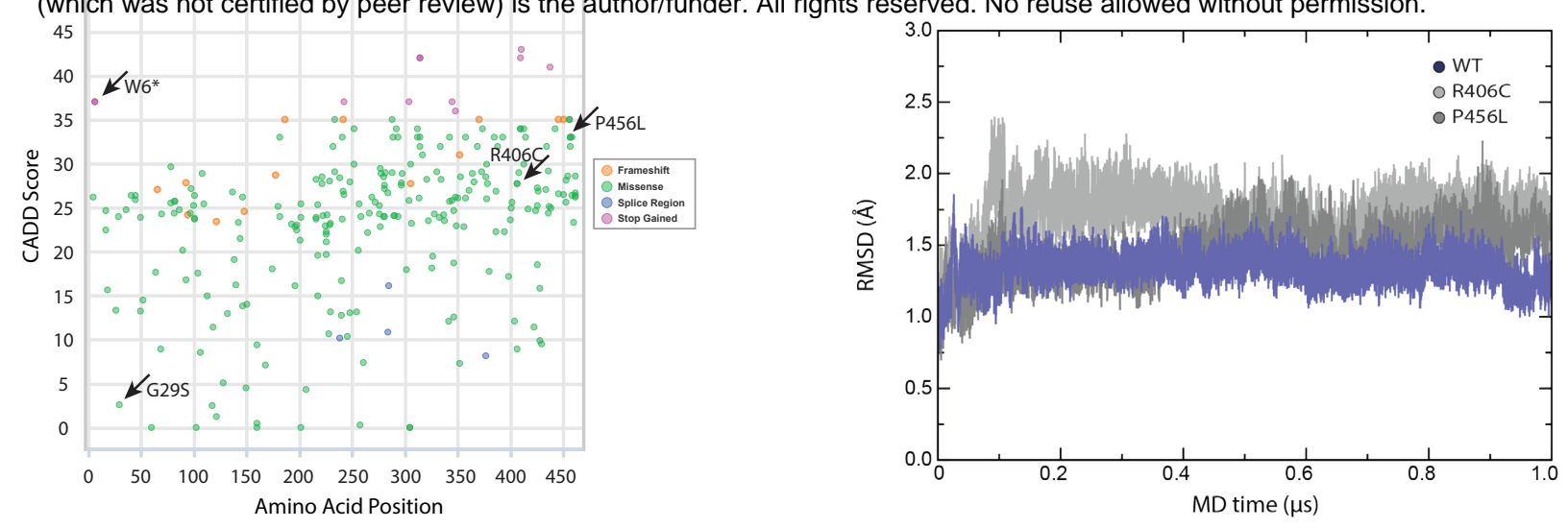

C

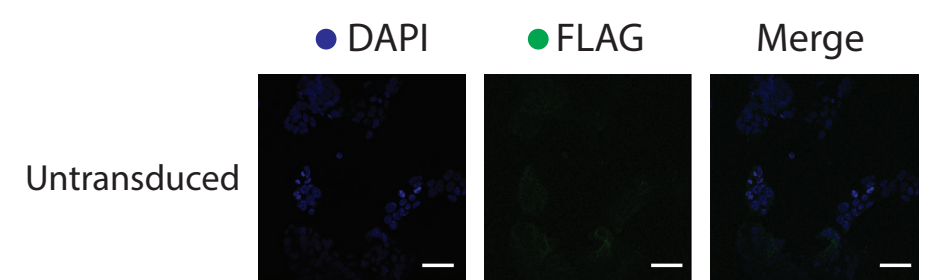

FIBCD1-FLAG_W6*
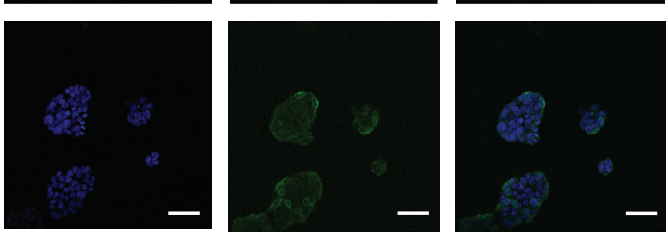

FIBCD1-FLAG
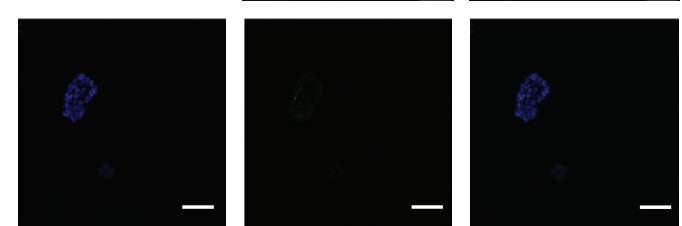

FIBCD1-FLAG_G29S
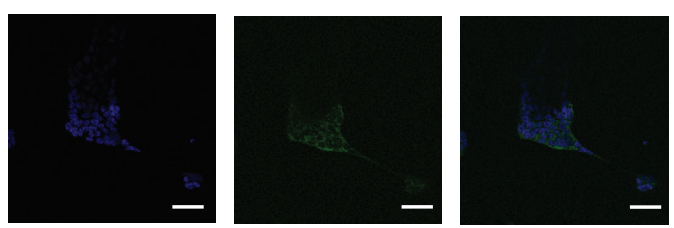

FIBCD1-FLAG_R406C
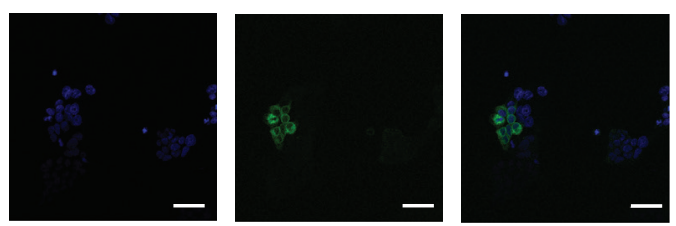

FIBCD1-FLAG_P456L
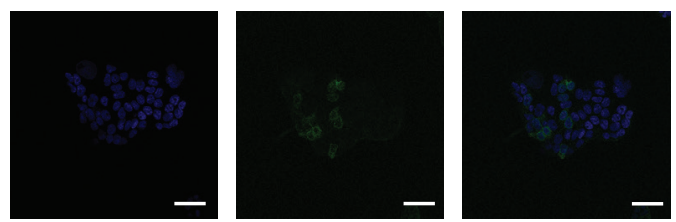
bioRxiv preprint doi: https://doi.org/10.1101/2021.09.09.459581; this version posted September 10, 2021. The copyright holder for this preprint (which was not certified by peer review) is the author/funder. All rights reserved. No reuse allowed without permission.

Figure S1: Fibcd1 expression in the adult and developing mouse brain.

(A) Fibcdl expression in bulk populations of sorted mouse brain cell population, from brainrnaseq.org. $\mathrm{OPC}=$ oligodendrocyte precursor cell. (B) Schematic of Fibcdl exons (grey rectangles) and introns (grey lines), and location of primer pair binding ('exons 1/2, 3/4 and 4/5') used for RT-qPCR. Exon sizes are to scale; introns and primer lengths are not. The exons coding for FIBCD1 FReD is indicated by a red dashed line. (C) Relative mRNA expression levels of Fibcdl (primers binding to exon 1 and 2) normalised to Gapdh in the indicated brain regions, analysed by RT-qPCR ( $=3$ ). (D) Relative mRNA expression levels of Fibcd1 (primers binding to exon 1 and 2 and exons 3 and 4) normalised to Gapdh in the hippocampus of the indicated time points, analysed by RT-qPCR $(\mathrm{N}=3)$. Error bars represent SD.

\section{Figure S2: Docking site of CS-6S in FIBCD1 FReD and validation of mFIBCD1} overexpressing N2a cell lines.

(A) Top binding pose for in silico docking of CS-6S to FIBCD1 FReD (PDB 4M7F). (B) Schematic representation of FIBCD1 domains, IC-intracellular domain (red), TMtransmembrane domain (pink), CC-coiled coil domain (dark blue), FReD (light blue), and location of V5-tag (grey) in full-length mFIBCD1 cDNA and truncated mFIBCD1 lacking the FReD domain (FIBCD1 $\triangle \mathrm{FReD}$ ). (C) Relative mRNA expression levels of Fibcdl in the N2a cells overexpressing full-length (Fibcdl) or truncated FIBCDI (Fibcd1 $\triangle F R e D$ ) and adult mouse WT brain for comparison, analysed by RT-qPCR $(\mathrm{n}=2)$. Primers binding to exon 1 and 2 before the FReD domain (B) or to exon 4 and 5 spanning the sequence encoding part of the FReD. Note the complete absence of endogenous Fibcdl expression in the 'empty vector' (red bar) control and the complete absence of expression when using primers against exon 4/5 (D), which span the FReD (see Figure S1B) in the Fibcdl $\Delta \mathrm{FReD}$ construct (C, pink bar), validating 
bioRxiv preprint doi: https://doi.org/10.1101/2021.09.09.459581; this version posted September 10, 2021. The copyright holder for this preprint
(which was not certified by peer review) is the author/funder. All rights reserved. No reuse allowed without permission. the generated cell lines. Gapdh was used as housekeeping control and values obtained from a control brain sample were set to 1. (E) Validation of transgenic N2a cell line at the protein level by immunoprecipitation with anti-V5 antibody as bait. Input (left) and V5-immunoprecipitated (right) lysates from N2a cells expressing V5-tagged full-length mFIBCD1 (mFIBCD1-V5, predicted size of 55kDa), V5-tagged mFIBCD1 lacking the FReD (V5-FIBCD1 $\triangle$ FReD, predicted size of $28 \mathrm{kDa}$ ) or the empty vector as negative control. Protein marker sizes are indicated.

\section{Figure S3: Fibcd1 expression, weight and brain tissue volumes in Fibcd1 WT and KO mice.}

(A) RT-qPCR of Fibcdl WT and KO adult mouse hippocampi using primer pairs binding to indicated exons (see Fig. S1B). N = 4. (B-D) Body weight (B), total brain volume (C) and brain volumes of denoted brain regions (D) of the indicated genotypes as assessed by MRI volumetric analysis $(\mathrm{N}>5)$. Inset are 3D representative MRI renditions of control (left) and Fibcdl KO (right) adult brains with analysed brain regions pseudo-coloured. Error bars represent SD.

\section{Figure S4: Additional RNA-seq analysis}

(A) z-score hierarchical clustering for each sample in Fibcdl $\mathrm{KO}$ vs WT, WT ${ }^{\mathrm{CSPG}}$ vs WT and $\mathrm{KO}^{\mathrm{CSPG}}$ vs KO. Colours represent scaled expression values, with blue for low and red for high expression levels. Legend is indicated. (B) Volcano plot depicting differential gene expression at DIV2 hippocampal cultures, comparing Fibcd1 KO vs WT, showing significantly upregulated (red) and downregulated (blue) genes. Top 20 differentially expressed genes are labelled. (C) Volcano plot depicting differential gene expression at DIV2 hippocampal cultures comparing $\mathrm{WT}^{\mathrm{CSPG}}$ vs WT, all genes that fall into "integrin binding" GO term category are labelled. 
bioRxiv preprint doi: https://doi.org/10.1101/2021.09.09.459581; this version posted September 10, 2021. The copyright holder for this preprint (which was not certified by peer review) is the author/funder. All rights reserved. No reuse allowed without permission.

1086

1087

1088

1089

1090

1091

1092

1093

1094

1095

1096

1097

1098

1099

1100

1101

1102

1103

1104

1105

1106

1107

1108

1109

\section{Figure S5: Analysis of Fibcd1 KO mouse neurological phenotype.}

(A) Percentage of time mice spent in the centre, open and closed arms of the Elevated Plus Maze (EPM) are shown for Fibcdl WT (blue) and KO (red). N=18 WT; 27 KO. (B-C) Mouse performance quantified by time to reach the target platform (B) and time spent in the target quadrant (C), in Morris Water Maze (MWM) hippocampal-dependent spatial learning task over 5 days. $\mathrm{N}=5 \mathrm{WT} ; 9 \mathrm{KO}$. (D) Acute pain responses to hotplate, acetone drop, or intraplantar capsaicin injections, quantified as time to first response or time spent licking or biting the injected paw, respectively. $\mathrm{N}=9 \mathrm{WT} ; \mathrm{N}=10 \mathrm{KO}$. (E-F) Input/output assessment of synaptic transmission in CA3-CA1 Schaffer collateral pathway of adult mouse hippocampal slices. Fibcd1 WT (blue) and KO (red) hippocampal slices, pre-treated with penicillinase (pen) or Chondroitinase $\mathrm{ABC}(\mathrm{ChABC}) . \mathrm{N}(\mathrm{WT}+$ pen $)=22 ; \mathrm{N}(\mathrm{KO}+$ pen $)=27 ; \mathrm{N}(\mathrm{WT}+\mathrm{ChABC})=21$; $\mathrm{N}(\mathrm{KO}+\mathrm{ChABC})=30 .(\mathrm{G}-\mathrm{H}) \mathrm{LTP}$ fold change of baseline at $2(\mathrm{G})$ and $70(\mathrm{H})$ minutes post theta-burst stimulation (TBS) in adult mouse hippocampal slices. $\mathrm{N}(\mathrm{WT}+$ pen $)=9 ; \mathrm{N}$ $(\mathrm{KO}+$ pen $)=15 ; \mathrm{N}(\mathrm{WT}+\mathrm{ChABC})=6 ; \mathrm{N}(\mathrm{KO}+\mathrm{ChABC})=12$. Not significant, n.s., ${ }^{*}=\mathrm{p} \leq 0.05$ $* *=\mathrm{p} \leq 0.01 ; * * *=\mathrm{p} \leq 0.001$. Error bars represent SEM.

\section{Figure S6: Description of $\boldsymbol{d F i b c d 1}$.}

(A) Alignment of human, mouse and fly (DROME) FReD protein sequence. Inset, percent identity matrix (\% homology) between Drosophila, human and mouse FReD protein sequences.

(B) Summary of 3 RNAi lines crossed to full body GAL4 driver (tubulin) or neuron-specific (Nsyb) and the effects on viability. (C) Number of flies analysed for the climbing assay in Fig 4I.

\section{Figure S7: Additional human Fibed1 data.}


bioRxiv preprint doi: https://doi.org/10.1101/2021.09.09.459581; this version posted September 10, 2021. The copyright holder for this preprint (which was not certified by peer review) is the author/funder. All rights reserved. No reuse allowed without permission.

1110 (A) Missense, frameshift, splice region and stop gain variants present in the population. Each

1111 dot represents one distinct variants, amino acid position and CADD score indicated on $\mathrm{x}$ and $\mathrm{y}$

1112 axis. Indicated with arrows are the variants discussed in the present study. Data originally from

1113 gnomAD. (B) Time course of the backbone RMSD from the starting configuration for WT

1114 (blue), R406C (pink) and P456L (red) MD simulations. (C) Validation of FIBCD1 expression

1115 in stably expressing HEK293t cells by immunofluorescence. Shown is DAPI (blue), anti-FLAG

1116 (green) and merge. Scale bar $=50 \mathrm{um}$. 
bioRxiv preprint doi: https://doi.org/10.1101/2021.09.09.459581; this version posted September 10, 2021. The copyright holder for this preprint (which was not certified by peer review) is the author/funder. All rights reserved. No reuse allowed without permission.

\section{REFERENCES}

1 Dityatev, A., Schachner, M. \& Sonderegger, P. The dual role of the extracellular matrix in synaptic plasticity and homeostasis. Nat Rev Neurosci 11, 735-746, doi:10.1038/nrn2898 (2010).

2 Smith, P. D., Coulson-Thomas, V. J., Foscarin, S., Kwok, J. C. \& Fawcett, J. W. "GAG-ing with the neuron": The role of glycosaminoglycan patterning in the central nervous system. Exp Neurol 274, 100-114, doi:10.1016/j.expneurol.2015.08.004 (2015).

3 Carulli, D., Laabs, T., Geller, H. M. \& Fawcett, J. W. Chondroitin sulfate proteoglycans in neural development and regeneration. Curr Opin Neurobiol 15, 116120, doi:10.1016/j.conb.2005.01.014 (2005).

4 Dityatev, A. \& Schachner, M. Extracellular matrix molecules and synaptic plasticity. Nat Rev Neurosci 4, 456-468, doi:10.1038/nrn1115 (2003).

5 Freeze, H. H., Eklund, E. A., Ng, B. G. \& Patterson, M. C. Neurology of inherited glycosylation disorders. Lancet Neurol 11, 453-466, doi:10.1016/S14744422(12)70040-6 (2012).

6 Freeze, H. H., Eklund, E. A., Ng, B. G. \& Patterson, M. C. Neurological aspects of human glycosylation disorders. Annu Rev Neurosci 38, 105-125, doi:10.1146/annurevneuro-071714-034019 (2015).

7 Dwyer, C. A. \& Esko, J. D. Glycan susceptibility factors in autism spectrum disorders. Mol Aspects Med 51, 104-114, doi:10.1016/j.mam.2016.07.001 (2016).

8 Kitagawa, H., Tsutsumi, K., Tone, Y. \& Sugahara, K. Developmental regulation of the sulfation profile of chondroitin sulfate chains in the chicken embryo brain. $J$ Biol Chem 272, 31377-31381, doi:10.1074/jbc.272.50.31377 (1997).

9 Miller, G. M. \& Hsieh-Wilson, L. C. Sugar-dependent modulation of neuronal development, regeneration, and plasticity by chondroitin sulfate proteoglycans. Exp Neurol 274, 115-125, doi:10.1016/j.expneurol.2015.08.015 (2015).

10 Sorg, B. A. et al. Casting a Wide Net: Role of Perineuronal Nets in Neural Plasticity. $J$ Neurosci 36, 11459-11468, doi:10.1523/JNEUROSCI.2351-16.2016 (2016).

11 Gogolla, N., Caroni, P., Luthi, A. \& Herry, C. Perineuronal nets protect fear memories from erasure. Science 325, 1258-1261, doi:10.1126/science.1174146 (2009).

12 Dickendesher, T. L. et al. NgR1 and NgR3 are receptors for chondroitin sulfate proteoglycans. Nat Neurosci 15, 703-712, doi:10.1038/nn.3070 (2012).

13 Shen, Y. et al. PTPsigma is a receptor for chondroitin sulfate proteoglycan, an inhibitor of neural regeneration. Science 326, 592-596, doi:10.1126/science. 1178310 (2009).

$14 \mathrm{Xu}, \mathrm{B}$. et al. Role of CSPG receptor LAR phosphatase in restricting axon regeneration after CNS injury. Neurobiol Dis 73, 36-48, doi:10.1016/j.nbd.2014.08.030 (2015).

15 Mikami, T., Yasunaga, D. \& Kitagawa, H. Contactin-1 is a functional receptor for neuroregulatory chondroitin sulfate-E. J Biol Chem 284, 4494-4499, doi:10.1074/jbc.M809227200 (2009).

16 Mizumoto, S., Takahashi, J. \& Sugahara, K. Receptor for advanced glycation end products (RAGE) functions as receptor for specific sulfated glycosaminoglycans, and anti-RAGE antibody or sulfated glycosaminoglycans delivered in vivo inhibit pulmonary metastasis of tumor cells. J Biol Chem 287, 18985-18994, doi:10.1074/jbc.M111.313437 (2012).

17 Donahue, J. E. et al. RAGE, LRP-1, and amyloid-beta protein in Alzheimer's disease. Acta Neuropathol 112, 405-415, doi:10.1007/s00401-006-0115-3 (2006).

18 Schlosser, A. et al. Characterization of FIBCD1 as an acetyl group-binding receptor that binds chitin. J Immunol 183, 3800-3809, doi:10.4049/jimmunol.0901526 (2009). 
bioRxiv preprint doi: https://doi.org/10.1101/2021.09.09.459581; this version posted September 10, 2021. The copyright holder for this preprint (which was not certified by peer review) is the author/funder. All rights reserved. No reuse allowed without permission.

116919 Moeller, J. B. et al. Modulation of the fungal mycobiome is regulated by the chitinbinding receptor FIBCD1. J Exp Med 216, 2689-2700, doi:10.1084/jem.20182244 (2019).

20 Thomsen, T. et al. The recognition unit of FIBCD1 organizes into a noncovalently linked tetrameric structure and uses a hydrophobic funnel (S1) for acetyl group recognition. J Biol Chem 285, 1229-1238, doi:10.1074/jbc.M109.061523 (2010).

21 Shrive, A. K. et al. Crystal structure of the tetrameric fibrinogen-like recognition domain of fibrinogen C domain containing 1 (FIBCD1) protein. J Biol Chem 289, 2880-2887, doi:10.1074/jbc.M113.520577 (2014).

22 Zhang, Y. et al. Purification and Characterization of Progenitor and Mature Human Astrocytes Reveals Transcriptional and Functional Differences with Mouse. Neuron 89, 37-53, doi:10.1016/j.neuron.2015.11.013 (2016).

23 Soares da Costa, D., Reis, R. L. \& Pashkuleva, I. Sulfation of Glycosaminoglycans and Its Implications in Human Health and Disorders. Annu Rev Biomed Eng 19, 1-26, doi:10.1146/annurev-bioeng-071516-044610 (2017).

24 Miyata, S. \& Kitagawa, H. Chondroitin 6-Sulfation Regulates Perineuronal Net Formation by Controlling the Stability of Aggrecan. Neural Plast 2016, 1305801, doi:10.1155/2016/1305801 (2016).

25 Miyata, S., Komatsu, Y., Yoshimura, Y., Taya, C. \& Kitagawa, H. Persistent cortical plasticity by upregulation of chondroitin 6-sulfation. Nat Neurosci 15, 414-422, S411412, doi:10.1038/nn.3023 (2012).

26 Ribeiro Ede, A., Jr. et al. The structure and regulation of human muscle alpha-actinin. Cell 159, 1447-1460, doi:10.1016/j.cell.2014.10.056 (2014).

27 Kurkcuoglu, Z et al. Performance of HADDOCK and a simple contact-based proteinligand binding affinity predictor in the D3R Grand Challenge 2. J Comput Aided Mol Des 32, 175-185, doi:10.1007/s10822-017-0049-y (2018).

28 Jin, J. et al. Effect of chondroitin sulfate proteoglycans on neuronal cell adhesion, spreading and neurite growth in culture. Neural Regen Res 13, 289-297, doi:10.4103/1673-5374.226398 (2018).

29 Tang, T. et al. A mouse knockout library for secreted and transmembrane proteins. Nat Biotechnol 28, 749-755, doi:10.1038/nbt.1644 (2010).

30 Zhao, R. R. \& Fawcett, J. W. Combination treatment with chondroitinase ABC in spinal cord injury--breaking the barrier. Neurosci Bull 29, 477-483, doi:10.1007/s12264-013-1359-2 (2013).

31 Bray, E. R. et al. Thrombospondin-1 Mediates Axon Regeneration in Retinal Ganglion Cells. Neuron 103, 642-657 e647, doi:10.1016/j.neuron.2019.05.044 (2019).

32 Collins-Racie, L. A. et al. ADAMTS-8 exhibits aggrecanase activity and is expressed in human articular cartilage. Matrix Biol 23, 219-230, doi:10.1016/j.matbio.2004.05.004 (2004).

33 Nieswandt, B. et al. Loss of talin1 in platelets abrogates integrin activation, platelet aggregation, and thrombus formation in vitro and in vivo. $J$ Exp Med 204, 3113-3118, doi:10.1084/jem.20071827 (2007).

34 Yoshino, Y. et al. Targeted deletion of HYBID (hyaluronan binding protein involved in hyaluronan depolymerization/ KIAA1199/CEMIP) decreases dendritic spine density in the dentate gyrus through hyaluronan accumulation. Biochem Biophys Res Commun 503, 1934-1940, doi:10.1016/j.bbrc.2018.07.138 (2018).

35 Begay, R. L. et al. Filamin C Truncation Mutations Are Associated With Arrhythmogenic Dilated Cardiomyopathy and Changes in the Cell-Cell Adhesion Structures. JACC Clin Electrophysiol 4, 504-514, doi:10.1016/j.jacep.2017.12.003 (2018). 
bioRxiv preprint doi: https://doi.org/10.1101/2021.09.09.459581; this version posted September 10, 2021. The copyright holder for this preprint (which was not certified by peer review) is the author/funder. All rights reserved. No reuse allowed without permission.

121936 Desnoyers, L., Arnott, D. \& Pennica, D. WISP-1 binds to decorin and biglycan. J Biol

1220

1221

1222

1223

1224

1225

1226

1227

1228

1229

1230

1231

1232

1233

1234

1235

1236

1237

1238

1239

1240

1241

1242

1243

1244

1245

1246

1247

1248

1249

1250

1251

1252

1253

1254

1255

1256

1257

1258

1259

1260

1261

1262

1263

1264

1265

1266

1267

1268 Chem 276, 47599-47607, doi:10.1074/jbc.M108339200 (2001).

37 Manso, A. M. et al. Loss of mouse cardiomyocyte talin-1 and talin-2 leads to beta-1 integrin reduction, costameric instability, and dilated cardiomyopathy. Proc Natl Acad Sci U S A 114, E6250-E6259, doi:10.1073/pnas.1701416114 (2017).

38 Haage, A. et al. Talin Autoinhibition Regulates Cell-ECM Adhesion Dynamics and Wound Healing In Vivo. Cell Rep 25, 2401-2416 e2405, doi:10.1016/j.celrep.2018.10.098 (2018).

39 Slaker, M. et al. Removal of perineuronal nets in the medial prefrontal cortex impairs the acquisition and reconsolidation of a cocaine-induced conditioned place preference memory. J Neurosci 35, 4190-4202, doi:10.1523/JNEUROSCI.3592-14.2015 (2015).

40 Bruckner, G. et al. Acute and long-lasting changes in extracellular-matrix chondroitinsulphate proteoglycans induced by injection of chondroitinase $\mathrm{ABC}$ in the adult rat brain. Exp Brain Res 121, 300-310, doi:10.1007/s002210050463 (1998).

41 Vegh, M. J. et al. Hippocampal extracellular matrix levels and stochasticity in synaptic protein expression increase with age and are associated with age-dependent cognitive decline. Mol Cell Proteomics 13, 2975-2985, doi:10.1074/mcp.M113.032086 (2014).

42 Yang, S. et al. Perineuronal net digestion with chondroitinase restores memory in mice with tau pathology. Exp Neurol 265, 48-58, doi:10.1016/j.expneurol.2014.11.013 (2015).

43 Wilson, M. A. \& Tonegawa, S. Synaptic plasticity, place cells and spatial memory: study with second generation knockouts. Trends Neurosci 20, 102-106, doi:10.1016/s0166-2236(96)01023-5 (1997).

44 Bukalo, O., Schachner, M. \& Dityatev, A. Modification of extracellular matrix by enzymatic removal of chondroitin sulfate and by lack of tenascin-R differentially affects several forms of synaptic plasticity in the hippocampus. Neuroscience 104, 359-369, doi:10.1016/s0306-4522(01)00082-3 (2001).

45 Nicoll, R. A. \& Malenka, R. C. Expression mechanisms underlying NMDA receptordependent long-term potentiation. Ann N Y Acad Sci 868, 515-525, doi:10.1111/j.1749-6632.1999.tb11320.x (1999).

$46 \quad$ Kochlamazashvili, G. et al. The extracellular matrix molecule hyaluronic acid regulates hippocampal synaptic plasticity by modulating postsynaptic L-type $\mathrm{Ca}(2+)$ channels. Neuron 67, 116-128, doi:10.1016/j.neuron.2010.05.030 (2010).

47 Karczewski, K. J. et al. The mutational constraint spectrum quantified from variation in 141,456 humans. Nature 581, 434-443, doi:10.1038/s41586-020-2308-7 (2020).

48 Sobreira, N., Schiettecatte, F., Valle, D. \& Hamosh, A. GeneMatcher: a matching tool for connecting investigators with an interest in the same gene. Hum Mutat 36, 928930, doi:10.1002/humu.22844 (2015).

49 Wu, J. et al. Genomic landscapes of Chinese sporadic autism spectrum disorders revealed by whole-genome sequencing. $J$ Genet Genomics 45, 527-538, doi:10.1016/j.jgg.2018.09.002 (2018).

50 Unlu, G. et al. Phenome-based approach identifies RIC1-linked Mendelian syndrome through zebrafish models, biobank associations and clinical studies. Nat Med 26, 98109, doi:10.1038/s41591-019-0705-y (2020).

51 Patel, N. et al. Novel phenotypes and loci identified through clinical genomics approaches to pediatric cataract. Hum Genet 136, 205-225, doi:10.1007/s00439-0161747-6 (2017).

52 Wang, J. et al. UNC13B variants associated with partial epilepsy with favourable outcome. Brain, doi:10.1093/brain/awab164 (2021). 
bioRxiv preprint doi: https://doi.org/10.1101/2021.09.09.459581; this version posted September 10, 2021. The copyright holder for this preprint (which was not certified by peer review) is the author/funder. All rights reserved. No reuse allowed without permission.

Thomsen, T., Schlosser, A., Holmskov, U. \& Sorensen, G. L. Ficolins and FIBCD1: soluble and membrane bound pattern recognition molecules with acetyl group selectivity. Mol Immunol 48, 369-381, doi:10.1016/j.molimm.2010.09.019 (2011).

54 Jepsen, C. S. et al. FIBCD1 Binds Aspergillus fumigatus and Regulates Lung Epithelial Response to Cell Wall Components. Front Immunol 9, 1967, doi:10.3389/fimmu.2018.01967 (2018).

55 Retterer, K. et al. Clinical application of whole-exome sequencing across clinical indications. Genet Med 18, 696-704, doi:10.1038/gim.2015.148 (2016).

56 Yan, H. et al. Genetic analysis of 20 patients with hypomyelinating leukodystrophy by trio-based whole-exome sequencing. J Hum Genet 66, 761-768, doi:10.1038/s10038020-00896-5 (2021).

57 Zhang, P. et al. PopViz: a webserver for visualizing minor allele frequencies and damage prediction scores of human genetic variations. Bioinformatics 34, 4307-4309, doi:10.1093/bioinformatics/bty536 (2018).

58 Lassen, N. E. et al. Coupling of Bone Resorption and Formation in Real Time: New Knowledge Gained From Human Haversian BMUs. J Bone Miner Res 32, 1395-1405, doi:10.1002/jbmr.3091 (2017).

59 Love, M. I., Huber, W. \& Anders, S. Moderated estimation of fold change and dispersion for RNA-seq data with DESeq2. Genome Biol 15, 550, doi:10.1186/s13059-014-0550-8 (2014).

60 Jalili, V. et al. The Galaxy platform for accessible, reproducible and collaborative biomedical analyses: 2020 update. Nucleic Acids Res 48, W395-W402, doi:10.1093/nar/gkaa434 (2020).

61 Liao, Y., Wang, J., Jaehnig, E. J., Shi, Z. \& Zhang, B. WebGestalt 2019: gene set analysis toolkit with revamped UIs and APIs. Nucleic Acids Res 47, W199-W205, doi:10.1093/nar/gkz401 (2019).

62 Jones, G., Willett, P., Glen, R. C., Leach, A. R. \& Taylor, R. Development and validation of a genetic algorithm for flexible docking. J Mol Biol 267, 727-748, doi:10.1006/jmbi.1996.0897 (1997).

63 van Zundert, G. C. P. et al. The HADDOCK2.2 Web Server: User-Friendly Integrative Modeling of Biomolecular Complexes. J Mol Biol 428, 720-725, doi:10.1016/j.jmb.2015.09.014 (2016).

64 Schrodinger, LLC. The PyMOL Molecular Graphics System, Version 1.8 (2015).

65 Abraham, M. J. et al. GROMACS: High performance molecular simulations through multi-level parallelism from laptops to supercomputers. Software $X$ 1-2, 19-25, doi:https://doi.org/10.1016/j.softx.2015.06.001 (2015).

66 Lindorff-Larsen, K. et al. Improved side-chain torsion potentials for the Amber ff99SB protein force field. Proteins 78, 1950-1958, doi:10.1002/prot.22711 (2010).

67 Jorgensen, W. L. Quantum and statistical mechanical studies of liquids. 10. Transferable intermolecular potential functions for water, alcohols, and ethers. Application to liquid water. Journal of the American Chemical Society 103, 335-340, doi:10.1021/ja00392a016 (1981).

68 Hoover, W. G. Canonical dynamics: Equilibrium phase-space distributions. Phys Rev A Gen Phys 31, 1695-1697, doi:10.1103/physreva.31.1695 (1985).

69 Parrinello, M. \& Rahman, A. Polymorphic transitions in single crystals: A new molecular dynamics method. Journal of Applied Physics 52, 7182-7190, doi:10.1063/1.328693 (1981).

70 Hess, B., Bekker, H., Berendsen, H. J. C. \& Fraaije, J. G. E. M. LINCS: A linear constraint solver for molecular simulations. Journal of Computational Chemistry 18, 1463-1472, doi:https://doi.org/10.1002/(SICI)1096-987X(199709)18:12<1463::AIDJCC4>3.0.CO;2-H (1997). 
bioRxiv preprint doi: https://doi.org/10.1101/2021.09.09.459581; this version posted September 10, 2021. The copyright holder for this preprint (which was not certified by peer review) is the author/funder. All rights reserved. No reuse allowed without permission.

71 Jurrus, E. et al. Improvements to the APBS biomolecular solvation software suite. Protein Sci 27, 112-128, doi:10.1002/pro.3280 (2018).

72 Nagy, V. et al. HACE1 deficiency leads to structural and functional neurodevelopmental defects. Neurol Genet 5, e330, doi:10.1212/NXG.0000000000000330

NG2018008979 [pii] (2019).

73 Paxinos, G. \& Watson, C. The rat brain in stereotaxic coordinates: hard cover edition. (Elsevier, 2006).

74 Takegawa, Y. et al. Simultaneous analysis of heparan sulfate, chondroitin/dermatan sulfates, and hyaluronan disaccharides by glycoblotting-assisted sample preparation followed by single-step zwitter-ionic-hydrophilic interaction chromatography. Anal Chem 83, 9443-9449, doi:10.1021/ac2021079 (2011).

75 Cicvaric, A. et al. Enhanced synaptic plasticity and spatial memory in female but not male FLRT2-haplodeficient mice. Sci Rep 8, 3703, doi:10.1038/s41598-018-22030-4 (2018).

76 Cicvaric, A. et al. The brain-tumor related protein podoplanin regulates synaptic plasticity and hippocampus-dependent learning and memory. Ann Med 48, 652-668, doi:10.1080/07853890.2016.1219455 (2016).

77 Rammes, G. et al. Isoflurane anaesthesia reversibly improves cognitive function and long-term potentiation (LTP) via an up-regulation in NMDA receptor 2B subunit expression. Neuropharmacology 56, 626-636 (2009).

78 Simon, W., Hapfelmeier, G., Kochs, E., Zieglgansberger, W. \& Rammes, G. Isoflurane blocks synaptic plasticity in the mouse hippocampus. Anesthesiology 94, 1058-1065 (2001).

79 Monje, F. J. et al. Focal adhesion kinase regulates neuronal growth, synaptic plasticity and hippocampus-dependent spatial learning and memory. Neuro-Signals 20, 1-14 (2012).

80 Kim, E. J. et al. Alzheimer's disease risk factor lymphocyte-specific protein tyrosine kinase regulates long-term synaptic strengthening, spatial learning and memory. Cell Mol Life Sci (2012).

81 Sievers, F. et al. Fast, scalable generation of high-quality protein multiple sequence alignments using Clustal Omega. Mol Syst Biol 7, 539, doi:10.1038/msb.2011.75 (2011). 